Florida International University FIU Digital Commons

$11-8-2013$

\title{
Real-time Biosensor for the Assessment of Nanotoxicity and Cancer Electrotherapy
}

Evangelia Hondroulis

ehond001@fiu.edu

DOI: $10.25148 /$ etd.FI13120408

Follow this and additional works at: https:// digitalcommons.fiu.edu/etd

Part of the Biomedical Engineering and Bioengineering Commons, and the Nanoscience and Nanotechnology Commons

\section{Recommended Citation}

Hondroulis, Evangelia, "Real-time Biosensor for the Assessment of Nanotoxicity and Cancer Electrotherapy" (2013). FIU Electronic Theses and Dissertations. 972.

https://digitalcommons.fiu.edu/etd/972

This work is brought to you for free and open access by the University Graduate School at FIU Digital Commons. It has been accepted for inclusion in FIU Electronic Theses and Dissertations by an authorized administrator of FIU Digital Commons. For more information, please contact dcc@fiu.edu. 


\title{
FLORIDA INTERNATIONAL UNIVERSITY
}

Miami, Florida

\section{REAL-TIME BIOSENSOR FOR THE ASSESSMENT OF NANOTOXICITY AND CANCER ELECTROTHERAPY}

\author{
A dissertation submitted in partial fulfillment of \\ the requirements for the degree of \\ DOCTOR OF PHILOSOPHY \\ in \\ BIOMEDICAL ENGINEERING \\ by
}

Evangelia Hondroulis

2013 
To: Dean Amir Mirmiran

College of Engineering and Computing

This dissertation, written by Evangelia Hondroulis, and entitled Real-time Biosensor for the Assessment of Nanotoxicity and Cancer Electrotherapy, having been approved in respect to style and intellectual content, is referred to you for judgment.

We have read this dissertation and recommend that it be approved.

Anthony McGoron

Yen-Chih Huang

Georgio Tachiev

Steven Melnick

Chenzhong Li, Major Professor

Date of Defense: November 8, 2013

The dissertation of Evangelia Hondroulis is approved.

Dean Amir Mirmiran

College of Engineering and Computing

Dean Lakshmi N. Reddi

University Graduate School

Florida International University, 2013 


\section{DEDICATION}

I dedicate this dissertation to my parents. Without their patience, understanding, support, and most of all love, the completion of this work would not have been possible. 


\section{ACKNOWLEDGMENTS}

This dissertation has been made possible by the collective support of my family, friends and mentors. I would like to thank my parents who are my greatest support system in life. Their unconditional love and support have kept me going through the hard times. My mentor Dr. Chenzhong Li has taught me a great deal and will be a mentor for life. He has always had my best interest at heart and has provided me with every opportunity to grow. I am grateful for all the kindness and patience that he has shown me over the years. I wish to thank the members of my lab for assisting me with my research. Dr. Subbiah Alwarappan, Dr. Shradha Prabulkar, Dr. Chang Liu, Xuena Zhu, Pratik Shah and Dr. Jennifer McKenzie have been great friends as well as colleagues and have helped me not just with academics but to grow as a person. I would also like to thank the undergraduate students Paula Sepulveda and Jairo Nelson whose invaluable help has enabled me to finish my experiments on schedule. It was a privilege to mentor them and I feel that I have also learned a great deal from them. Finally, I want to acknowledge the University Graduate School for awarding me the Dissertation Year Fellowship (DYF). It allowed me to completely focus on completing my dissertation and finishing in a timely manner. Other sources of funding to be recognized are the grant FA9550-06-1-046 and FA9550-07-1-0344 of Department of Defense/Air Force Office of Scientific Research,

Wallace H Coulter Young Inventor Award, NSFMRI 0821582 and 2008 FIU Faculty Research Award and the grant NIH R15 ES021079-01 and Young Inventor Award by W. H. Coulter Foundation. Of course, finally, I would like to thank the Advanced Material Engineering Research Institute (AMERI) at FIU for allowing me to use their MEMS facilities. 


\title{
ABSTRACT OF THE DISSERTATION \\ REAL-TIME BIOSENSOR FOR THE ASSESSMENT OF NANOTOXICITY AND \\ CANCER ELECTROTHERAPY
}

\author{
by \\ Evangelia Hondroulis \\ Florida International University, 2013 \\ Miami, Florida

\section{Professor Chenzhong Li, Major Professor}

Knowledge of cell electronics has led to their integration to medicine either by physically interfacing electronic devices with biological systems or by using electronics for both detection and characterization of biological materials. In this dissertation, an electrical impedance sensor (EIS) was used to measure the electrode surface impedance changes from cell samples of human and environmental toxicity of nanoscale materials in 2D and 3D cell culture models. The impedimetric response of human lung fibroblasts and rainbow trout gill epithelial cells when exposed to various nanomaterials was tested to determine their kinetic effects towards the cells and to demonstrate the biosensor's ability to monitor nanotoxicity in real-time. Further, the EIS allowed rapid, real-time and multi-sample analysis creating a versatile, noninvasive tool that is able to provide quantitative information with respect to alteration in cellular function.

We then extended the application of the unique capabilities of the EIS to do realtime analysis of cancer cell response to externally applied alternating electric fields at different intermediate frequencies and low-intensity. Decreases in the growth profiles of the ovarian and breast cancer cells were observed with the application of 200 and 100 
$\mathrm{kHz}$, respectively, indicating specific inhibitory effects on dividing cells in culture in contrast to the non-cancerous HUVECs and mammary epithelial cells. We then sought to enhance the effects of the electric field by altering the cancer cell's electronegative membrane properties with HER2 antibody functionalized nanoparticles. An Annexin V/EthD-III assay and zeta potential were performed to determine the cell death mechanism indicating apoptosis and a decrease in zeta potential with the incorporation of the nanoparticles. With more negatively charged HER2-AuNPs attached to the cancer cell membrane, the decrease in membrane potential would thus leave the cells more vulnerable to the detrimental effects of the applied electric field due to the decrease in surface charge. Therefore, by altering the cell membrane potential, one could possibly control the fate of the cell. This whole cell-based biosensor will enhance our understanding of the responsiveness of cancer cells to electric field therapy and demonstrate potential therapeutic opportunities for electric field therapy in the treatment of cancer. 


\section{TABLE OF CONTENTS}

CHAPTER

PAGE

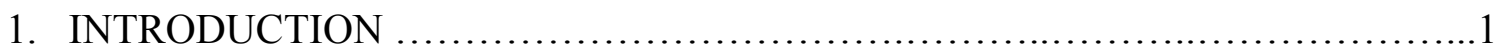

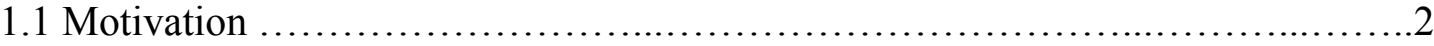

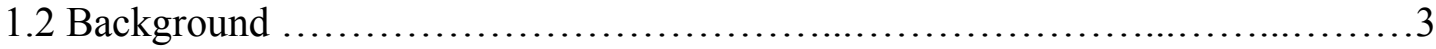

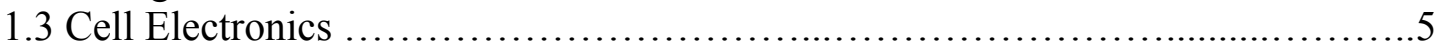

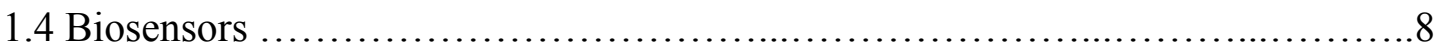

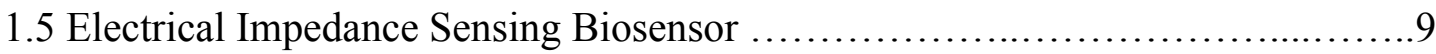

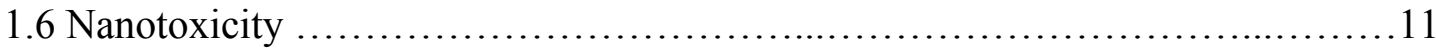

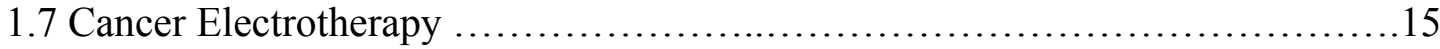

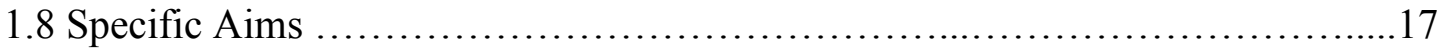

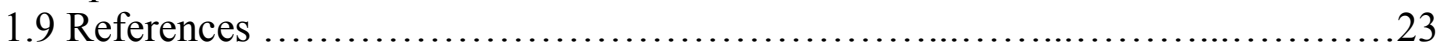

2. WHOLE CELL BASED ELECTRICAL IMPEDANCE SENSING APPROACH

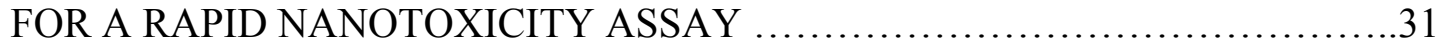

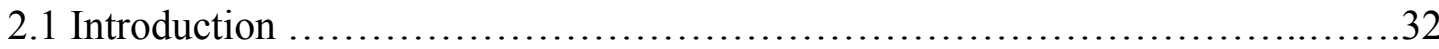

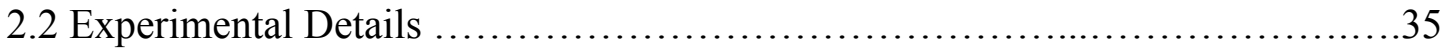

2.2.1 Chemicals and reagents.............................................. 35

2.2.2 Nanomaterial selection and preparation ................................36

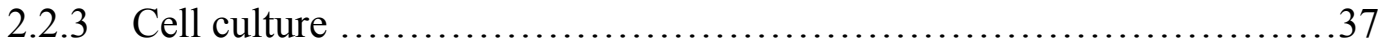

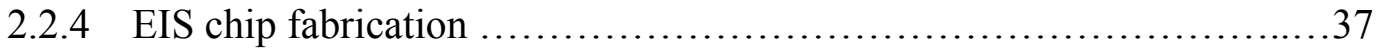

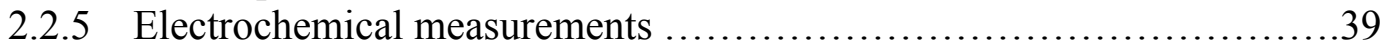

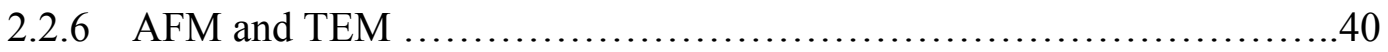

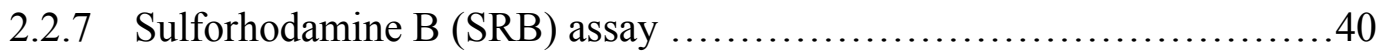

2.3 Results and Discussion ......................................................

2.3.1 Impedance and resistance measurements using EIS chip ...............41

2.3.2 Electrochemical characterization of the EIS chip ......................43

2.3.3 Nanomaterial characterization ..................................... 45

2.3.4 Cell exposure to cadmium oxide ....................................46

2.3.5 Cell exposure to gold and silver nanoparticles .........................49

2.3.6 Cell exposure to SWCNTs …........................................5

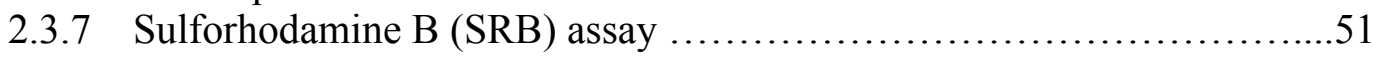

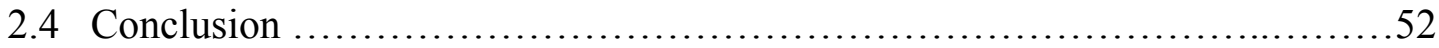

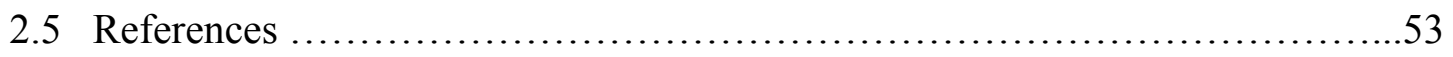


3. IMPEDANCE BASED NANOTOXICITY ASSESSMENT OF GRAPHENE NANOMATERIALS AT THE CELLULAR AND TISSUE LEVEL .................56

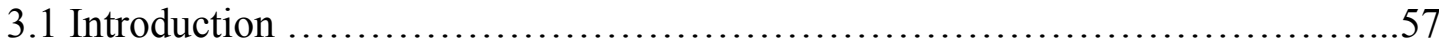

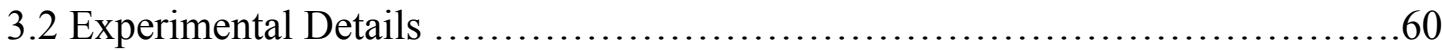

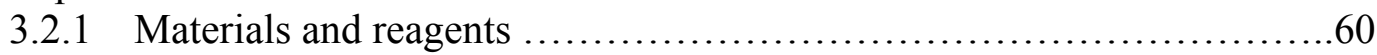

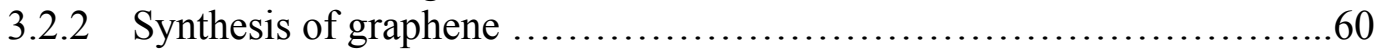

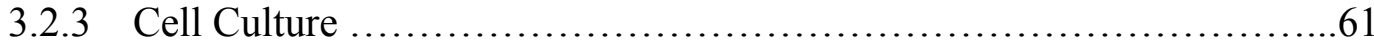

3.2.4 In vitro BBB models ...................................................61

3.2.5 Detection of Tight Junction Protein Occludin .........................62

3.2.6 Trans Endothelial-Electrical Resistance (TEER) Measurement ...........63

3.2.7 Resistance Measurements Using EIS chip ...........................63

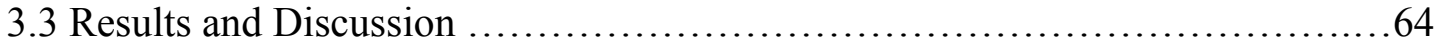

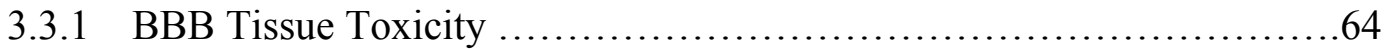

3.3.2 BBB Cellular Component Toxicity ..................................66

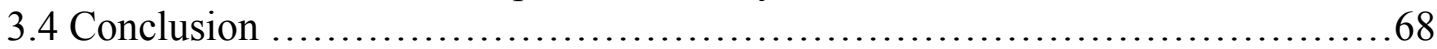

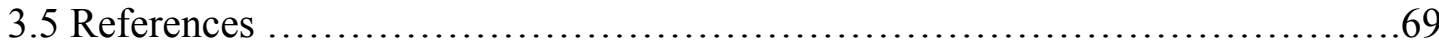

4. ELECTRICAL FIELD MANIPULATION OF CANCER CELL BEHAVIOR MONITORED BY WHOLE CELL BIOSENSING DEVICE ..................72

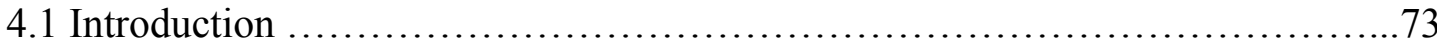

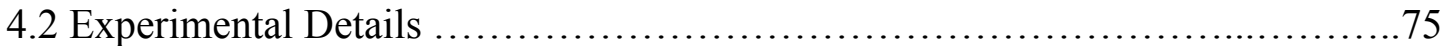

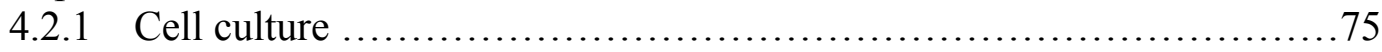

4.2.2 Electrical impedance sensing (EIS) .....................................75

4.2.3 Application of external electric field ................................75

4.2.4 Immunofluorescence Staining …...................................... 76

4.2.5 Cell Viability Assay ................................................... 76

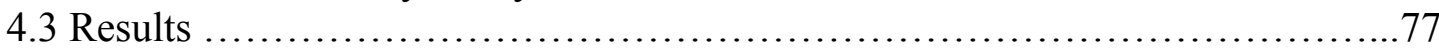

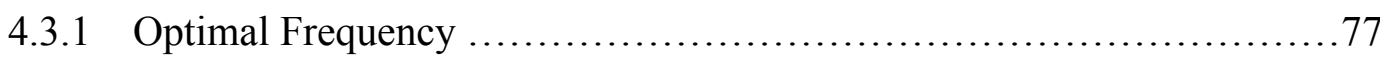

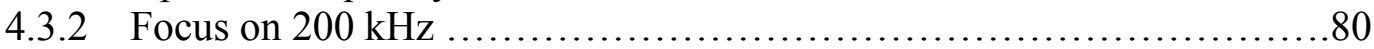

4.3.3 Immunofluorecence Staining and Cell Viability Assay ...................82

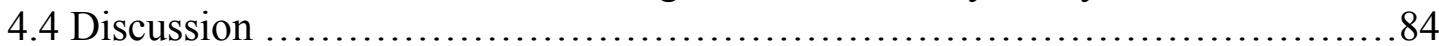

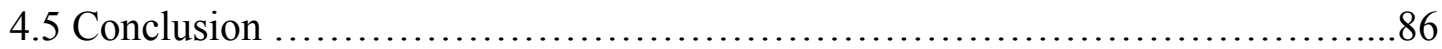

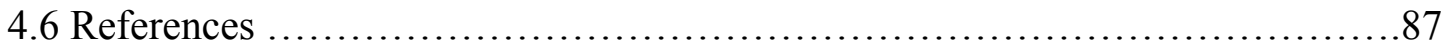


5. TARGETED ELECTRICAL FIELD MANIPULATION OF CANCER CELLS USING ANTIBODY FUNCTIONALIZED NANOPARTICLES .................89

5.1 Introduction ............................................................. 90

5.2 Experimental Details ................................................. 93

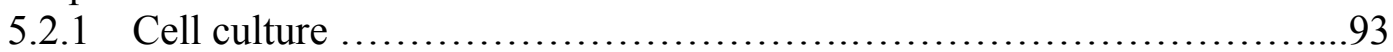

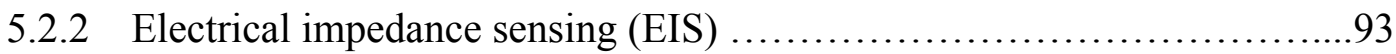

5.2.3 Application of external electric field .................................94

5.2 .4 Synthesis of AuNPs .............................................. 94

5.2.5 HER2 antibody functionalization of AuNps ........................... 95

5.2.6 Apoptosis / Necrosis Assay ......................................... 95

5.2.7 Zeta potential measurement ...................................... 96

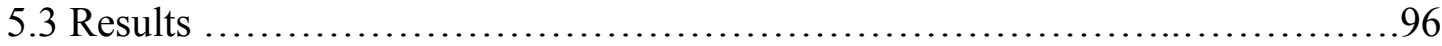

5.3.1 Optimal frequency for MCF7 ....................................... 96

5.3.2 HER2-AuNPs targeted enhancement .................................99

5.3.3 Apotosis / Necrosis Assay ............................................... 101

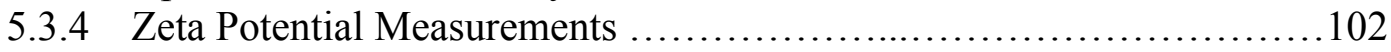

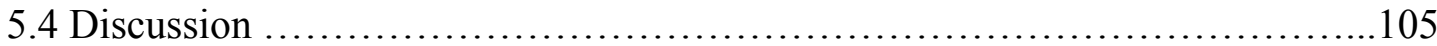

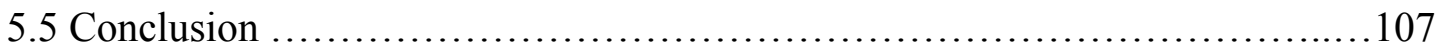

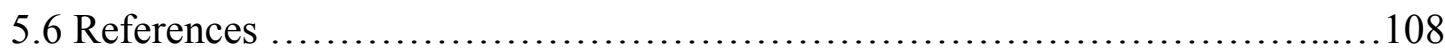

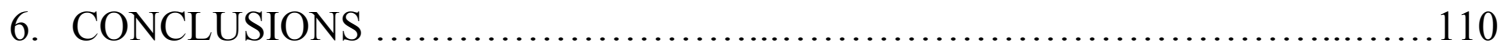

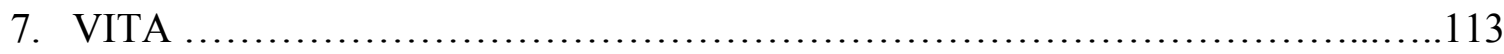




\section{LIST OF FIGURES}

FIGURE

PAGE

1.1 A cell can be thought of as a circuit made up of capacitors and resistors with the membrane acting like a capacitor and the the cytosol as a resistor..................6

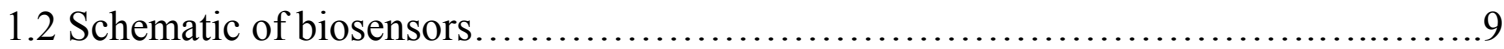

2.1 Flow diagram of fabrication of the mask (left) and the array chip (right)............38

2.2 Design of the electrical impedance sensing chip showing the array of eight detecting gold electrodes. The cells attach on the electrode surface altering the measured resistance values

2.3 Cyclic voltammogram of four electrodes on the fabricated EIS chip demonstrating the reproducibility of electrochemical activities of the fabricated gold microelectrodes.. 44

2.4 Transmission electron microscopy imaging of: (a) AuNPs (10 nm), (b) AgNPs (10 $\mathrm{nm})$, (c) cut SWCNTs, (d) SWCNTs, (e) raw SWCNTs and (f) purified SWCNTs...45

2.5 Resistance readings for CdO (a), Au (b), Ag (c) and SWCNT (d) on CCL-153. Lines $\mathrm{A}$ and $\mathrm{B}$ in all graphs represent the Blank and the Control (cells only) resistance readings. In (a), $\mathrm{CdO}$ is added initially (line $\mathrm{C}$ ) and after 20 hours of cell attachment (line D). In (b), lines C and D represent AuNPS sized $10 \mathrm{~nm}$ and $100 \mathrm{~nm}$ respectively. In (c), lines C and D represent AgNPS sized $10 \mathrm{~nm}$ and $100 \mathrm{~nm}$ respectively, and in (d), lines $\mathrm{C}$ and D represent the cut and uncut SWCNTs respectively .48

2.6 Resistance readings for CdO (a), Au (b), Ag (c) and SWCNT (d) on RTgill-W1. Lines A and B in all graphs represent the Blank and the Control (cells only) resistance readings. In (a), CdO is added initially (line C) and after 20 hours of cell attachment (line D). In (b), lines C and D represent AuNPS sized $10 \mathrm{~nm}$ and $100 \mathrm{~nm}$ respectively. In (c), lines $C$ and D represent AgNPS sized $10 \mathrm{~nm}$ and $100 \mathrm{~nm}$ respectively, and in (d), lines $\mathrm{C}$ and $\mathrm{D}$ represent the cut and uncut SWCNTs respectively...

3.1 SEM image of graphene.

3.2 Schematic of the setup for the in vitro BBB model showing the three layers: confluent mouse endothelial cells, aECM, and confluent rat astrocytes grown on opposite sides of COL Transwell inserts for 24-well plates and the control model without the aECM .62

3.3 Immuno-fluorescence microscopy on the BBB model without the aECM (A) and with the aECM (B) layer. The arrows both figures indicate the tight junctions formed....63

3.4 Trans-Endothelial Electrical Resistance (TEER) values taken for the empty COL 
Transwell inserts (blank), the in vitro BBB model (control), the model with graphene nanomaterials, and the model with cadmium oxide $(\mathrm{CdO})$ as a negative control. The resistance values of the in vitro model should increase as the days progress due to the growth of the cells in the insert. The results show consistent resistance values in both the control and the graphene samples over a three day timeframe and a decrease in resistance values for the $\mathrm{CdO}$

3.5 Resistance measurements for rat astrocytes CRL-2006 over 20 hours. The solid line and the dashed line represent the resistance measurements for the astrocytes and the astrocytes with graphene nanomaterials respectively. The resistance measurements are very similar indicating low cytotoxicity of graphene toward the astrocytes as compared to the $\mathrm{CdO}$ resistance values which remain low indicating low cell attachment .....................................................................66

3.6 Resistance measurements for mouse endothelial cells CRL-2583 over 20 hours. The solid line and the dashed line represent the resistance measurements for the endothelial cells and the endothelial cells with graphene nanomaterials respectively. The resistance measurements are very similar indicating low cytotoxicity of graphene toward the endothelial cells as compared to the $\mathrm{CdO}$ resistance values which remain low indicating low cell attachment

4.1 Schematic of wire setup for application of external alternating electric fields to the EIS chip. The two wires (black lines) were spaced at approximately $1 \mathrm{~mm}$ apart to encompass the entire electrode (gold circles) on the EIS chip. The red lines represent the resulting electric field generated .75

4.2 Resistance values of HUVECs (a) and SKOV3 (b) under electric fields of frequencies 100, 150 and $200 \mathrm{kHz}$. No apparent effect was noticed for the normal HUVECs, however, a significant decrease in resistance values was observed for the SKOV3 for all three frequencies. For further comparison, $50 \mathrm{kHz}$ (c) and $2 \mathrm{MHz}$ (d) frequencies were tested on SKOV3 and showed no apparent effect on the cell proliferation as seen in the similar resistance curves to the control. $200 \mathrm{kHz}$ showed the largest decrease out of all the frequencies .79

4.3 Resistance values of SKOV3 cells when subjected to $200 \mathrm{kHz}$ electric field after 40 hours on the electrode (a). Digital images were taken of this electrode to visualize the cell attachment process. Figure $4 \mathrm{~b}$ shows the electrode after the cells reached confluency over the electrode. After this, the $200 \mathrm{kHz}$ field was applied and within an hour another image was taken (c). The cells have changed morphology to a more rounded shape compared to the initial image. After an additional 40 hours of exposure to the electric field, another image was taken (d) which shows a significant decrease in cell number on the electrode .82 
4.4 Fluorescence imaging using propiduim iodide (PI). SKOV3 cells were grown on petri dish, one control (a) with no external electric field and one with wires providing 200 $\mathrm{kHz}$ frequency (b). After 40 hours, the cells were stained with PI and the cells exposed to $200 \mathrm{kHz}$ showed significant cell death as seen in the increase in fluorescence compared to the control. To further justify the effects of the $200 \mathrm{kHz}$ electric field on SKOV3, Trypan Blue exclusion test for cell viability was performed for 100,150 and $200 \mathrm{kHz}$ (c). $200 \mathrm{kHz}$ showed the lowest percent viability of $58 \%$

5.1 Resistance values of MCF10a (a) and MCF7 (b) under electric fields of frequencies 100, 150 and $200 \mathrm{kHz}$. No apparent effect was noticed for the normal MCF10a, however, a significant decrease in resistance values was observed for the MCF7 for all three frequencies. $50 \mathrm{kHz}$ and $2 \mathrm{MHz}$ frequencies were tested on both MCF10a (c) and MCF7 (d). The MCF10a showed no apparent effect on the cell proliferation as seen in the similar resistance curves to the control. $100 \mathrm{kHz}$ showed the largest decrease out of all the frequencies for the MCF7

5.2 Average temperature readings for the 8 wells on a chip at various time points throughout an EIS run for SKOV3 (a) and MCF7 (b)

5.3 Resistance values for HUVECs (a), SKOV3 (b), MCF10a (c) and MCF7 (d) under the effects of the optimal frequencies (SKOV3 $200 \mathrm{kHz}$, MCF7 100kHz) with and without the application of HER2-AuNPS 101

5.4 Fluorescent staining of MCF7 cells after 20 hours of exposure to $100 \mathrm{kHz}$ electric field. The image on the left shows EthD-III stained cells (necrotic) and the image on the right shows Annexin V stained cells (apoptotic) .103

5.5 Zeta potential values for HUVECs (a), SKOV3 (b), MCF10a (c), and MCF7 (d). With the integration of the HER2-AuNPs, the zeta potential of both cancer cells decreased in comparison to the two noncancerous cell types........................105 


\section{LIST OF ACRONYMS}

aECM : Acellular extracellular matrix

$\mathrm{AgNO}_{3}$ : Silver nitrate

AgNPs : Silver nanoparticles

AFM : Atomic force microscopy

AuNPs : Gold nanoparticles

BBB : Blood brain barrier

CdO : Cadmium oxide

CV : Cyclic voltammetry

DMEM : Dulbecco's modified eagle's medium

EIS : Electrical impedance sensing

EthD-III : Ethidium Homodimer III

EVOM $^{\circledR}:$ Epithelial voltohmmeter

FBS : Fetal bovine serum

FITC : Fluorescein isothiocyanate

GO : Graphitic oxide

$\mathrm{H}_{2} \mathrm{SO}_{4}$ : Sulfuric acid

$\mathrm{HAuCL}_{4}$ : Hydrogen tetrachloroaurate

HER2 : Human epidermal growth factor receptor 2

HER2-AuNPs : HER2 antibody functionalized gold nanoparticles

$\mathrm{HNO}_{3}:$ Nitric acid

IPA : Isopropyl alcohol

$\mathrm{KH}_{2} \mathrm{PO}_{4}$ : Potassium dihydrogen phosphate 
$\mathrm{KCl}$ : Potassium chloride

LDH : Lactate dehydrogenase

$\mathrm{NaBH}_{4}$ : Sodium borohydride

$\mathrm{Na}_{2} \mathrm{HPO}_{4}$ : Sodium phosphate

$\mathrm{Na}_{3} \mathrm{C}_{6} \mathrm{H}_{5} \mathrm{O}_{7}$ : Trisodium citrate

$\mathrm{NaOH}$ : sodium hydroxide

PBS : Phosphate-buffered saline

PI : Propidium iodide

ROS : Reactive oxygen species

SEM : Scanning electron microscope

SRB : Sulforhodamine B

SWCNTs : Single wall carbon nanotubes

TEER : Trans endothelial-electrical resistance

TEM : transmission electron microscopy 


\section{Chapter 1}

INTRODUCTION 


\subsection{Motivation}

Electrically directed and coordinated cell movement plays a significant role in mammalian cell behavior starting from embryonic development. Cells have intrinsic electrical properties which determine how they are affected under different stimuli. Understanding these electrical properties will lead to further information on how the cell functions allowing the cells to be used as sensors for monitoring cellular behavior.

The motivation behind this doctoral study is to analyze the electronic properties of cells by using a whole cell electrical impedance sensing (EIS) biosensor to monitor their behavior in real-time. The capability of the biosensor to monitor the cellular behavior was first demonstrated by testing human and environmental toxicity of nanoscale materials in $2 \mathrm{D}$ and $3 \mathrm{D}$ cell culture models, and then the biosensor was ultimately used to test the effects of external alternating electric fields in combination with antibody targeted nanoparticle therapy on the behavior of cancer cells. The biosensor provides a rapid, real-time and multi-sample technique to get more information about living cells without disturbing the cellular sub-systems creating a versatile, noninvasive tool that is able to provide quantitative information with respect to alteration in cellular function when subjected to the various stimuli. Studying nanotoxicity demonstrated the ability of the EIS biosensor to monitor the kinetic effects of the cellular reaction pattern towards various nanoparticles, allowing better understanding of the nanoparticle-cell interaction over time. The cancer electrotherapy study improved our fundamental understanding of the behavior of cancer cells to alternating electric fields and allowed us to define a 
strategy and optimal parameters of antibody targeted nanoparticle electrotherapy for clinical and drug delivery applications.

\subsection{Background}

Biosensors are becoming valuable tools for analyzing various physical, chemical and biological processes. Since 1962 when Professor Leland C. Clark Jr. first published a paper on the oxygen electrode [1], researchers have incorporated and enhanced biosensing technology in fields such as in health care, the food industry and environmental monitoring. The attraction to biosensors stems from their accurate, precise, reproducible measurements in a cheap, small, portable fashion. Most current biosensors are used to detect enzymes, DNA/RNA and immunological components converting the biological phenomena into electrical signals [2-4] allowing for specifically targeted results. Whole cell impedance based biosensors, pioneered by Giaever and Keese (1984), were developed to monitor proliferation and motion of a population of anchorage dependent cell cultures. By monitoring whole cell activity, one can monitor changes in membrane receptors, channels, and enzymes that may be expressed by the cell. Morphological changes can also be monitored using EIS biosensors since cellular membranes exhibit dielectric properties [5]. EIS biosensors are especially beneficial for monitoring whole cell behavior because they provide information about the total physiological responses of cells to external stimuli. Biosensors that incorporate whole cells can have an advantage over other biosensors for certain applications because they can provide functional information without damaging the cells. 
Nanotechnology has great potential benefits in rapidly developing fields such as biomedical engineering, drug delivery, environmental health, pharmaceutical industries and even electronics and communication technologies. For instance, in the healthcare field, nanomaterials are being considered in the development of new drugs and new therapies for disease control and improving the quality of life [6-8]. More recently, nanomaterials have been used in tissue engineering and medical imaging, leading to improved diagnostics and new therapeutic treatments [9-11]. However, with this rapid development, these new nanoscale materials (including nanotubes, nanowires, nanowhiskers, fullerenes or buckyballs and quantum dots) might have unintended hazards for human health and the environment [12-13]. Current in vitro techniques to measure nanotoxicity, including mitochondrial reduction of tetrazolium salts into an insoluble dye (the MTT test) and enzyme lactate dehydrogenase (LDH) release tests are used as markers for cell viability and provide only a final measurement of toxicity to a cell culture overlooking the ongoing cytotoxic effects of the nanoparticles over time. EIS biosensors are ideal for detecting toxic nanomaterials in industrial products, chemical substances, environmental samples (e.g. air, soil and water) or biological systems (e.g. bacteria, viruses or tissue components) as they are able to monitor the progression of the cytotoxicity in real time demonstrating the kinetic effects of the nanomaterials towards whole cells.

Living cells are associated with electrical characteristics and are thus responsive to and even generate electric fields and currents. Cells control the exchange of electrically charged ions across their membrane creating a membrane potential with different 
amounts of electrical charges inside and outside the cell. A shift in membrane potential will alter the exchange of ions across it and vice versa. For instance, it has been shown that alteration in membrane potential can alter the signal pathways involved in mitosis of the cell and thus its proliferation [14]. Recently, there has been interest in the use of electrotherapy as a treatment for cancer. Since the electrical properties of cancer cells differ from normal proliferating cells, electric fields may induce differential effects in normal and cancerous cells. For example, cancer cells exhibit a lower electrical potential of their membrane compared to healthy cells. Cancer cells also exhibit disorganized growth, weak interactions with their neighboring cells and do not exhibit contact inhibition of their growth [15]. Consequently further research is warranted to establish the role of electric field therapy for the treatment of cancer.

\subsection{Cell Electronics}

Electrically directed and coordinated cell movement plays a significant role in mammalian cell behavior starting from embryonic development. Cells have intrinsic electrical properties that fuel this behavior, the most prevalent stemming from the cellular membrane consisting of a lipid bilayer riddled with various transmembrane proteins creating ionic channels responsible for the survival of the cell. Due to these channels, the membrane can be considered to have mostly capacitive properties with the inside of the cell more resistive creating a membrane potential (Figure 1.1). Understanding these electrical properties of the cell and how they are affected under different stimuli, we can find out more information on how the cell functions. Changes in these electrical 
properties allow the cells to be used as sensors for monitoring cellular behavior under various stimuli.

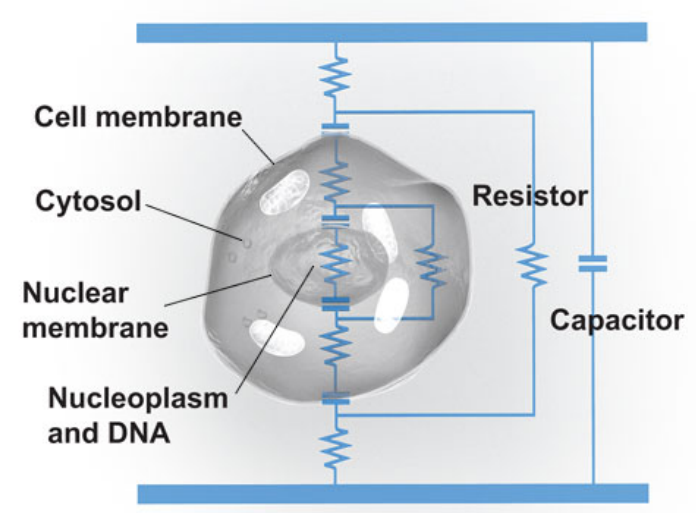

Figure 1.1 - A cell can be thought of as a circuit made up of capacitors and resistors with the membrane acting like a capacitor and the the cytosol as a resistor. (Source: biotele.com. Image by Bryan Christie)

Cells have electrostatic forces due to the charged ions within the cell creating an electric field creating the cell's permittivity, the ability to form an electric field, and its conductivity, the ability to conduct an electric current. Cells also have electromotive forces to maintain a required potential difference such as voltage, current, resistance, and capacitance. All these properties are found in developing, wounded, normal, and diseased tissues and are the center of various technologies such as dielectrophoresis, electroporation, and impedance spectroscopy.

The structure of the cellular membrane plays an important role in the electronic properties of the cell. The cell membrane creates the boundary between the regulated internal environment of the cell and the external environment. The membrane is constructed from molecules with long fatty chains with electrically charged head groups in contact with the surrounding water allowing it to be water soluble. Within the 
membrane structure are various types of proteins responsible for a variety of cellular functions. The integral proteins, passing through the cell membrane, and the peripheral proteins, lining the inside and outside of the membrane, give the cell control of motion, transport of molecules, and adhesion to surfaces. The integral proteins are the ones that form pumps that actively transport ions across the cell membrane developing the transmembrane potential. Since the membrane is semipermeable to certain ions, a concentration gradient forms causing a potential to develop across the membrane as defined by the Nernst equation:

$$
E_{S}=\frac{R T}{F} \ln \frac{[S]_{2}}{[S]_{1}}
$$

where $E_{\mathrm{s}}$ is the equilibrium potential $[\mathrm{S}]_{1}$ and $[\mathrm{S}]_{2}$ represent the concentrations of the ion $\mathrm{S}$ on each side of the membrane, $\mathrm{R}$ is the gas constant $\left(8.315 \mathrm{~J} \cdot \mathrm{K}^{-1} \cdot \mathrm{mol}^{-1}\right)$ and $\mathrm{F}$ is Faraday's constant $\left(9.648 \times 10^{4} \mathrm{C} \cdot \mathrm{mol}^{-1}\right)$. Concerning the cell membrane, the ions of interest are $\mathrm{K}^{+}, \mathrm{Na}^{+}, \mathrm{Ca}^{2+}$, and $\mathrm{Cl}^{-}$with potassium and chloride creating negative and sodium and calcium creating positive intracellular potential with respect to the extracellular potential. For most electrically active cells, there is a higher concentration of $\mathrm{K}^{+}$ions on the inside of the cell and a higher concentration of $\mathrm{Na}^{+}$and $\mathrm{Cl}^{-}$on the outside creating an overall negative transmembrane potential. Changes in the cell's membrane potential cause action potentials, electrical signals that send messages around the body to perform the appropriate reaction. 
The origin of measuring the electrical activity of cultured cells involved the use of micropipettes or microwire electrodes to measure the transmembrane potential. However, this technique, consisting of inserting a micropipette electrode through the membrane, has its downfalls. The interface between the cell and the microelectrode is unstable and thus limits the duration of the experiment and do not provide information about long-term temporal changes and can potentially cause damage to the cell. The setup is also designed to record from only a single cell at a time and thus is laborious and low-throughput [16-18]. To get long term recordings and non-invasively monitor the electrical activity in terms of impedance and/or physiologic state of cultured cells planar microelectrode array biosensors were developed in the 1970s [19].

\subsection{Biosensors}

Knowledge of these electrical properties of cells has led to the development of the field of bioelectronics. Bioelectronics is the application of electronics to biology and medicine and can be broken down into two categories. Physically interfacing electronic devices with biological systems has led to technologies such as the cardiac pacemaker, implantable electrical bone growth simulators, deep brain simulators and electrical nerve simulation [20]. The other aspect of bioelectronics is electronics for both detection and characterization of biological materials, such as on the cellular and subcellular level. This can be seen in the example of cell based biosensors that use live cells as sensing

elements to monitor physiological changes induced by internal aberration or external stimuli [21]. 
A biosensor is commonly defined as a device that detects, records, and transmits information regarding a physiological change or process. Biologically derived recognition entities (enzymes, antibodies, microorganisms, cell receptors, cells, etc.) are coupled to a transducer which detects the biological reaction and converts it into a signal which can be physicochemical, optical, electrochemical, thermometric, or magnetic (Figure 1.2)[22].

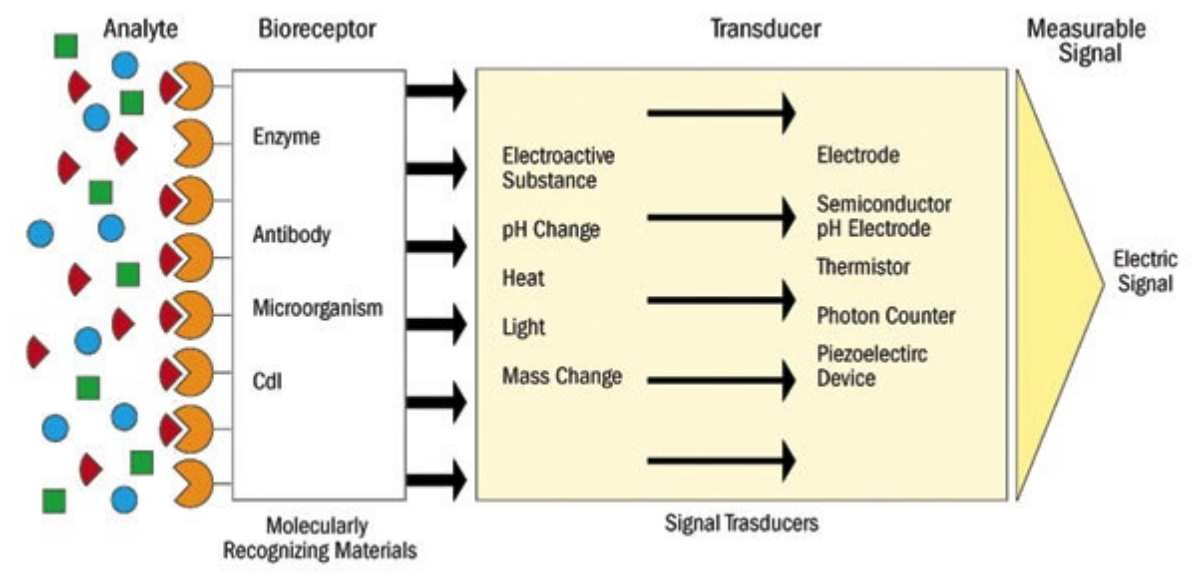

Figure 1.2 - Schematic of biosensors

Biosensing technology has spread throughout many disciplines due to its great specificity, sensitivity, and diversity in uses. Molecular and enzymatic biosensors were among the first to be introduced in the 1970's [23-24] with thermal, optical and electrochemical following shortly thereafter [25-28].

\subsection{Electrical Impedance Sensing Biosensor}

Planar microelectrode biosensors used to monitor cellular behavior were first introduced by C.A. Thomas, et al. in 1972 to monitor the electrical activity of contracting embryonic chick heart cells [19]. Since then, microelectrode biosensors have been used 
to study cell cultures in vitro under different conditions. For instance, Gross et al. used a microelectrode biosensor to monitor and eventually stimulate neuronal cell activity in vitro from the brain and spine [29-31]. Other uses include monitoring metabolism [32], fluorescent probes and reporter genes [33], and electrophysiology [34].

Whole cell electrical impedance based biosensors pioneered by Giaever and Keese (1984) were the first demonstration of a system capable of monitoring proliferation and motion of a population of anchorage dependent cell cultures in vitro [35]. Giaever and Keese cultured human lung fibroblasts cells on modified cell culture dishes consisting of a large reference electrode $\left(2 \mathrm{~cm}^{2}\right)$ and 4 smaller electrodes $\left(3 \times 10^{-4} \mathrm{~cm}^{2}\right)$. They applied an AC voltage through a resistor to a single small electrode in the dish resulting in a constant current source which enabled the impedance to be determined by measurement of the resulting voltage. They were able to observe the effects of cell proliferation (impedance increase) as well as the micromotion of the cells (fluctuations in observed impedance).

Giaever and Keese then used their biosensor to examine the effects of different proteins on cell adhesion, spreading, and motility [36]; to create a mathematical model of cell motion [37]; the use of this impedance method in cell based sensor applications [3840]. Connelly et al. modified Giaever and Keese's biosensor design by adding a glass ring around the electrode area to contain the cell culture media and inserting a permeable, cellulose nitrate membrane to separate the culture dish into two sides, each with two measurement electrodes creating a control and a test electrode [41]. 


\subsection{Nanotoxicity}

Testing for toxicological parameters is a necessary first step toward ensuring the compatibility of nanomaterials for medical applications and for the safety of the environment. The properties of metals change when they are in the nanoscale and they may pose certain threats to biological systems that their bulk counterparts may not. To date, nanotoxicity is a crucial topic that is being addressed by a number of studies [4244]; however, there is a lack of consensus in the published literature on nanoparticle toxicity due to the variability of methods, materials and cell lines used [45]. With the increase in research and commercial use of these nanomaterials, standardization of methods in nanotoxicity testing is becoming increasingly important to validate these novel techniques.

The main risk associated with the use and manufacture of nanomaterials is human and environmental exposure. One of the more common impacts of the use of nanomaterials is the emission of hazardous air pollutants which contain particulate matter on the order of 1-100 nm in size. Any material in the respirable size range, less than 100 $\mathrm{nm}$ in diameter, may have toxic effects on the lung fibroblasts after inhalation [46]. In particular, nanoparticles with sizes less than $20 \mathrm{~nm}$ affect the alveolar region of the lung [47]. The use of nanomaterials in biomedical sciences has placed nanomaterials directly in contact with biological materials, and thus it is necessary to observe their interaction closely. 
In the environment, nanotechnology is being used to solve problems such as soil and groundwater remediation, air purification, pollution detection and sensing [48-50]. Manufactured nanoparticles are being engineered for projects that will benefit the environment as well in the form of environmental cleanup tools. For instance, in the UN Millennium Project, fullerenes are being used to absorb various toxins and iron nanoparticles to catalyze the breakdown of solvents. There have been debates on whether the disposal of these manufactured nanoparticles causes significant harm to the environment as there is a lack of validated protocols for their disposal and removal [51].

A particular nanomaterial that is of interest is graphene, with its simple structure, single-atom-thick sheets of carbon, its potential in the scientific world has been quite intense. Due to its unique features, researchers have rushed to study its many potential applications such as nanoelectronic devices, transparent conductors and nanocomposites [52-53], while possibly overlooking any potential hazards. The cytotoxic effects of other carbon nanomaterials such as fullerenes, nanotubes and nanofibers have been studied before with mixed results [54]. The general consensus for the cause of cytotoxicity of these materials seems to be due to their byproducts or residues such as metal traces and amorphous carbon which cause oxidative stress to the cells [55-57]. The cytotoxic effects of graphene may be different than those of other graphitic materials as cytotoxicity studies on graphene are far and few between.

Biomedical engineering applications using graphene have surfaced recently in the form of biosensing devices [58], enzymatic biofuel cells [59], microbial detection, disease diagnosis and drug delivery systems [60], creating a cell-graphene interface that 
must be explored further. Although similar in chemical composition, graphene compared to its carbon counterparts may behave differently when interacting with biological elements as it lacks the transition metals, $\mathrm{Fe}$, $\mathrm{Ni}$ etc. that are present with carbon nanotubes for example, leading to its high purity [61]. It has been shown that cells could grow on graphene sheets [62]; however, one must still examine the cellular interaction of graphene as a nanomaterial as the graphene's properties may change and may produce certain threats to the biological systems that its bulk counterpart may not.

One major potential application of carbon based nanomaterials is for drug delivery. The use of nanomaterials for targeted drug delivery is becoming a popular topic of interest in the field of biomedical engineering with many recent advances. For instance, Liu et al. recently tested single walled carbon nanotubes as carriers for the drug paclitaxel to target tumors in mice and showed higher ratios of tumor to normal organ uptake of the drug-carbon nanotube combination [63]. Using nanomaterials to transport the desired drug prevents unwanted side effects since the drug is targeted only in the desired site, and can minimize drug dilution throughout the body increasing the drug concentration delivered to the pathological area. Graphene and graphene oxide with their unique properties are on the forefront of this technology [64].

One area of interest in particular to drug delivery is the blood brain barrier (BBB), a tight seal of endothelial cells that lines the blood vessels in the brain that selectively allows the entry of certain molecules from blood circulation into the brain. Maintaining the integrity of the BBB is an important issue when designing a drug delivery system and 
thus the interaction of these graphene nanomaterials with the BBB must be explored further.

Traditional biological methods for measurement of cellular activity and proliferation are used in current nanotoxicity studies. These methods include mitochondrial reduction of tetrazolium salts into an insoluble dye (the MTT test) and enzyme lactate dehydrogenase $(\mathrm{LDH})$ release tests. These methods are used as markers for cell viability and consist of procedures that provide a general sense of cytotoxicity as they show results only at a final time point [65]. As a result, the kinetic model (absorption, distribution, metabolism and excretion) of the nanoparticle uptake is not usually observed with these conventional methods. Following biological exposure, the particles may transport across cell membranes, especially into mitochondria, causing internal damage that may affect cell behavior and over time, lead to cell death [66].

Integration of biomolecules with nanotechnology has great future perspectives in rapidly developing fields of environmental (pollution control and monitoring), biomedical research, drug delivery, electronics and communication technologies. With the increasing number of nanomaterial applications, assessing their toxicity should be the first important step toward creating safety guidelines for their handling and disposal. Studies of biological effects of nanoscale materials that might answer these questions have lagged behind other aspects of nanotechnology development. EIS technology is shown to be sensitive enough to measure the micro-motion of a cell and therefore able to monitor the progression of the cytotoxicity with rapid, real-time and multi-sample analysis creating a versatile, noninvasive tool that is able to provide quantitative 
information with respect to alteration in cellular function under various nanomaterial exposures.

\subsection{Cancer Electrotherapy}

Currently, 1 in 4 deaths in the United States is due to cancer with a total of $1,596,670$ new cancer cases and 571,950 deaths from cancer projected to occur in the United States in 2011 [67]. Current advancements in cancer treatments such as surgery, radiotherapy and chemotherapy have proven to be successful, however, with many side effects. Surgery is the best chance of cure for many cancers that have not spread, however, as with all surgeries, there are complications. Radiotherapy, the use of ionizing radiation to damage the DNA of exposed cells, kills cancer cells in and around a specific tumor however, it also kills surrounding normal cells producing deleterious side effects known as radiation toxicities. Chemotherapy, the use of drugs to destroy cancer cells is beneficial in destroying cancer cells that may have spread, however, like radiotherapy; it also kills the surrounding healthy cells.

The effects of exogenous electric fields on physiology and their possible relationship to diseases have interested researchers for years [68-70]. In 1855, Guillaume Duchenne discovered that alternating current leads to electrotherapeutic triggering of muscle contractions thus spurring the use of electrical energy as medical treatment. Since then, the use of electric fields has become popular in fields such as gene and cellular therapies [71-73], and has even progressed to clinical trials for drug delivery [74], however; still little is known how electric fields may interact with intracellular signaling pathways to potentially alter cell physiology. 
Living cells are associated with electrical characteristics including resting membrane potential, ionic current flow, resistance, capacitance, permittivity, and conductivity and are thus responsive to and even generate electric fields and currents. The idea of classifying cancers by their electrical properties was first proposed by Fricke and Morse in 1926 [75]. Recently, there has been interest in the use of electrotherapy as a treatment for cancer. Since the electrical and physical properties of cancer cells differ from normal proliferating cells, electric fields may induce differential effects in normal and cancerous cells. For example, cancer cells exhibit a lower electrical potential of their membrane compared to healthy cells. Cancer cells also exhibit disorganized growth, weak interactions with their neighboring cells and do not exhibit contact inhibition of their growth. Consequently further research is warranted to establish the role of electric field therapy for the treatment of cancer.

Current treatments for cancer have much potential; however, a major limitation in these treatments is the negative side effects that occur. Electrotherapy for cancer treatment is very promising alternative as it eliminates the toxic chemicals and possible immunogenic responses in the host tissue. The outcome of this research will improve our fundamental understanding of the behavior of cancer cells to alternating electric fields and define a strategy and optimal parameters of electrotherapy for clinical and drug delivery applications. This whole cell-based biosensor will enhance our understanding of the responsiveness of cancer cells to electric field therapy and demonstrate potential therapeutic opportunities for electric field therapy in the treatment of cancer. 


\subsection{Specific Aims}

Specific Aim 1 - Electronic Platform for Monitoring Cellular Behavior - Nanotoxicity

Task 1: Testing reproducibility and sensitivity of EIS biosensor

Electrochemical testing of the EIS biosensor is done to ensure consistent and

accurate readings for every experiment. We tested the reproducibility and sensitivity of the EIS biosensor by performing cyclic voltammetry, one of the most widely used techniques for acquiring qualitative information about electrochemical reactions. In situ biosensor testing also allows for rejection of biosensors which might have been damaged due to improper storage or handling (e.g. at excessive temperatures) ensuring accurate data. We achieved consistent cyclic voltammograms among the electrodes of the EIS biosensor demonstrating its high reproducibility and sensitivity.

\section{Task 2: Nanoparticle preparation and characterization}

Characterization of the nanomaterials to be tested is necessary as specific properties of the materials depend on their size and purity. Most cell types undergo phagocytosis or endocytosis to eliminate large particles that interact with the cell membrane; however, the smaller sized particles may bypass the natural mechanical barriers of the cells which may result in severe tissue damage [76]. Once inside the cells, the nanoparticles may interfere with the functions of the cell's organelles and other biomolecular structures leading to damage and even death of the cell. The exact mechanisms of this process are still not fully understood [77-78]. 
After selecting various nanomaterials for testing, gold (AuNPs), silver (AgNPs), and single wall carbon nanotubes (SWCNTs), we manufactured and prepared these materials for the nanotoxicity study. Once made, we characterized the materials using transmission electron microscopy (TEM). The SWCNTs used in this study were purified in diluted acids to prevent unwanted contamination of impurities such as amorphous carbon, graphite and catalyst metal particles which may reside on the tubes. The AuNPs and AgNPs were fabricated at different sizes $(10$ and $100 \mathrm{~nm})$ to further understand the size effects of the particles and the underlying mechanisms that govern the uptake of nanoparticles into cells.

\section{Task 3: Real-time detection of nanotoxicity on $2 D$ and $3 D$ living cell models}

Traditional biological methods for measurement of cellular activity and proliferation are used in current nanotoxicity studies. These methods include the MTT assay and the LDH release test which are used as markers for cell viability and consist of procedures that provide a general sense of cytotoxicity as they show results only at a final time point. As a result, the kinetic model (absorption, distribution, metabolism and excretion) of the nanoparticle uptake is not usually observed with these conventional methods.

The EIS biosensor is capable of monitoring cellular behavior electronically in real-time. By monitoring the toxicity of a known toxin, cadmium oxide (CdO), towards cells, we were able to confirm the suitability of the EIS biosensor for our further studies. Once this was done, we continued on to test the toxicity of other nanomaterials for better understanding of their interaction with different 2D living cell models (human lung 
fibroblasts (CCL-153) and rainbow trout gill epithelial cells (RTgill-W1)). We also performed another impedance based technique, Trans Endothelial-Electrical Resistance (TEER), to measure the toxicity of graphene on a 3D BBB tissue model. We used the EIS to monitor the effects of graphene towards the individual components of the 3D tissue model (rat astrocytes (CRL-2006 ${ }^{\mathrm{TM}}$ ) and mouse endothelial cells (CRL-2583 $\left.{ }^{\mathrm{TM}}\right)$ ).

Specific Aim 2 - Electronic Platform for Monitoring Cellular Behavior - Cancer Electrotherapy

\section{Task 1: Determination of optimal frequency}

Recently, there has been interest in the use of electrotherapy as a treatment for cancer. Since the electrical and physical properties of cancer cells differ from normal proliferating cells, electric fields may induce differential effects in normal and cancerous cells. We tested various frequencies $(50,100,150,200 \mathrm{kHz}$ and $2 \mathrm{MHz})$ of low intensity alternating electric fields on the behavior of human ovarian cancer cells (SKOV3) in order to determine an optimal frequency that will hinder the cell proliferation for this cell line. Tests were also performed on non-cancerous endothelial cells (HUVECs) for a comparison. After testing this range of frequencies of low intensity alternating electric fields on both types of cancer cells, we obtained an optimal frequency of $200 \mathrm{kHz}$ for the SKOV3 by analyzing the change in the resistance values with and without the applied field. We noticed no significant effect of the fields at any of the frequencies on the noncancerous cells demonstrating that this method is detrimental to cancer cells only. 


\section{Task 2: Focus on optimal frequency}

Once the optimal frequency was determined, other studies were performed using these particular frequencies to find the appropriate parameters to ultimately create an ideal method for cancer electrotherapy treatments. To understand how the low intensity alternating electric fields affect the cell behavior, the field was applied at the beginning of the experiment and also after the cells had attained a confluent monolayer. Digital images were taken at various time points throughout the experiment to observe any changes in the cell morphology.

After applying the electric field to a confluent cell layer, we noticed a decrease in the resistance values indicating disruption in the cell proliferation. We documented the changes in the cell morphology with the digital images taken before and after the field was applied. Two additional methods for measuring cell viability after exposure to the alternating electric fields were performed to justify the results obtained by the EIS. Immunofluorecence images were taken using Propidium Iodide, a fluorescent molecule that binds to the DNA of cells, and a cell viability assay was performed using Trypan Blue, a dye that cannot penetrate the intact cell membranes of viable cells.

\section{Task 3: Other types of cancer cells}

According to Kirson et al. [79], different types of cancer cells react to alternating electric fields differently. It was observed that this difference was frequency dependent since the cell membrane electric impedance properties are dependent on frequency. 
After completing Tasks 1 and 2, we studied a different type of cancer cell line, breast cancer cells (MCF7), to further understand the mechanism behind the phenomenon. We tested the same frequencies as with the SKOV3 $(50,100,150,200$ $\mathrm{kHz}$ and $2 \mathrm{MHz}$ ) of low intensity alternating electric fields in order to determine an optimal frequency that will hinder the cell proliferation for this cell line. Tests were also performed on non-cancerous mammary endothelial cells (MCF10A) for a comparison. After testing this range of frequencies of low intensity alternating electric fields, we obtained an optimal frequency of $100 \mathrm{kHz}$ for the MCF7 by analyzing the change in the resistance values. We noticed no significant effect of the fields on the non-cancerous cells demonstrating that this method is detrimental to cancer cells only.

Specific Aim 3: Antibody-Nanoparticle Enhancement of Cancer Electrotherapy Task 1: Nanoparticle enhancement of electric field effects

Nanoparticles have been extensively studied for use in biomedical applications, particularly gold nanoparticles, due to their low cytotoxicity [80]. Specifically, gold nanoparticles are being studied for use in targeted drug deliveries to specific cells [81]. Further experiments using gold nanoparticles were performed to determine if the nanomaterials enhance the effects of the electric fields towards the SKOV3 and MCF 7 without affecting non-cancerous HUVECs and MCF10a. We observed a lowering in the resistance values of the SKOV3 and MCF7 cells under the electric field with presence of the gold nanoparticles. 


\section{Task 2: Antibody functionalization of nanoparticles for targeted delivery}

HER2, human epidermal growth factor receptor 2, is a cell membrane surface-bound receptor tyrosine kinase that is responsible for intracellular signal transduction and ultimately cell growth and differentiation [82]. HER2 overexpression leads to cancerous cell proliferation and is seen in cancers such as breast cancer, ovarian cancer, stomach cancer, and even lung cancer [83].

We proposed that nanoparticles functionalized with specific antibodies to target the cancer cells would enhance the effects of the electric field towards the cells without affecting the non-cancerous cells due to the different membrane properties of the cancerous cells. With the attached nanoparticles, the cell membrane is more vulnerable to the effects of the external electric field due to the decrease in membrane potential, as seen in the decrease in zeta potentials of the cells before and after nanoparticle incorporation. The decrease in membrane potential would thus leave the cells more vulnerable to the detrimental effects of the applied electric field. Finally, an Annexin V/ EthD-III assay was performed to determine whether the cell death mechanism involved after the application of the field was apoptosis or necrosis. 


\subsection{References}

1. Clark, L.C., Jr. (1956) Monitor and control of blood tissue $\mathrm{O}_{2}$ tensions. Transactions - American Society for Artificial Internal Organs 2, 41-48.

2. Luong J.H.T., Male K.B., Glennon J.D. (2008) Biosensor technology: technology push versus market pull, Biotechnology Advances 26, 492-500.

3. Katz, E., Willner, I. (2003) Probing biomolecular interactions at conductive and semiconductive surfaces by impedance spectroscopy: Routes to impedimetric immunosensors, DNA-sensors, and enzyme biosensors, Electroanalysis 15, 913947.

4. Song, S., Xu, H., Fan, C. (2006) Potential diagnostic applications of biosensors: current and future directions, International Journal of Nanomedicine 1, 433-440.

5. Pancrazio, J.J., Whelan, J.P., Borkholder, D.A., Ma, W., Stenger, D.A. (1999) Development and Application of Cell-Based Biosensors, Annals of Biomedical Engineering 27, 697-711.

6. Bianco, A., Kostarelos, K., Prato, M. (2005) Applications of carbon nanotubes in drug delivery, Current Opinion in Chemical Biology 9, 674-679.

7. Slowing, I.I., Trewyn, B.G., Giri, S., Lin, V.S.Y. (2007) Mesoporous Silica Nanoparticles for Drug Delivery and Biosensing Applications, Advanced Functional Materials 17, 1225-1236.

8. Faraji, A.H., Wipf, P. (2009) Nanoparticles in cellular drug delivery, Bioorganic and Medicinal Chemistry 17, 2950-2962.

9. Harrison, B.S., Atala, A. (2007) Carbon nanotube applications for tissue engineering, Biomaterials 28, 344-353.

10. Kim, J., Lee, J.E., Lee, S.H., Yu, J.H., Lee, J.H., Park, T.G., Hyeon, T. (2008) Designed Fabrication of a Multifunctional Polymer Nanomedical Platform for Simultaneous Cancer-Targeted Imaging and Magnetically Guided Drug Delivery, Advanced Materials 20, 478-483.

11. Shi, D. (2009) Integrated multifunctional nanosystems for medical diagnosis and treatment, Advanced Functional Materials 19, 3356-3373. 
12. Oberdörster, G., Maynard, A., Donaldson, K., Castranova, V., Fitzpatrick, J., Ausman, K., Carter, J., Karn, B., Kreyling, W., Lai, D., Olin, S., MonteiroRiviere, N., Warheit, D., Yang, H. (2005) Principles for characterizing the potential human health effects from exposure to nanomaterials: elements of a screening strategy, Environmental health perspectives 113, 823-839.

13. Kreyling, W.G., Semmler-Behnke, M., Moller, W. (2006) Health implications of nanoparticles, Journal of Nanoparticle Research: an interdisciplinary forum for nanoscale science and technology 8, 543-562.

14. Blackiston, D.J., McLaughlin, K.A., Levin, M. (2009) Bioelectric controls of cell proliferation: ion channels, membrane voltage and the cell cycle, Cell Cycle 8, 3527-3536.

15. Lock, F.E., Underhill-Day, N., Dunwell, T., Matallanas, D., Cooper, W., Hesson, L., Recino, A., Ward, A., Pavlova, T., Zabarovsky, E., Grant, M.M., Maher, E.R., Chalmers, A.D., Kolch, W., Latif, F. (2010) The RASSF8 candidate tumor suppressor inhibits cell growth and regulates the Wnt and NF-kappaB signaling pathways, Oncogene 29, 4307-4316.

16. Stuart, G.J., Palmer, L.M. (2006) Imaging membrane potential in dendrites and axons of single neurons, Pflügers Archiv: European journal of physiology 453, 403-410.

17. González, J.E., Tsien, R.Y. (1997) Improved indicators of cell membrane potential that use fluorescence resonance energy transfer, Chemistry and Biology 4, 269-277.

18. Loew, L.M. (1992) Voltage-sensitive dyes: measurement of membrane potentials induced by DC and AC electric fields, Bioelectromagnetics Supplemental 1, 179189.

19. Thomas, C.A., Jr., Springer, P.A., Loeb, G.E., Berwald-Netter, Y., Okun, L.M. (1972) A miniature microelectrode array to monitor the bioelectric activity of cultured cells, Experimental Cell Research 74, 61-66.

20. Nowak, K., Mix, E., Gimsa, J., Strauss, U., Sriperumbudur, K.K., Benecke, R., Gimsa, U. (2011) Optimizing a Rodent Model of Parkinson's Disease for Exploring the Effects and Mechanisms of Deep Brain Stimulation, Parkinson's Disease 414682.

21. Asphahani, F., Zhang, M. (2007) Cellular Impedance Biosensors for Drug Screening and Toxin Detection, Analyst 132, 835-841. 
22. Kivirand, K., Kagan, M., Rinken, T. (2013). Calibrating Biosensors in FlowThrough Set-Ups: Studies with Glucose Optrodes, State of the Art in Biosensors General Aspects, (Ed. T. Rinken), ISBN: 978-953-51-1004-0, InTech, DOI: $10.5772 / 54127$

23. Updike, S.J., Hicks, J.P. (1967) The enzyme electrode, Nature 214, 986-988.

24. Guilbault, G.G., Montalvo, J. (1969) A urea-specific enzyme electrode, Journal of the American Chemical Society 91, 2164-2569.

25. Cooney, C.L., Weaver, J.C., Tannebaum, S.R., Faller, S.R., Shields, D.V., Jahnke, M. (1974) Enzyme Engineering (Eds. E.K. Pye and L.B. Wingard Jr.) 2, 411-417. Plenum, New York

26. Mosbach, K., Danielsson, B. (1974) An Enzyme Thermistor, Biochimica et Biophysica Acta 364, 140-145.

27. Voelkl, K.P., Opitz, N., Lubbers, D.W. (1980) Continuous measurement of concentrations of alcohol using a fluorescence-photometric enzymatic method, Fresenius Zeitschrift für Analytische Chemie 301, 162-163.

28. Clemens, A.H., Chang, P.H., Myers, R.W. (1976) Development of an automatic system of insulin infusion controlled by blood sugar, its system for the determination of glucose and control algorithms, Journées Annuelles de Diabétologie de l'Hôtel-Dieu, Paris.

29. Gross, G.W., Rieske, E., Kreutzberg, G.W., Meyer, A. (1977) A new fixed-array multi-microelectrode system designed for long-term monitoring of extracellular single unit neuronal activity in vitro, Neuroscience Letters 6, 101-105.

30. Gross, G.W., Williams, A.N., Lucas, J.H. (1982) Recording of spontaneous activity with photoetched microelectrode surfaces from mouse spinal neurons in culture, Journal of Neuroscience Methods 5, 13-22.

31. Gross, G.W., Rhoades, B.K., Reust, D.L., Schwalm, F.U. (1993) Stimulation of monolayer networks in culture through thin-film indium-tin oxide recording electrodes, Journal of Neuroscience Methods 50, 131-143.

32. McConnell, H.M., Owicki, J.C., Parce, J.W., Miller, D.L., Baxter, G.T., Wada, H.G., Pitchford, S. (1992) The cytosensor microphysiometer: biological applications of silicon technology, Science 257, 1906-1912. 
33. Zysk, J.R., Baumbach, W.R. (1998) Homogeneous pharmacologic and cell-based screens provide diverse strategies in drug discovery: somatostatin antagonists as a case study, Combinatorial Chemistry High Throughput Screening 1, 171-183.

34. Borkholder, D.A., DeBusschere, B.D., Kovacs, G.T.A. (1998) An Approach to the Classification of Unknown Biological Agents with Cell Based Sensors, Technical Digest of the 1998 Solid-State Sensor and Actuator Workshop 178-182.

35. Giaever, I., Keese, C.R. (1984) Monitoring fibroblast behavior in tissue culture with an applied electric field, Proceedings of the National Academy of Sciences of the United States of America 81, 3761-3764

36. Giaever, I., Keese, C.R. (1986) Use of electric fields to monitor the dynamical aspect of cell behavior in tissue culture, IEEE Transactions on Biomedical Engineering 33, 242-247.

37. Giaever, I., Keese, C.R. (1989) Fractal Motion of Mammalian Cells, Physica D: Nonlinear Phenomena 38, 128-133.

38. Giaever, I., Keese, C.R. (1991) Micromotion of mammalian cells measured electrically, Proceedings of the National Academy of Sciences of the United States of America 88, 7896-7900.

39. Giaever, I., Keese, C.R. (1992) Toxic? Cells can tell, Chemtech February, 116125.

40. Giaever, I., Keese, C.R. (1993) A morphological biosensor for mammalian cells, Nature 366, 591-592.

41. Connolly, P., Clark, P., Dow, J.A.T., Curtis, A.S.G., Lind, R., Wilkinson, C.D.W. (1989) Extracellular electrodes for monitoring cell cultures, Institute of Physics Short Meeting Series No. 21.

42. Soto, K.F., Carrasco, A., Powell, T.G., Garza, K.M., Murr, L.E. (2005) Comparison in vitro cytotoxicity assessment of some manufactured nanoparticulate materials characterized by transmission electron microscopy, Journal of Nanoparticle Research : an interdisciplinary forum for nanoscale science and technology 7,145-169.

43. Hillegass, J.M., Shukla, A., Lathrop, S.A., MacPherson, M.B., Fukagawa, N.K., Mossman, B.T. (2009) Assessing nanotoxicity in cells in vitro, Wiley Interdisciplinary Reviews: Nanomedicine and Nanobiotechnology 2, 219-231. 
44. Soenen, S.J., Rivera-Gil, P., Montenegro, J.M., Parak, W.J., De Smedt, S.C., Braeckmans, K. (2011) Cellular toxicity of inorganic nanoparticles: Common aspects and guidelines for improved nanotoxicity evaluation, Nano Today 6, 446465.

45. Lewinski, N., Colvin, V., Drezek, R. (2008) Cytotoxicity of nanoparticles, Small 4, 26-49.

46. Mossman, B.T., Borm, P.J., Castranova, V., Costa, D.L., Donaldson, K., Kleeberger, S.R. (2007) Mechanisms of action of inhaled fibers, particles and nanoparticles in lung and cardiovascular diseases, Particle and Fibre Toxicology $4,1-4$.

47. Elder, A., Vidyasagar, S., DeLouise, L. (2009) Physicochemical factors that affect metal and metal oxide nanoparticle passage across epithelial barriers, Wiley Interdisciplinary Reviews. Nanomedicine and Nanobiotechnology 1,434-450.

48. Cundy, A.B., Hopkinson, L., Whitby, R.L.D. (2008) Use of iron-based technologies in contaminated land and groundwater remediation: a review, Science of The Total Environment 400, 42-51.

49. Besov, A.S., Krivova, N.A., Vorontsov, A.V., Zaeva, O.B., Kozlov, D.V., Vorozhtsov, A.B., Parmon, V.N., Sakovich, G.V., Komarov, V.F., Smirniotis, P.G., Eisenreich, N. (2010) Air detoxification with nanosize $\mathrm{TiO}_{2}$ aerosol tested on mice, Journal of Hazardous Materials 173, 40-46.

50. Zhang, L., Fang, M. (2010) Nanomaterials in pollution trace detection and environmental improvement, Nano Today 5, 128-142.

51. Ghosh, P.S., Kim, C.K., Han, G., Forbes, N.S., Rotello, V.M. (2008) Efficient gene delivery vectors by tuning the surface charge density of amino acidfunctionalized gold nanoparticles, ACS Nano 2, 2213-2218.

52. Liu, Y., Yu, D., Zeng, C., Miao, Z., Dai, L. (2010) Biocompatible graphene oxide-based glucose biosensors, Langmuir 26, 6158-6160.

53. Biswas, S., Drzal, L.T. (2009) A Novel Approach to Create a Highly Ordered Monolayer Film of Graphene Nanosheets at the Liquid-Liquid Interface, Nano Letters 9, 167-172.

54. Hurt, R.H., Monthioux, M., Kane, A. (2006) Toxicology of carbon nanomaterials: status, trends, and perspectives on the special issue, Carbon 44, 1028-1033. 
55. Chang, Y., Yang, S.T., Liu, J.H., Dong, E., Wang, Y., Cao, A., Liu, Y., Wang, H. (2011) In vitro toxicity evaluation of graphene oxide on A549 cells, Toxicology Letters 200, 201-210.

56. Fenoglio, I., Greco, G., Tomatis, M., Muller, J., Raymundo-Pinero, E., Beguin, F., Fonseca, A., Nagy, J.B., Lison, D., Fubini, B. (2008) Structural defects play a major role in the acute lung toxicity of multiwall carbon nanotubes: physicochemical aspects, Chemical Research in Toxicology 21, 1690-1697.

57. Pulskamp, K., Diabaté, S., Krug, H.F. (2007) Carbon nanotubes show no sign of acute toxicity but induce intracellular reactive oxygen species in dependence on contaminants, Toxicology Letters 168, 58-74.

58. Alwarappan, S., Erdem, A., Liu, C., Li, C.Z. (2009) Probing the electrochemical properties of graphene nanosheets for biosensing applications, The Journal of Physical Chemistry C 113, 8853-8857.

59. Liu, C., Alwarappan, S., Chen, Z., Kong, X., Li, C.Z. (2010) Membraneless enzymatic biofuel cells based on graphene nanosheets, Biosensors and Bioelectronics 25, 1829-1833.

60. Zhang, Y., Ali, S.F., Dervishi, E., Xu, Y., Li, Z., (2010) Casciano, D., Biris, A.S. Cytotoxicity effects of graphene and single-wall carbon nanotubes in neural phaeochromocytoma-derived PC12 cells, ACS Nano 4, 3181-3186.

61. Shao, Y., Wang, J., Wu, H., Liu, J., Aksay, I. A., Lin, Y. (2009) Graphene Based Electrochemical Sensors and Biosensors: A Review, Electroanalysis 22, 10271036.

62. Chen, H., Müller, M.B., Gilmore, K.J., Wallace, G.G., Li, D. (2008) Mechanically Strong, Electrically Conductive, and Biocompatible Graphene Paper, Advanced Materials 20, 3557-3561.

63. Liu, Z., Chen, K., Davis, C., Sherlock, S., Cao, Q., Chen, X., Dai, H. (2008) Drug delivery with carbon nanotubes for in vivo cancer treatment, Cancer Research 68, 6652-6660.

64. Sun, X., Liu, Z., Welsher, K., Robinson, J., Goodwin, A., Zaric, S., Dai, H. (2008) Nano-Graphene Oxide for Cellular Imaging and Drug Delivery, Nano Research 1, 203-212.

65. Hussain, S.M., Hess, K.L., Gearhart, J.M., Geiss, K.T., Schlager, J.J. (2005) In vitro toxicity of nanoparticles in BRL 3A rat liver cells, Toxicology in Vitro: an international journal published in association with BIBRA 19, 975-983. 
66. Wilhelm, C., Gazeau, F., Roger, J., Pons, J.N., Bacri, J.C. (2002) Interaction of anionic superparamagnetic nanoparticles with cells: kinetic analysis of membrane adsorption and subsequent internalization, Langmuir 18, 8148-8155.

67. American Cancer Society, Cancer Facts \& Figures 2011

68. Barker, A.T. (1984) Pulsed Magnetic Field Therapy for Tibial Non-Union, Lancet 8384, 994-996.

69. Ieran, M., Zaffuto, S., Bagnacani, M., Annovi, M., Moratti, A., Cadossi, R. (1990) Effect of low frequency pulsing electromagnetic fields on skin ulcers of venous origin in humans: A double-blind study, Journal of Orthopaedic Research $8,276-282$.

70. Sandyk, R. (1997) Therapeutic effects of alternating current pulsed electromagnetic fields in multiple sclerosis, Journal of Alternative and Complementary Medicine 3, 365-386.

71. Song, L., Chau, L., Sakamoto, Y., Nakashima, J., Koide, M., Tuan, R.S. (2004) Electric field-induced molecular vibration for noninvasive, high-efficiency DNA transfection, Molecular Therapy 9, 607-616.

72. Golzio, M., Rols, M.P., Teissie, J. (2004) In vitro and in vivo electric fieldmediated permeabilization, gene transfer, and expression, Methods 33, 126-135.

73. Teissie, J., Escoffre, J.M., Rols, M.P., Golzio, M. (2008) Time dependence of electric field affects on cell membranes. A review for a critical selection of pulse duration for therapeutic applications, Radiology and Oncology 42, 196-206.

74. Fantozzi, F., Arturoni, E., Barbucci, R. (2010) The effects of the electric fields on hydrogels to achieve antitumoral drug release, Bioelectrochemistry 78, 191-195.

75. Fricke, H., Morse, S. (1926) The electrical capacity of tumors of the breast, Journal of Cancer Research 10, 340-376.

76. Barnes, P.J., Shapiro, S.D., Pauwels, R.A. (2003) Chronic obstructive pulmonary disease: molecular and cellular mechanisms, European Respiratory Journal 22, $672-688$.

77. Brayner, R. (2008) The toxicological impact of nanoparticles, NanoToday 3, 4855.

78. Connor, E.E., Mwamuka, J., Gole, A., Murphy, C.J., Wyatt, M.D. (2005) Gold nanoparticles are taken up by human cells but do not cause acute cytotoxicity, Small 1, 325-327. 
79. Kirson, E.D., Gurvich, Z., Schneiderman, R., Dekel, E., Itzhaki, A., Wasserman, Y., Schatzberger, R., Palti, Y. (2004) Disruption of cancer cell replication by alternating electric fields, Cancer Research 64, 3288-3295.

80. De Jong, W.H., Borm, P.J.A. (2008) Drug delivery and nanoparticles: Applications and hazards, International Journal of Nanomedicine 3, 133-149.

81. Hondroulis, E., Liu, C., Li, C.Z. Whole cell based electrical impedance sensing approach for a rapid nanotoxicity assay, Nanotechnology 21, 315103.

82. Lantz, E., Cunningham, I., Higa, G.M. (2010) Targeting HER2 in breast cancer: overview of long-term experience, International Journal of Women's Health 1, 155-171.

83. Menard, S., Casalini, P., Campiglio, M., Pupa, S., Agresti, R., Tagliabue, E. (2001) HER2 over-expression in various tumor types, focusing on its relationship to the development of invasive breast cancer, Annals of Oncology 12, S15-S19. 


\section{Chapter 2}

\section{WHOLE CELL BASED ELECTRICAL IMPEDANCE SENSING APPROACH FOR A RAPID NANOTOXICITY ASSAY}

This chapter was submitted as follows (with slight modifications): Hondroulis, E., Liu, C., Li, C.Z. (2010) Whole cell based biosensing device for in vitro nanotoxicity assay at cellular and tissue level, Nanotechnology 21, 315103.

\subsection{Introduction}


Nanotechnology has great potential benefits in rapidly developing fields such as biomedical engineering, drug delivery, environmental health, pharmaceutical industries and even electronics and communication technologies. For instance, in the healthcare field, nanomaterials are being considered in the development of new drugs and new therapies for disease control and improving the quality of life. More recently, nanomaterials have been used in tissue engineering and medical imaging, leading to improved diagnostics and new therapeutic treatments. With the increasing number of nanomaterial applications, assessing their toxicity should be the first important step toward creating safety guidelines for their handling and disposal as these new nanoscale materials (including nanotubes, nanowires, nanowhiskers, fullerenes or buckyballs and quantum dots) might have unintended hazards for human health and the environment [12]. Current technologies to measure nanotoxicity are limited in the sense that they only provide final time point data. Assessing the real-time effects of the nanomaterials on cellular behavior is crucial for developing knowledge on the nanomaterial behavior.

The main risks associated with the use and manufacture of nanomaterials is human and environmental exposure. Testing for toxicological parameters is a necessary first step toward ensuring the compatibility of nanomaterials for medical applications and for the safety of the environment as the properties of metals change when they are in the nanoscale and they may pose certain threats to biological and ecosystems that their bulk counterparts may not. One of the more common impacts of the use of nanomaterials is the emission of hazardous air pollutants which contain particulate matter on the order of $1-100 \mathrm{~nm}$ in size. Any material in the respirable size range, less than $100 \mathrm{~nm}$ in diameter, 
may have toxic effects on the lung fibroblasts after inhalation [3]. In particular, nanoparticles with sizes less than $20 \mathrm{~nm}$ affect the alveolar region of the lung [4]. More recently, the use of nanomaterials in biomedical sciences has placed nanomaterials directly in contact with biological materials, and thus it is necessary to observe their interaction closely.

In the environment, nanotechnology is being used to solve problems such as soil and groundwater remediation, air purification, pollution detection and sensing. Manufactured nanoparticles are being engineered for projects that will benefit the environment as well in the form of environmental cleanup tools, for example for groundwater for remediation. For instance, in the UN Millennium Project, fullerenes are being used to absorb various toxins and iron nanoparticles to catalyze the breakdown of solvents. There have been debates on whether the disposal of these manufactured nanoparticles causes significant harm to the environment as there is a lack of validated protocols for their disposal and removal [5].

To date, nanotoxicity is a crucial topic that is being addressed by a number of studies [6]; however, there is a lack of consensus in the published literature on nanoparticle toxicity due to the variability of methods, materials and cell lines used [7]. With the increase in research and commercial use of these nanomaterials, standardization of methods in nanotoxicity testing is becoming increasingly important to validate these novel techniques. Recent studies measuring nanoparticle cytotoxicity in vitro provide a final measurement of toxicity to a cell culture overlooking the ongoing cytotoxic effects of the nanoparticles over the desired timeframe. Traditional biological methods for 
measurement of cellular activity and proliferation are used in current nanotoxicity studies. These methods include mitochondrial reduction of tetrazolium salts into an insoluble dye (the MTT test) and enzyme lactate dehydrogenase (LDH) release tests. These methods are used as markers for cell viability and consist of procedures that provide a general sense of cytotoxicity as they show results only at a final time point [8]. As a result, the kinetic model (absorption, distribution, metabolism and excretion) of the nanoparticle uptake is not usually observed with these conventional methods. Following biological exposure, the particles may transport across cell membranes, especially into mitochondria, causing internal damage that may affect cell behavior and over time, lead to cell death [9].

Biosensors are becoming valuable tools for detecting toxic chemical compounds in industrial products, chemical substances, environmental samples (e.g. air, soil and water) or biological systems (e.g. bacteria, viruses or tissue components). Most current biosensors are used to detect enzymes, DNA/RNA and immunological components [10]. Biosensors that incorporate whole cells can have an advantage over these previous biosensors as they are able to provide information about the total physiological effect of a toxin towards the whole cell.

The first goal of this dissertation was to validate the use of a biosensor for monitoring cellular behavior. We used a whole cell based array-formatted electrical impedance sensing system (EIS) capable of monitoring cell morphological changes in real-time to test human and environmental toxicity of nanoscale materials and to ultimately evaluate the sensors suitability for various cytotoxicity measurements. We 
used the EIS to monitor the kinetic effects of AuNPs; 10, $100 \mathrm{~nm}, \mathrm{AgNPs} ; 10,100 \mathrm{~nm}$, SWCNTs; cut, uncut, and CdO when in contact with human lung fibroblasts (CCL-153) and rainbow trout gill epithelial cells (RTgill-W1). The EIS measures the resistance produced by growing cell monolayers over electrodes and can detect changes in resistance that may occur with changes in the cell layer after nanoparticle exposure. The EIS offers compact structure, ease of use and the ability to measure multiple samples simultaneously in real time, a critical feature in monitoring cytotoxicity. Moreover, the EIS chip is sensitive enough to measure the micro-motion of a cell and therefore able to monitor the progression of the cytotoxicity demonstrating the kinetic effects of the nanoparticles on the cells. The results obtained from the EIS studies were compared to the Sulforhodamine B colorimetric (SRB) assay commonly used for cytotoxicity screening.

\subsection{Experimental Details}

\subsubsection{Chemicals and reagents}

Acetone, isopropyl alcohol (IPA), phosphate-buffered saline (PBS), sodium phosphate $\left(\mathrm{Na}_{2} \mathrm{HPO}_{4}\right)$, potassium dihydrogen phosphate $\left(\mathrm{KH}_{2} \mathrm{PO}_{4}\right)$, potassium chloride $(\mathrm{KCl})$, sodium hydroxide $(\mathrm{NaOH})$, hydrogen tetrachloroaurate $\left(\mathrm{HAuCL}_{4}\right)$, trisodium citrate $\left(\mathrm{Na}_{3} \mathrm{C}_{6} \mathrm{H}_{5} \mathrm{O}_{7}\right)$, sodium borohydride $\left(\mathrm{NaBH}_{4}\right)$, silver nitrate $\left(\mathrm{AgNO}_{3}\right)$, sulfuric acid $\left(\mathrm{H}_{2} \mathrm{SO}_{4}\right)$ nitric acid $\left(\mathrm{HNO}_{3}\right)$, trichloroacetic acid and acetic acid were all purchased from Fisher. CdO and SWCNTs were purchased from Sigma Aldrich.

\subsubsection{Nanomaterial selection and preparation}


The nanomaterials in this study-AuNPs, AgNPs and SWCNTs-were chosen for the reason that they have attracted substantial research efforts for potential biomedical and energy applications [11-15].

Synthesis of AuNPs - $\mathrm{HAuCL}_{4}(40 \mathrm{ml}, 1.0 \mathrm{mM})$ was added to an Erlenmeyer flask (250 $\mathrm{ml})$, stirred and brought to the boil on a hotplate. $\mathrm{Na}_{3} \mathrm{C}_{6} \mathrm{H}_{5} \mathrm{O}_{7}(4 \mathrm{ml}, 1 \%)$ was added to the boiling solution. Three minutes after the addition of $\mathrm{Na}_{3} \mathrm{C}_{6} \mathrm{H}_{5} \mathrm{O}_{7}, 100 \mathrm{~nm} \mathrm{Au}$ particles formed. An additional 10 minutes of stirring produced $10 \mathrm{~nm}$ AuNPs. Phase imaging and force spectroscopy were performed by AFM and TEM to characterize the nanoparticles.

Synthesis of $A g N P s-\mathrm{NaBH}_{4}(60 \mathrm{ml}, 2 \mathrm{mM})$ was added to an Erlenmeyer flask $(250 \mathrm{ml})$ placed in an ice-bath and stirred. To this solution, $\mathrm{AgNO}_{3}(4 \mathrm{ml}, 1.0 \mathrm{mM})$ solution was added and stirred. Three minutes after the addition of $\mathrm{AgNO}_{3}, 100 \mathrm{~nm} \mathrm{Ag}$ particles were formed and upon stirring for 30 more minutes, $10 \mathrm{~nm} \mathrm{Ag} \mathrm{particles} \mathrm{were} \mathrm{formed.} \mathrm{Phase}$ imaging and force spectroscopy were performed by AFM and TEM to characterize the nanoparticles.

Preparation of SWCNTs - The SWCNTs were placed into a 3:1 mixture of $95 \% \mathrm{H}_{2} \mathrm{SO}_{4}-$ $60 \%\left(\mathrm{HNO}_{3}\right)$. The solution was sonicated for 5 hours and following this the sample was dried in an oven for 24 hours. Phase imaging and force spectroscopy were performed by AFM and TEM to characterize the nanoparticles.

\subsubsection{Cell culture}


CCL-153 ${ }^{\mathrm{TM}}$ and RTgill-W1 ${ }^{\mathrm{TM}}$ cells were purchased from American Type Culture Collection (ATCC, Rockville, MD, USA) and were cultured in F-12K medium and Leibovitz's L-15 medium, respectively, with each of the media containing $10 \%$ fetal bovine serum, $0.3 \mathrm{mg} \mathrm{ml}^{-1}$ L-glutamine, $100 \mathrm{U} \mathrm{ml}^{-1}$ penicillin and $100 \mathrm{mg} \mathrm{ml}^{-1}$ streptomycin. The cell cultures were placed in an incubator $\left(37^{\circ} \mathrm{C}, 5 \% \mathrm{CO}_{2}\right.$ atmosphere $)$ for 24 hours prior to the experiment so that the cells reached confluency with a final concentration of $10^{6}$ cells ml ${ }^{-1} .0 .4 \mathrm{ml}$ of cell suspension was inoculated into each well in the EIS for the experiment.

\subsubsection{EIS chip fabrication}

Photolithographic technology was employed for the gold patterning of the microelectrode array on the substrate. A mask defines the area of the chip that will be exposed to UV light. The mask is placed on top of the photoresist during the exposure process so that only the photoresist under the transparent part of the mask gets exposed. Our fabrication procedure required two lithography masks, one for defining the pattern of the gold electrode circuit and the other for defining the SU-8 isolating polymer layer. The masks were made by sputtering a thin chromium layer on a 4' $\times 4^{\prime}$ glass slide. A positive photoresist (AZ1518) was spin coated on top of the thin chromium layer. Figure 2.1 illustrates the flow diagrams of the fabrication of the mask on the left and the microelectrode array on the right. 


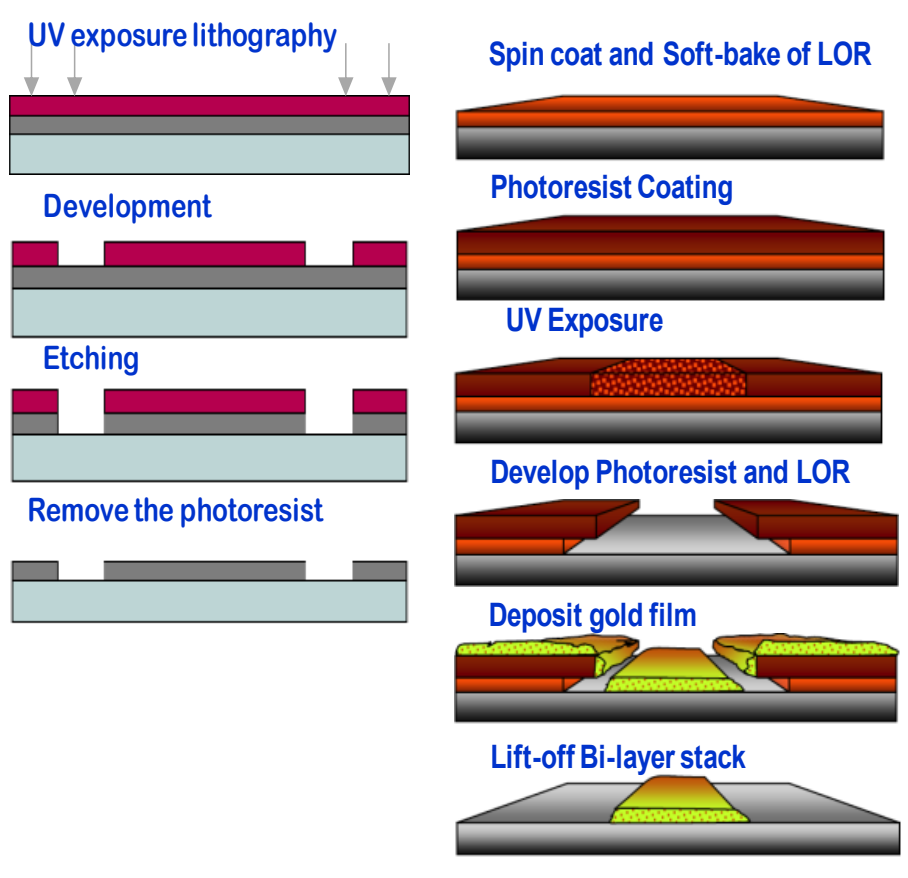

Figure 2.1 - Flow diagram of fabrication of the mask (left) and the array chip (right).

Substrate cleaning and dehydration - To provide a conductive and transparent sidewall for both electrochemical and optical monitoring, a clear microscope slide was used as the substrate. The slide was cleaned with acetone, rinsed with deionized (DI) water and then baked at $200{ }^{\circ} \mathrm{C}$ for 5 minutes on a contact hotplate.

Sacrifice layer coating - MicroChem's LOR 3B was spin coated at $2500 \mathrm{rpm}$ for 45 seconds followed by 10 minutes of baking on a hotplate at $150{ }^{\circ} \mathrm{C}$. On top of the LOR layer, AZ1518 positive photoresist was spin coated at $3500 \mathrm{rpm}$ for 45 seconds and baked in the oven at $110{ }^{\circ} \mathrm{C}$ for 6 minutes.

Exposure and development - After baking, the photoresist was exposed through a mask under $12.5 \mathrm{~mW} \mathrm{~cm}{ }^{-2}$ for 15 seconds (total dose is $187.5 \mathrm{~mW} \mathrm{~cm}^{-2}$ ). The slide was then submerged in a 1:4 diluted AZ400K developer for 60 seconds for development. 
Deposition - $10 \mathrm{~nm}$ of Ti thin film was deposited with a growth rate of $3 \mathrm{~nm}$ per minute at room temperature by a rf-magnetron sputtering system (AJA) using a Ti target. After Ti deposition, a $150 \mathrm{~nm}$ (7 minutes) Au thin film was deposited on top of the Ti thin film. Both the Ti and Au deposition was done in Ar ambient (10 sccm flow rate) at $75 \mathrm{~W}$ of $\mathrm{rf}$ power, $5 \mathrm{mTorr}$ pressure and room temperature.

Lift-off - The slide was then submerged in MicroChem's Remover PG and the sacrificial layer was dissolved to form the desired pattern.

Protection layer coating - SU-8 was spin coated onto the slide at $2000 \mathrm{rpm}$ for 45 seconds followed by 13 minutes of baking on a hotplate at $95{ }^{\circ} \mathrm{C}$.

Final exposure and development - The photoresist was exposed through the mask under $12.5 \mathrm{~mW} \mathrm{~cm}^{-2}$ for 24 seconds (total dose is $300 \mathrm{~mW} \mathrm{~cm}^{-2}$ ) and then baked on a hotplate for $16 \mathrm{~min}$ at $95^{\circ} \mathrm{C}$. The substrate was finally dipped in SU-8 developer for 4 minutes, and rinsed with IPA and DI water.

\subsubsection{Electrochemical measurements}

Cyclic voltammetric and differential pulse voltammetric measurements were carried out using a CHI-630A electrochemical analyzer (CH Instruments, Inc., Austin, TX, USA). The required redox solutions were freshly prepared every day before the start of experiments. PBS $(0.1 \mathrm{M})$ containing $\mathrm{Na}_{2} \mathrm{HPO}_{4}(50 \mathrm{mM}), \mathrm{KH}_{2} \mathrm{PO}_{4}(50 \mathrm{mM})$ and $\mathrm{KCl}$ (100 mM) was adjusted to $\mathrm{pH} 7.2$ by adding $\mathrm{NaOH}(0.1 \mathrm{M})$. 


\subsubsection{AFM and TEM}

Phase imaging and force spectroscopy were performed by using a Multimode Nanoscope IIIa system from Veeco Instruments (Santa Barbara, CA, USA) in air with a relative humidity $40-50 \%$ at room temperature. A $200 \mathrm{keV}$ transmission electron microscope (Hitachi HF-2000 FEG) was used to analyze the structure and composition of the nanomaterials. The TEM samples were dispersed in ethanol followed by sonication for 15 minutes. The suspension was placed onto a copper grid covered with a carbon thin film for analysis.

\subsubsection{Sulforhodamine B (SRB) assay}

The sulforhodamine B (SRB) assay was used for comparison of results by measuring cell density based on the measurement of cellular protein content. SRB is commonly used for toxicity screening of materials to adherent cells. CCL-153 ${ }^{\mathrm{TM}}$ and RTgill-W1TM were inoculated in a 12-well plate with a concentration of $10^{6} \mathrm{cells} \mathrm{ml}^{-1}$ in each well. After an incubation period of 48 hours, the cell monolayers were fixed with $10 \%(\mathrm{wt} / \mathrm{vol})$ trichloroacetic acid and stained for 30 minutes, after which the excess dye was removed by washing repeatedly with $1 \%$ ( $\mathrm{vol} / \mathrm{vol}$ ) acetic acid. The protein-bound dye was dissolved in $10 \mathrm{mM}$ Tris base solution for optical density determination at 510 nm using a microplate reader. 


\subsection{Results and Discussion}

\subsubsection{Impedance and resistance measurements using EIS chip}

The EIS chip design (Figure 2.2) consists of an array of eight detecting gold electrodes ( $250 \mu \mathrm{m}$ in diameter) each on the bottom of individual tissue culture wells of volume $9 \times 9 \times 10 \mathrm{~mm}^{3}$ to measure the change in impedance to $\mathrm{AC}$ current flow (approximately $1 \mu \mathrm{A}$ ). A gold counter electrode $\left(7 \times 46 \mathrm{~mm}^{2}\right)$ is linked to each individual detecting electrode.

To provide a conductive and transparent sidewall for both electrochemical and optical monitoring, a clear microscope slide $(3 " \times 1.5 " \times 1.2 \mathrm{~mm})$ was used as the substrate, on top of which a $200 \mathrm{~nm}$ thick gold thin film was patterned by photolithographic technology based upon the designed electrical circuit. Since the sensing mechanism of the system is based upon the measurement of electrode surface resistances, the electrode surface area plays an important role in the sensitivities. The impedance of the circuit with a resistance $(R)$ and a capacitor $(C)$ in series can be measured for each well by applying an alternating potential (AC) to the two electrodes present in the EIS chip through a $1 \mathrm{M} \Omega$ resistor. Cells are placed in each well, drift downward and attach themselves onto the electrode surface over time. The current flowing though each electrode is now impeded by the cell monolayer, increasing the impedance and resistance measurements. The smaller sized detecting electrode will dominate the overall impedance in the circuit which will increase in just a few hours as the cells gradually attach to the surface. From Ohm's law, $V=I R$, it is possible to 
monitor the cell attachment and proliferation from the increase in impedance or resistance measurements.

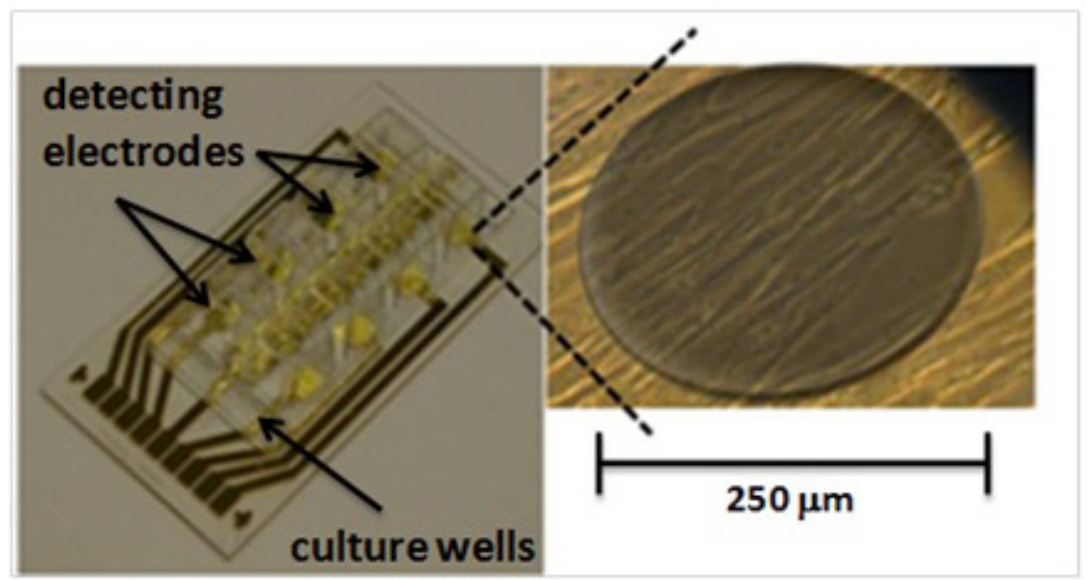

Figure 2.2 - Design of the electrical impedance sensing chip showing the array of eight detecting gold electrodes. The cells attach on the electrode surface altering the measured resistance values

Using this system, nanotoxicity measurements can be made by monitoring the change in resistance of each electrode. An extremely toxic material would cause the cells to die and detach from the electrode at a rapid rate which, in turn, would decrease the resistance reading of the system. On the other hand, a nontoxic material would not affect the attachment of the cells; hence the resistance measurements would be similar to the measurements of the cells by themselves (control).

An array design was chosen for the electrodes because of its potential to measure multiple experimental designs simultaneously, allowing side by side comparison of the various nanomaterials tested. This design also allows for relatively short measurement times as the EIS is able to detect any interference in cell attachment within a few hours. 


\subsubsection{Electrochemical characterization of the EIS chip}

In order to successfully monitor cellular activity, we performed cyclic voltammetry, one of the most widely used techniques for acquiring qualitative information about electrochemical reactions, to test the reproducibility and sensitivity of the EIS biosensor. Electrochemical testing of the EIS biosensor is done to ensure consistent and accurate readings for every experiment. In situ biosensor testing also allows for rejection of biosensors which might have been damaged due to improper storage or handling (e.g. at excessive temperatures) ensuring accurate data.

Quality electrochemical testing of the chips immediately before the measurements will markedly increase the reliability of the chip's performance. In situ chip testing not only provides the possibility to correct minor chip fabrication errors, but also allows rejection of chips which might have been damaged due to improper storage or handling (e.g. at excessive temperatures). The electrochemical testing was carried out by running cyclic voltammetry $(\mathrm{CV})$ using a potassium ferricyanide $\left(\mathrm{Fe}(\mathrm{CN})_{6}{ }^{3-/ 4-}\right)$ redox probe. $\mathrm{CV}$ is the most widely used technique for acquiring qualitative information about electrochemical reactions. During the potential sweep, the potentiostat measures the redox current resulting from the applied potential using the Randles-Sevcik equation [16]:

$$
i_{p}=\left(2.69 \times 10^{5}\right) n^{3 / 2} A C D^{1 / 2} v^{1 / 2}
$$

where $i_{p}$ is the peak current, $n$ is the number of electrons, $A$ is the surface area of the working electrode, $C$ is the bulk concentration of the electroactive species, $D$ is the diffusion coefficient of the electroactive species and $v$ is the scan rate of voltammograms. 
The sensing electrode activity and the actual active electrode surface can be best understood by carefully examining the current-concentration profiles during the potential sweep. Four observables from the cyclic voltammetric response, the two peak currents and two peak potentials, provide the basis for quality testing of the sensing electrodes.

The functionality of the EIS chip was measured by performing $\mathrm{CV}$ in $\mathrm{Fe}(\mathrm{CN})_{6}{ }^{3-/ 4-}$ (Figure 2.3). The gold microelectrodes designed in our laboratory exhibited reversibility $\left(\Delta \mathrm{E}_{\mathrm{p}}=64 \mathrm{mV}\right)$ with a $6 \%$ attenuation in the observed peak current value after four consecutive cycles showing high electrochemical activity and reproducible responses of the redox probes.

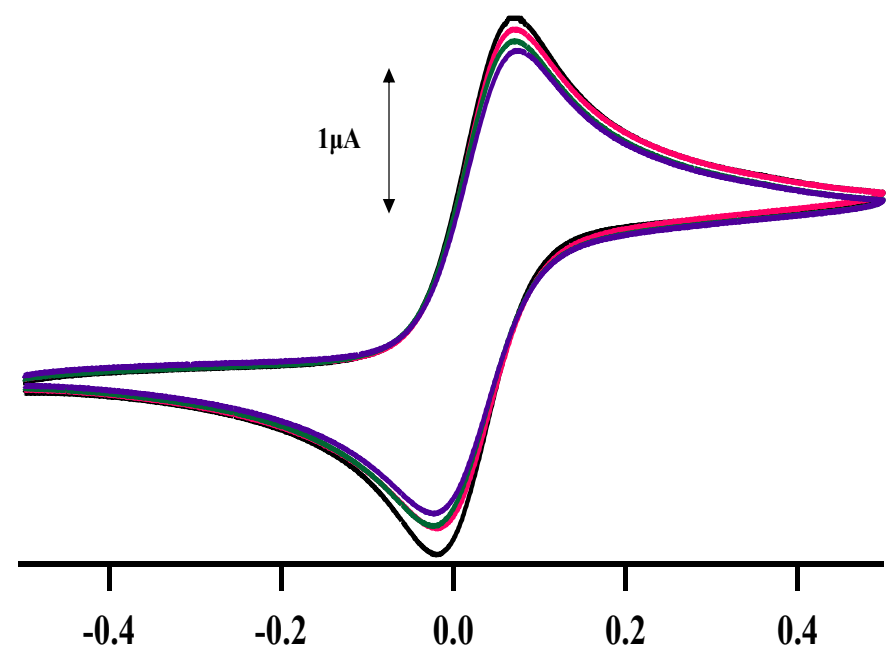

$\mathrm{E} \mid \mathrm{V}$ vs $\mathbf{A g} \mid \mathbf{A g C l}$

Figure 2.3. Cyclic voltammogram of four electrodes on the fabricated EIS chip demonstrating the reproducibility of electrochemical activities of the fabricated gold microelectrodes 


\subsubsection{Nanomaterial characterization}

In order to perform the nanotoxicity studies, we first fabricated and characterized the nanomaterials using standard fabrication protocols and TEM imaging. The nanoparticles tested in this study, AuNPs $(10,100 \mathrm{~nm}), \operatorname{AgNPs}(10,100 \mathrm{~nm})$ and SWCNTs (cut, uncut), were all characterized using TEM and AFM (Figure 2.4). The AuNPs and AgNPs were fabricated at different sizes $(10$ and $100 \mathrm{~nm})$ and the SWCNTs be purified in diluted acids to prevent unwanted contamination of impurities as specific properties of the materials depend on their size and purity. The EIS was then used to monitor the behavior of the nanomaterials in real-time over 40 hours on different $2 \mathrm{D}$ living cell models (CCL-153, RTgill-W1) after exposure to the nanomaterials.
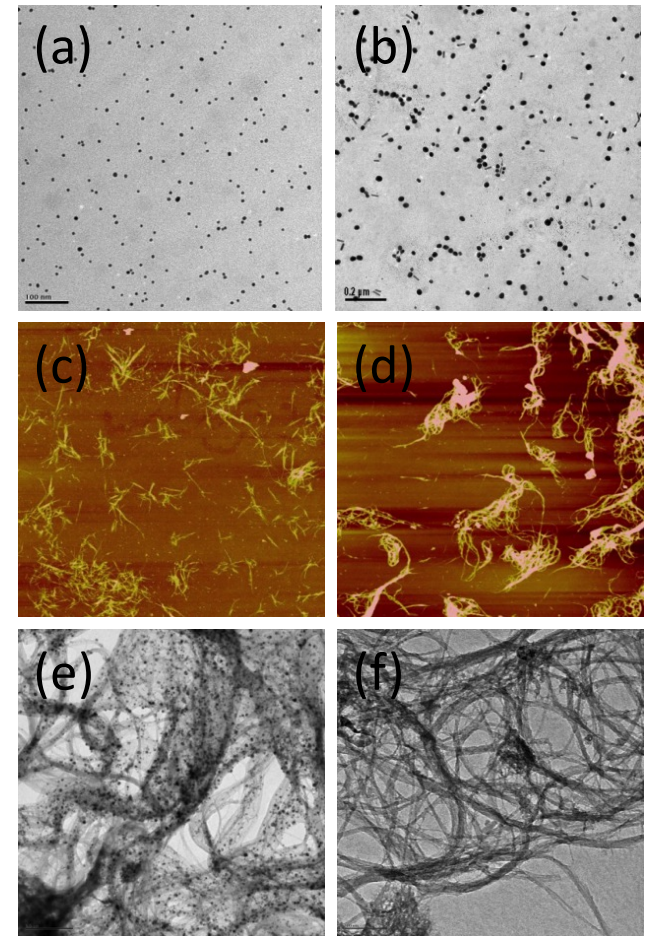

Figure 2.4. Transmission electron microscopy imaging of: (a) AuNPs (10 nm), (b) AgNPs (10 nm), (c) cut SWCNTs, (d) SWCNTs, (e) raw SWCNTs and (f) purified SWCNTs. 
Nanomaterial characterization is necessary as specific properties of the materials depend on their size and purity. The SWCNTs used in this study were purified in diluted acids. Purified SWCNTs were tested to prevent unwanted contamination of impurities such as amorphous carbon, graphite and catalyst metal particles which may reside on the tubes. The AuNPs and AgNPs were fabricated at different sizes (10 and $100 \mathrm{~nm}$ ) to further understand the size effects of the particles and the underlying mechanisms that govern the uptake of nanoparticles into cells. Most cell types undergo phagocytosis or endocytosis to eliminate large particles that interact with the cell membrane; however, the smaller sized particles may bypass the natural mechanical barriers of the cells which may result in severe tissue damage [17]. Once inside the cells, the nanoparticles may interfere with the functions of the cell's organelles and other biomolecular structures leading to damage and even death of the cell. The exact mechanisms of this process are still not fully understood [18-19]. However, with the EIS, the affects of the cellular uptake of the nanoparticles on the proliferation of the cells will be demonstrated.

\subsubsection{Cell exposure to cadmium oxide}

$\mathrm{CdO}$, which is extremely toxic, was employed to demonstrate the ability of the EIS to measure kinetic effects of the nanoparticles before and after exposure to both CCL-153 and RTgill-W1 cell lines. Cadmium is a toxic material that has been shown to cause lysosomal damage and DNA breakage in mammalian cells and disrupt mitochondrial function and promote apoptosis [20]. 
In the first setup, the $\mathrm{CdO}$ was added to the wells along with the cells in the beginning of the experimental run. This was done to observe the rapid toxic effects of the $\mathrm{CdO}$ towards the cells. The resistance changes produced by the attachment of cells to the electrodes were monitored over a 40 hour time period (Figures 2.5(a) and 2.6(a) green lines (C lines)). Results indicated that upon inoculation of the $\mathrm{CdO}$ particles, a steady resistance value was observed (similar to the resistance value of the blank) indicating disruption in cell attachment. In the second setup, the cells were allowed to grow on the electrode to confluency over a period of 20 hour before the $\mathrm{CdO}$ was added. This setup would provide the kinetics of the interaction of $\mathrm{CdO}$ with the cells. Once the $\mathrm{CdO}$ was added to the cells, we observed a rapid decrease in the resistance values measured, eventually returning to readings similar to the blank, indicating cell detachment and the harsh cytotoxic effect of CdO towards both CCL-153 and RTgill-W1 (Figures 2.5(a) and 2.6(a) blue lines (D lines)). These results demonstrate the capability of the EIS to monitor cytotoxicity instantaneously and continuously. 

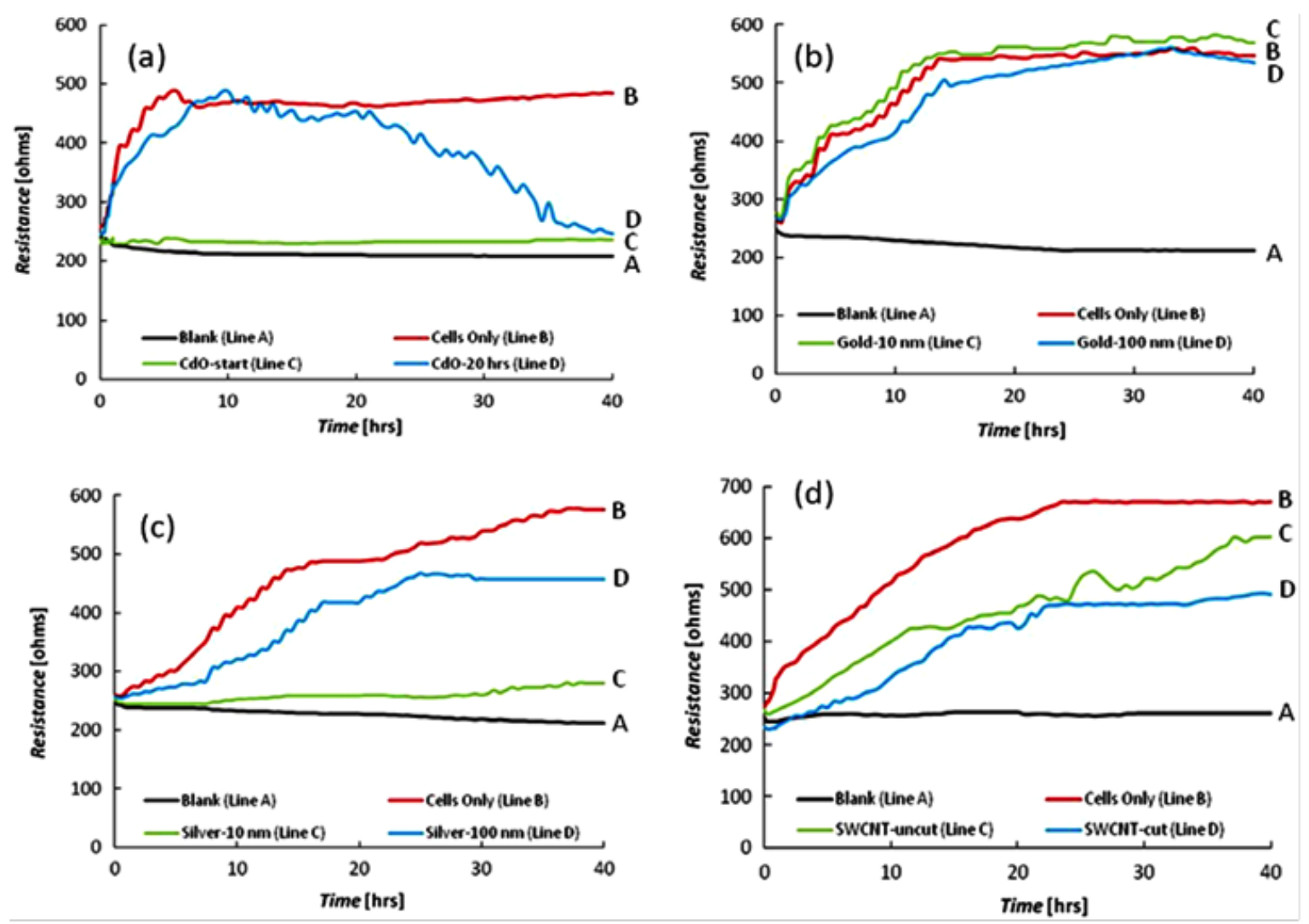

Figure 2.5 - Resistance readings for CdO (a), Au (b), Ag (c) and SWCNT (d) on CCL-153. Lines A and B in all graphs represent the Blank and the Control (cells only) resistance readings. In (a), $\mathrm{CdO}$ is added initially (line C) and after 20 hours of cell attachment (line D). In (b), lines C and D represent AuNPS sized $10 \mathrm{~nm}$ and $100 \mathrm{~nm}$ respectively. In (c), lines C and D represent AgNPS sized $10 \mathrm{~nm}$ and $100 \mathrm{~nm}$ respectively, and in (d), lines $\mathrm{C}$ and D represent the cut and uncut SWCNTs respectively 

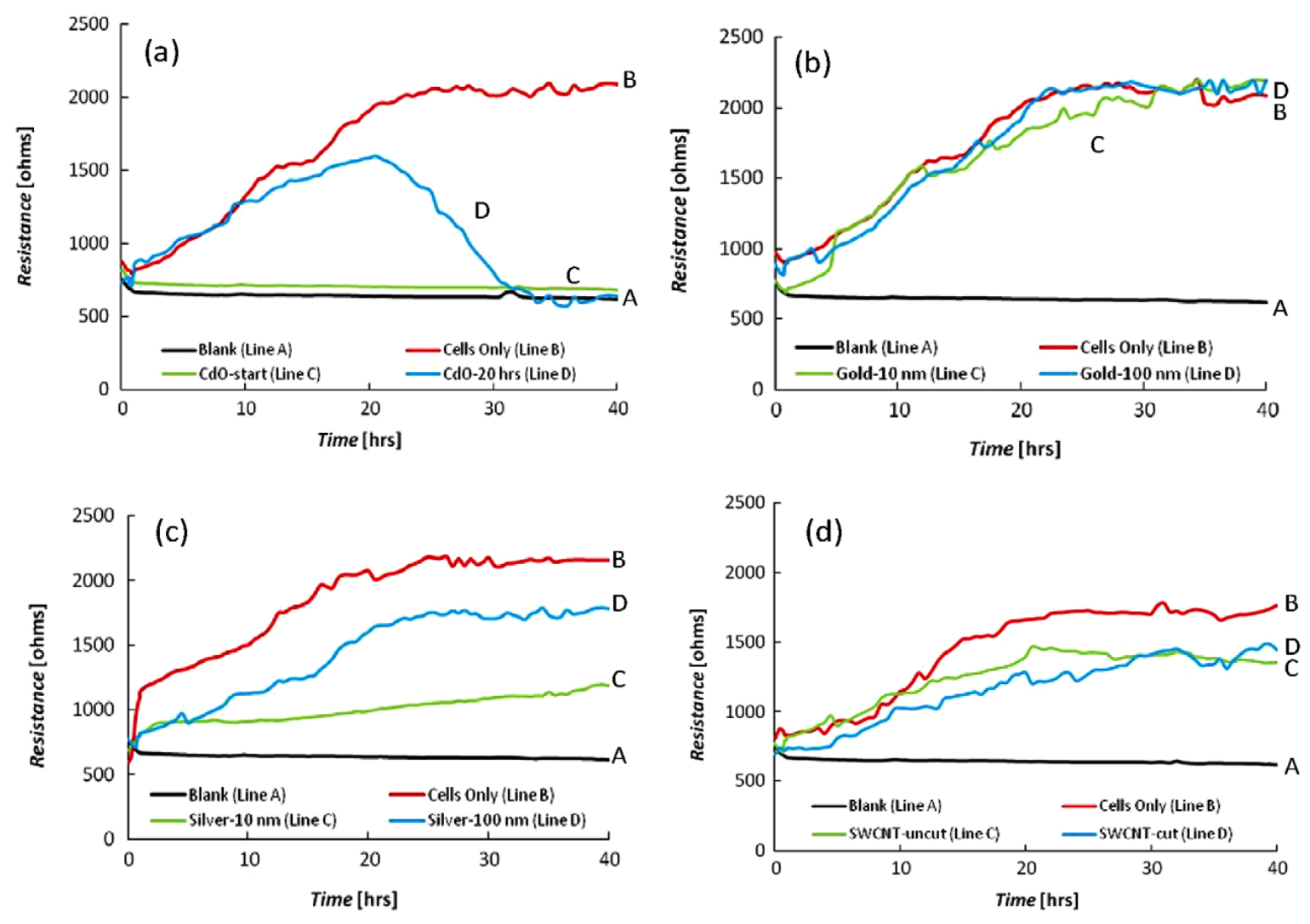

Figure 2.6. Resistance readings for $\mathrm{CdO}$ (a), $\mathrm{Au}$ (b), $\mathrm{Ag}$ (c) and SWCNT (d) on RTgill-W1. Lines A and B in all graphs represent the Blank and the Control (cells only) resistance readings. In (a), CdO is added initially (line C) and after 20 hours of cell attachment (line D). In (b), lines C and D represent AuNPS sized

$10 \mathrm{~nm}$ and $100 \mathrm{~nm}$ respectively. In (c), lines C and D represent AgNPS sized $10 \mathrm{~nm}$ and $100 \mathrm{~nm}$ respectively, and in (d), lines C and D represent the cut and uncut SWCNTs respectively.

\subsubsection{Cell exposure to gold and silver nanoparticles}

AuNPs have been reported to exhibit inert properties, as previous studies have shown that AuNPs with a size less than $100 \mathrm{~nm}$ did not induce any adverse effects in human cells [18-19]. Due to these inert properties, AuNPs are often employed in research for various applications such as gene and drug delivery transfection vectors, DNAbinding agents and in various imaging systems [5]. 
The cytotoxic measurements of AuNPs (10,100 nm) towards CCL-153 and RTgill-W1 over a 40 hour time period showed little difference in resistance values to those observed for the control (Figures 2.5(b) and 2.6(b) green and blue lines $(\mathrm{C}$ and $\mathrm{D}$ lines) respectively). From this observation, it is evident that AuNPs have few cytotoxic effects on both the CCL-153 and the RTgill-W1.

In contrast, Ag has been shown to exhibit a strong toxicity to a wide range of micro-organisms and is widely used in antibacterial solutions [21], and when eukaryotic cells are exposed to Ag nanoparticles an apoptotic effect is noticed [22]. When CCL-153 and RTgill-W1 cells were both exposed to AgNPs $(10,100 \mathrm{~nm})$ noticeable changes in resistance were observed. The measurements for the $100 \mathrm{~nm}$ AgNPs exhibited overall lower resistance values compared to the control, indicating a slower attachment rate of the cells (Figures 2.5(c) and 2.6(c) green lines (C lines)). However, for the $10 \mathrm{~nm}$ sized particles, the resistance changes were very small, almost negligible, showing a stronger cytotoxicity for the smaller particles (Figures 2.5(c) and 2.6(c) blue lines (D lines)). The observed phenomena may be attributed to the fact that the smaller AgNPs can enter the cell easily and possibly interfere with the cellular mechanism thereby decreasing the cell attachment and thus lowering the resistance values.

\subsubsection{Cell exposure to SWCNTs}

Rapid advancements in SWCNTs research call for a clearer picture of their cytotoxicity as the effects of SWCNT surface chemistry, surface area and aggregation on the cell cycle is not well established [20]. Further, the length of the SWCNTs is an important factor to consider, as it is evident from previous works that ultra-short 
SWCNTs can be used as reinforcing agents to enhance the mechanical properties of certain polymers in various biomedical applications [23]. Shorter SWCNTs may affect the cells in a different manner than their longer counterparts as they may enter and damage the cells more easily.

We have thus evaluated the cytotoxic effect of SWCNTs (cut and uncut) on CCL153 and RTgill-W1 cells by monitoring the resistance values over $40 \mathrm{~h}$. Results indicated that the SWCNTs (cut and uncut) exhibited a similar decrease in the resistance value to the control (Figures 2.5(d) and 2.6(d) green and blue lines ( $\mathrm{C}$ and $\mathrm{D}$ lines) respectively). From this, it is evident that SWCNTs affected the growth mechanism of the CCL-153 and RTgill-W1.

\subsubsection{Sulforhodamine B (SRB) assay}

The optical density values obtained from the SRB assay correlate with total protein content and therefore with cell number. Table 2.1 lists the values obtained for the SRB assays with CdO, AuNPs, AgNPs and SWCNTs.

\begin{tabular}{ll}
\hline & Optical Density \\
\hline Control & 2.7 \\
CdO & 0.6 \\
AuNPs (10 nm) & 2.5 \\
AuNPs (100 nm) & 2.6 \\
\hline AgNPs (10 nm) & 1.3 \\
\hline AuNPs (100 nm) & 1.6 \\
\hline SWCNTs (cut) & 2.2 \\
\hline SWCNTs (uncut) & 2.1 \\
\hline
\end{tabular}

Table 2.1 - Optical density values obtained from the SRB assay on CCL-153. 


\subsection{Conclusion}

With the increasing number of nanomaterial applications, assessing their toxicity should be the first important step toward creating safety guidelines for their handling and disposal. In this work, we have successfully designed an EIS chip and evaluated its suitability for various cytotoxicity measurements by electrochemical experiments. Results indicated that the EIS chip exhibited a stable and reproducible response when measuring the effects of various nanomaterials-AuNPs (10, $100 \mathrm{~nm}), \operatorname{AgNPs}(10,100$ nm), SWCNTs (cut, uncut) and CdO — towards CCL-153 and RTgill-W1 cells. Moreover, the EIS chip was sensitive enough to measure the micro-motion of a cell and therefore was able to monitor the progression of the cytotoxicity demonstrating the kinetic effects of the nanoparticles on the cells. Further, the EIS chip allowed rapid, real-time and multisample analysis creating a versatile, noninvasive tool that is able to provide quantitative information with respect to alteration in cellular function under various nanomaterial exposures. 


\subsection{References}

1. Oberdörster, G., Maynard, A., Donaldson, K., Castranova, V., Fitzpatrick, J., Ausman, K., Carter, J., Karn, B., Kreyling, W., Lai, D., Olin, S., MonteiroRiviere, N., Warheit, D., Yang, H. (2005) Principles for characterizing the potential human health effects from exposure to nanomaterials: elements of a screening strategy, Particle and Fibre Toxicology 2, 8.

2. Kreyling, W.G., Semmler-Behnke, M., Moller, W. (2006) Health implications of nanoparticles, Journal of nanoparticle research: an interdisciplinary forum for nanoscale science and technology 8, 543-562.

3. Mossman, B.T., Borm, P.J., Castranova, V., Costa, D.L., Donaldson, K., Kleeberger S.R. (2007) Mechanisms of action of, inhaled fibers, particles and nanoparticles in lung and cardiovascular diseases, Particle and Fibre Toxicology $4,1-4$

4. Elder, A., Vidyasagar, S., DeLouise, L. (2009) Physicochemical factors that affect metal and metal oxide nanoparticle passage across epithelial barriers Wiley Interdisciplinary Reviews. Nanomedicine and Nanobiotechnology. 1 434-450

5. Ghosh, P.S., Kim, C.K., Han, G., Forbes, N.S., Rotello, V.M. (2008) Efficient gene delivery vectors by tuning the surface charge density of amino acidfunctionalized gold nanoparticles, ACS Nano 2, 2213-2218

6. Soto, K.F., Carrasco, A., Powell, T.G., Garza, K.M., Murr, L.E. (2005) Comparative in vitro cytotoxicity assessment of some manufactured nanoparticulate materials characterized by transmission electron microscopy, Journal of Nanoparticle Research: an interdisciplinary forum for nanoscale science and technology 7, 145-169

7. Lewinski, N., Colvin, V., Drezek, R. (2008) Cytotoxicity of nanoparticles, Small 4, 26-49

8. Hussain, S.M., Hess, K.L., Gearhart, J.M., Geiss, K.T., Schlager, J.J. (2005) In vitro toxicity of nanoparticles in BRL 3A rat liver cells, Toxicology in Vitro: an international journal published in association with BIBRA 19, 975-983

9. Wilhelm, C., Gazeau, F., Roger, J., Pons, J.N., Bacri, J.C. (2002) Interaction of anionic superparamagnetic nanoparticles with cells: kinetic analyses of membrane adsorption and subsequent internalization, Langmuir 18, 8148-8155

10. Luong, J.H.T., Male, K.B., Glennon, J.D. (2008) Biosensor technology: technology push versus market pull, Biotechnology Advances 26, 492-500 
11. Banerjee, R., Katsenovich, Y., Lagos, L., Senn, M., Naja, M., Balsamo, V., Pannell, K.H., Li, C.Z. (2010) Functional magnetic nanoshells integrated nanosensor for trace analysis of environmental uranium contamination Electrochim. Acta. 55, 7897-7902

12. Liu, C., Alwarappan, S., Li, C.Z. (2010) Design and characterization of novel membraneless enzymatic biofuel cell based on graphene nanosheets, Biosensors and Bioelectronics 7, 1829-1833

13. Alwarappan, S., Li, C.Z. (2010) Simultaneous detection of dopamine, ascorbic acid and uric acid at electrochemically activated carbon nanotube biosensors, Nanomedicine: Nanotechnology, Biology and Medicine 6, 52-57

14. Alwarappan, S., Prabhulkar, S., Durygin, A., Li, C.Z. (2009) The effect of electrochemical pretreatment on the sensing performance of single walled carbon nanotubes, Journal of Nanoscience and Nanotechnology 9, 2991-2996

15. Li, C.Z., Choi, W.B., Chuang, C.H. (2008) Enhancement of photocurrents by finite-sized SWNT based thin films, Electrochimica Acta 54, 821-828

16. Bard, A.J., Faulkner, L.R. (2001) Electrochemical Methods: Fundamental and Applications $2^{\text {nd }}$ Edition (New York: Wiley)

17. Barnes, P.J., Shapiro, S.D., Pauwels, R.A. (2003) Chronic obstructive pulmonary disease: molecular and cellular mechanisms, The European Respiratory Journal $22,672-688$

18. Brayner, R. (2008) The toxicological impact of nanoparticles, NanoToday 3, 4855

19. Connor, E.E., Mwamuka, J., Gole, A., Murphy, C.J., Wyatt, M.D. (2005) Gold nanoparticles are taken up by human cells but do not cause acute cytotoxicity, Small 1, 325-327

20. Tian, F., Cui, D., Schwarz, H., Estrada, G.G., Kobayashi, H. (2006) Cytotoxicity of single-wall carbon nanotubes on human fibroblasts, Toxicology in Vitro: an international journal published in association with BIBRA 20, 1202-1212

21. Elechiguerra, J.L., Burt, J.L., Morones, J.R., Camacho-Bragado, A., Gao, X., Lara, H.H., Yacaman, M.J. (2005) Interaction of silver nanoparticles with HIV-1, Journal of Nanobiotechnology 3,6 
22. Arora, S., Jain, J., Rajwade, J.M., Paknikar, K.M. (2009) Interactions of silver nanoparticles with primary mouse fibroblasts and liver cells, Toxicology and applied pharmacology 236, 310-318

23. Xinfeng, S., Balaji, S., Quynh, P.P., Patrick, P.S., Jared, L.H., Lon, J.W., James, M.T., Robert, M.R., Antonios, G.M. (2008) In vitro cytotoxicity of single-walled carbon nanotube/biodegradable polymer nanocomposites, Journal of Biomedical Materials Research. Part A 86, 813-823 


\section{Chapter 3}

\section{IMPEDANCE BASED NANOTOXICITY ASSESSMENT OF GRAPHENE NANOMATERIALS AT THE CELLULAR AND TISSUE LEVEL}

This chapter was submitted as follows (with slight modifications): Hondroulis, E.,

Zhang, Z., Li, C.Z. (2012) Impedance based Nanotoxicity Assessment of Graphene Nanomaterials at the Cellular and Tissue Level. Analytical Letters 45, 2-3. 


\subsection{Introduction}

After successfully demonstrating the EIS' capability of monitoring the behavior of $2 \mathrm{D}$ cell cultures in real-time when exposed to various nanomaterials, we took the nanotoxicity study one step further by analyzing the effects of graphene on a novel 3D tissue model and its individual components. The interest in graphene for biomedical applications has grown substantially in the past few years creating a need for biocompatibility testing. Biomedical engineering applications using graphene such as biosensing devices, microbial detection, disease diagnosis and drug delivery systems are progressing rapidly, perhaps overlooking any possible hazards as graphene nanomaterials may interact with biological materials differently than other graphitic materials such as carbon nanotubes and fullerenes.

Graphene's structure is simple, single-atom-thick sheets of carbon; however, its potential in the scientific world has been intense. Due to its unique features, researchers have rushed to study its many potential applications such as Nanoelectronic devices, transparent conductors, and nanocomposites [1-2], while possibly overlooking any potential hazards. The cytotoxic effects of other carbon nanomaterials such as fullerenes, nanotubes, and nanofibers have been studied before with mixed results [3-4]. The general consensus for the cause of cytotoxicity of these materials seems to be due to their byproducts or residues such as metal traces and amorphous carbon which cause oxidative stress to the cells [5-7]. The cytotoxic effects of graphene may be different than those of other graphitic materials as cytotoxicity studies on graphene are far and few between. 
Biomedical engineering applications using graphene have surfaced recently in the form of biosensing devices [8-9], enzymatic biofuel cells [10], microbial detection, disease diagnosis, and drug delivery systems [11], creating a cell-graphene interface that must be explored further. Although similar in chemical composition, graphene compared to its carbon counterparts may behave differently when interacting with biological elements as it lacks the transition metals, $\mathrm{Fe}, \mathrm{Ni}$, and so forth, which are present with carbon nanotubes, for example, leading to its high purity [12]. It has been shown that cells could grow on graphene sheets [13]; however, one must still examine the cellular interaction of graphene as a nanomaterial as the graphene's properties may change and may produce certain threats to the biological systems that its bulk counterpart may not.

One major potential application of carbon based nanomaterials is for drug delivery. The use of nanomaterials for targeted drug delivery is becoming a popular topic of interest in the field of biomedical engineering with many recent advances. For instance, Z. Liu et al. [14] recently tested single walled carbon nanotubes as carriers for the drug paclitaxel to target tumors in mice and showed higher ratios of tumor to normal organ uptake of the drug-carbon nanotube combination. Using nanomaterials to transport the desired drug prevents unwanted side effects since the drug is targeted only in the desired site, and can minimize drug dilution throughout the body increasing the drug concentration delivered to the pathological area [15]. Graphene and graphene oxide with their unique properties are on the forefront of this technology [16]. 
One area of interest in particular to drug delivery is the blood brain barrier (BBB), a tight seal of endothelial cells that lines the blood vessels in the brain that selectively allows the entry of certain molecules from blood circulation into the brain. Maintaining the integrity of the BBB is an important issue when designing a drug delivery system and thus the interaction of these graphene nanomaterials with the BBB must be explored further. Recently, Z. Zhang et al. [17] created an in vitro BBB model consisting of immortalized rat astrocytes and mouse brain endothelial cells as the building blocks and a novel astrocyte derived acellular extracellular matrix (aECM) as the biomimetic basement membrane for the endothelial cells. This model proved successful in testing the transport rate of doxorubicin through the $\mathrm{BBB}$ while maintaining the integrity of the structure. In this study, the cytotoxicity of graphene nanomaterials was measured on this in vitro model by measuring the Trans Endothelial-Electrical Resistance (TEER) values of the tissue before and after exposure to the graphene.

Biosensors for real-time monitoring of cellular activity when subjected to various compounds such as nanoparticles has been the focus of this dissertation since conventional biological methods for measurement of cytotoxicity measure toxicity at a final time point. To obtain the kinetic model of the graphene uptake in the individual cells of the $\mathrm{BBB}$, it is also necessary to test the cytotoxicity of the individual components of the $\mathrm{BBB}$, rat astrocytes (CRL-2006) and mouse endothelial cells (CRL-2583) using the EIS [18-19]. 


\subsection{Experimental Details}

\subsubsection{Chemicals and reagents}

Phenol red-free Dulbecco's Modified Eagle's Medium (DMEM), 0.25\%Trypsin/EDTA, Penicillin-Streptomycin-Glutamine, Dulbecco's phosphate buffered saline (PBS), and distilled water were purchased from Invitrogen (Carlsbad, CA). Fetal bovine serum was purchased from Hyclone (Logan, UT). Mouse endothelial cells from yolk sac and rat astrocyte from 1-day old rats were purchased from American Type Culture Collection (ATCC) (Manassas, VA). Graphite and hydrazine hydrate were purchased from Sigma.

\subsubsection{Synthesis of graphene}

The graphene was synthesized in the following manner. Graphitic oxide (GO) was prepared from graphite powder as described by Hummers and Offeman (1958) [20] then was then mixed with water to yield a yellow-brown suspension. The suspension was then ultrasonicated until the solution was free of any particulates, was treated with hydrazine hydrate, and then heated in an oil bath at about $100{ }^{\circ} \mathrm{C}$ in a water cooled condenser for about 24 hours. The reduced GO gradually precipitated as a black solid which was then filtered and washed with deionized water $(5 \times 100 \mathrm{~mL})$ and methanol $(5$ $\times 100 \mathrm{~mL}$ ) then dried using continuous $\mathrm{N}_{2}$ flow for about 10 hours [9]. Figure 3.1 is a scanning electron microscope (SEM) image of the graphene produced. 


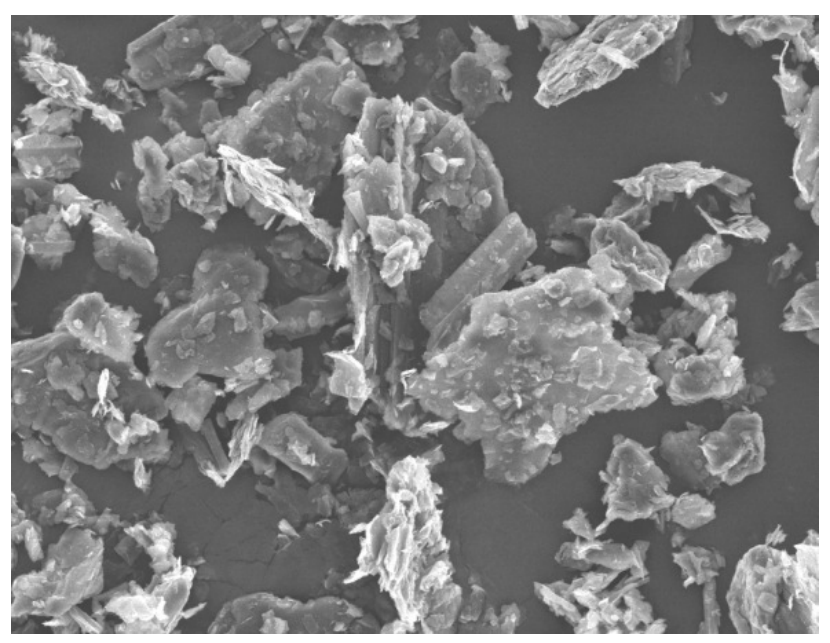

Figure 3.1 - SEM image of graphene

\subsubsection{Cell Culture}

CRL-2006 ${ }^{\mathrm{TM}}$ and CRL-2583 ${ }^{\mathrm{TM}}$ cells were purchased from American Type Culture Collection (ATCC, Rockville, MD, USA) and were cultured in DMEM supplemented with $10 \%$ FBS and 1\% Penicillin/Streptomycin. The cell cultures were placed in an incubator $\left(37^{\circ} \mathrm{C}, 5 \% \mathrm{CO}_{2}\right.$ atmosphere) for 24 hours prior to the experiment so that the cells reached confluency with a final concentration of $10^{5}$ cells $\mathrm{ml}^{-1}$.

\subsubsection{In vitro $B B B$ models}

The in vitro $\mathrm{BBB}$ model was designed with three layers: confluent mouse endothelial cells, aECM and confluent rat astrocytes grown on opposite sides of COL Transwell inserts for 24-well plates. As a control, the aECM was removed from some of the inserts to ensure the purpose of the aECM to closely mimic the in vivo $\mathrm{BBB}$. Figure 3.2 shows a schematic of the setup to create the in vitro BBB model with and without the aECM. 


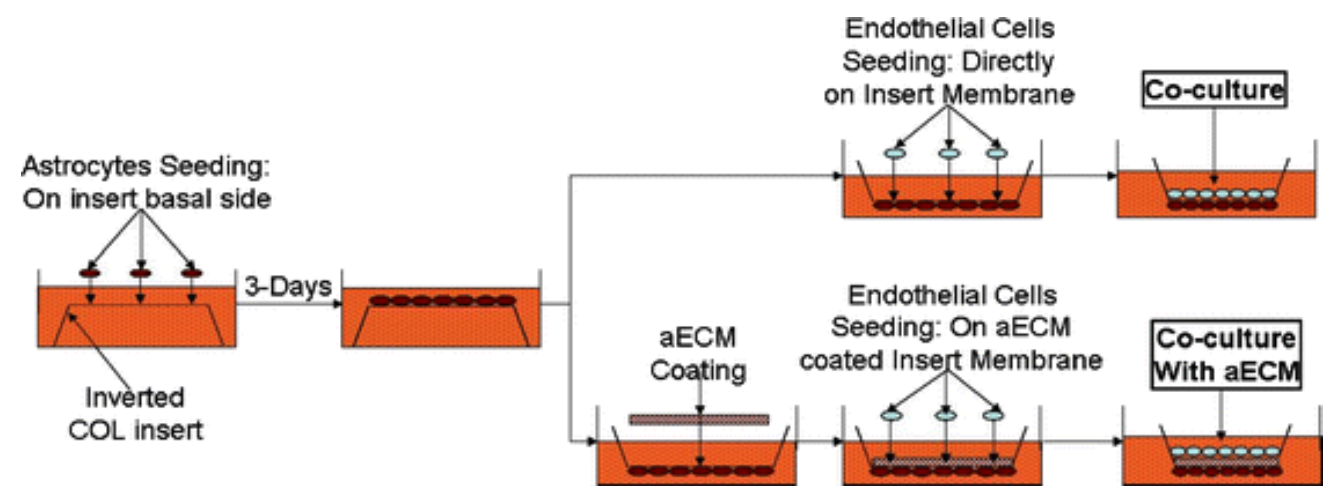

Figure 3.2 - Schematic of the setup for the in vitro BBB model showing the three layers: confluent mouse endothelial cells, aECM, and confluent rat astrocytes grown on opposite sides of COL Transwell inserts for 24-well plates and the control model without the aECM

\subsubsection{Detection of Tight Junction Protein Occludin}

One main aspect of the BBB that needs to be considered when creating an in vitro model is the formation of tight junctions that occur in vivo. To ensure that our model had the required tight junction formations, immuno-fluorescence microscopy was done on our BBB model with the aECM layer and the control model without to observe the expression of occludin, a plasma-membrane protein located specifically at the tight junctions. Figure 3.3 shows the immuno-fluorescence microscopy on the BBB model without the aECM (A) and with the aECM (B) layer. Occludin's contours could be observed in both sample setups, however, they were more abundant in the model with the aECM. The details can be found elsewhere [17]. 

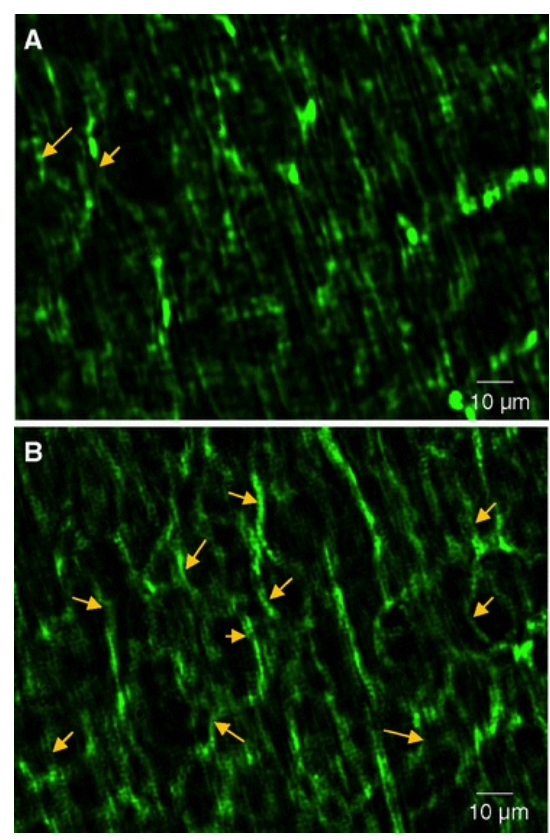

Figure 3.3 - Immuno-fluorescence microscopy on the BBB model without the aECM (A) and with the aECM (B) layer. The arrows both figures indicate the tight junctions formed.

\subsubsection{Trans Endothelial-Electrical Resistance (TEER) Measurement}

TEER values were measured for the in vitro BBB model before and after exposure to graphene for three consecutive days using $\mathrm{EVOM}^{\circledR}$ epithelial voltohmmeter with EndOhm tissue resistance measurement chambers especially designed for tissue culture inserts (World Precision Instruments, Sarasota, FL). The TEER values were calculated by taking the meter reading and multiplying by the surface area of the individual chamber. The final values were recorded in units of $\Omega \mathrm{cm}^{2}$.

\subsubsection{Resistance Measurements Using EIS chip}

The purpose of the design of the EIS chip is to allow continuous monitoring of cellular behavior, thus the design must incorporate culture wells for the cells to grow. Through photolithographic technology, the EIS chip was designed with an array of eight 
detecting gold electrodes ( $250 \mu \mathrm{m}$ in diameter) each on the bottom of individual tissue culture wells of volume $9 \times 9 \times 10 \mathrm{~mm}^{3}$ that measure the change in impedance to $\mathrm{AC}$ current flow (approximately $1 \mu \mathrm{A}$ ). Cells are placed in each well and as they gradually attach themselves to the surface of the electrode, the current though each electrode is now impeded by the cell monolayer, increasing the impedance and resistance measurements. The details can be found elsewhere [18]. $0.4 \mathrm{ml}$ of cell suspension was inoculated into each well in the EIS chip for the experiments.

\subsection{Results and Discussion}

With the increasing number of cytotoxicity studies on carbon based materials such as carbon nanotubes [21-22] and fullerenes [23-24] attention needs to be focused on the 2D counterpart graphene. Very few studies have been done on graphene toxicity; however, the results look promising. Graphene paper has been shown to be biocompatible because L929 cells were successfully cultivated on it [25], and graphene

oxide has been used to create glucose biosensors with good biocompatibility [1]. However, once in nanoparticle form, the size and shape of the graphene can change the interaction of the graphene and the biological material.

\subsubsection{BBB Tissue Toxicity}

In the first experiment, the integrity of the in vitro model of the BBB after exposure to graphene nanomaterials was tested. Trans-Endothelial Electrical Resistance (TEER) values were taken for the empty COL Transwell inserts (blank), the in vitro BBB model (control), the model with graphene nanomaterials, and the model with cadmium oxide $(\mathrm{CdO})$ as a negative control. The TEER values show the confluence of a cell 
monolayer with the increase in resistance values. Figure 3.4 is a graph of the TEER measurements taken each day over a timeframe of three days. The results indicate that the TEER values of the in vitro BBB model after exposure to graphene nanomaterials remained similar to the TEER values of the model control, each increasing as the monolayers start to form. The TEER values of the model incorporated with $\mathrm{CdO}$ demonstrated a sharp decrease as expected since cadmium is a known toxin that has been shown to cause lysosomal damage, DNA breakage, disruption of mitochondrial function, and promotion of apoptosis in mammalian cells [26]. With the graphene present, the integrity of the in vitro BBB model remained strong thus showing the low cytotoxicity of graphene toward the tissue model.

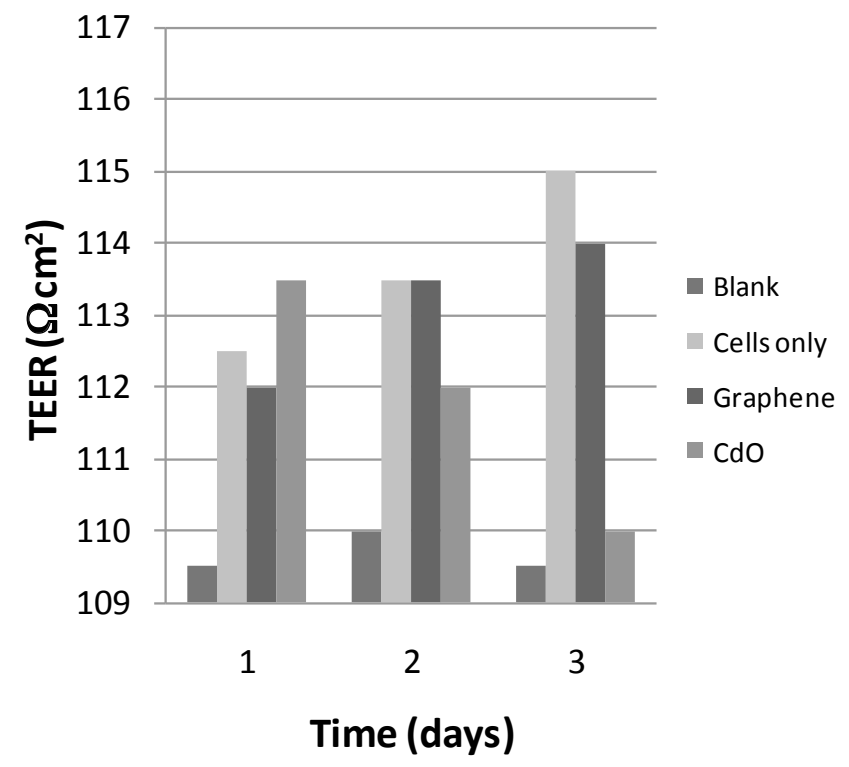

Figure 3.4 - Trans-Endothelial Electrical Resistance (TEER) values taken for the empty COL Transwell inserts (blank), the in vitro BBB model (control), the model with graphene nanomaterials, and the model with cadmium oxide $(\mathrm{CdO})$ as a negative control. The resistance values of the in vitro model should increase as the days progress due to the growth of the cells in the insert. The results show consistent resistance values in both the control and the graphene samples over a three day timeframe and a decrease in resistance values for the $\mathrm{CdO}$ 


\subsubsection{BBB Cellular Component Toxicity}

On the cellular level, the EIS chip was used to detect cytotoxicity of astrocytes and endothelial cell monolayers by monitoring the change in resistance of each electrode with the cells in place. A typical cell attachment curve would have a continuous increase in resistance at a rate depending on the proliferation rate of the type of cells studied. If an extremely toxic material were added to the sample, such as $\mathrm{CdO}$, there would be a decrease in the resistance values compared to the control as the cells would be damaged and eventually detach from the electrode. This can be seen in the resistance values of both the CRL-2006 and the CRL-2583 when exposed to the negative control CdO seen in

Figures 3.5 and 3.6, respectively. With both cell types, the resistance levels remained at a fairly constant level indicating very low cell attachment and thus cell death.

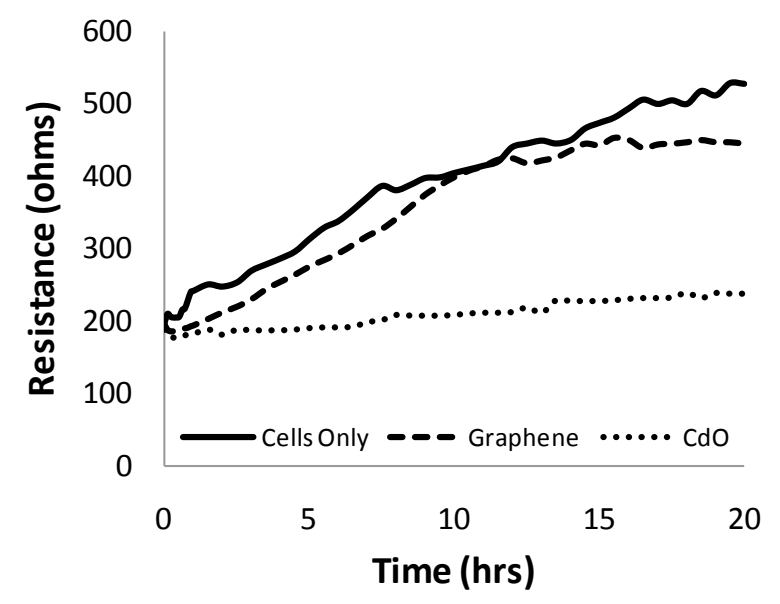

Figure 3.5 - Resistance measurements for rat astrocytes CRL-2006 over 20 hours. The solid line and the dashed line represent the resistance measurements for the astrocytes and the astrocytes with graphene nanomaterials respectively. The resistance measurements are very similar indicating low cytotoxicity of graphene toward the astrocytes as compared to the $\mathrm{CdO}$ resistance values which remain low indicating low cell attachment 


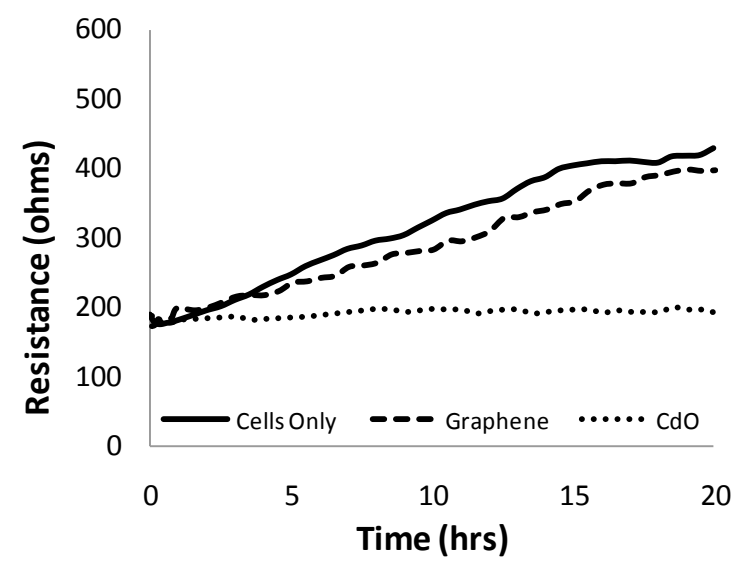

Figure 3.6 - Resistance measurements for mouse endothelial cells CRL-2583 over 20 hours. The solid line and the dashed line represent the resistance measurements for the endothelial cells and the endothelial cells with graphene nanomaterials respectively. The resistance measurements are very similar indicating low cytotoxicity of graphene toward the endothelial cells as compared to the $\mathrm{CdO}$ resistance values which remain low indicating low cell attachment

On the contrary, a nontoxic material would not affect the attachment of the cells leading to similar resistance measurements to the cells alone (control). For example, gold was previously tested using this biosensing chip on human lung fibroblasts [18] as gold has been shown to have inert properties toward biological materials and has been widely used in biomedical engineering applications [27]. The resistance values measured after the gold was incorporated with the cells showed little difference compared to the control. Our results for the graphene are similar to those of the gold such that after 20 hours of exposure to graphene, neither the CRL-2006 nor the CRL-2583 were affected as seen in the small difference in resistance values to those observed for the control. From this observation, it is evident that the graphene has little cytotoxic effects on both the cell types. 
A possible explanation of this low cytotoxicity could be that graphene, when produced, is a highly pure material lacking the common residual elements seen in other carbon materials such as carbon nanotubes. These residuals, such as $\mathrm{Fe}, \mathrm{Ni}, \mathrm{Co}$, and $\mathrm{Mo}$, even after washing mechanisms seem to remain attached to the nanotubes, a possible result of the nanotubes shape [28]. Pulskamp, Diabate' and Krug (2007) [7] recently showed that carbon nanotubes with the residuals still attached produced an increase in the formation of the reactive oxygen species (ROS) commonly produced by cells under stress compared to more purified carbon nanotubes.

\subsection{Conclusion}

With the increasing number of graphene based biomedical applications, assessing the cytotoxicity is an important first step toward ensuring biocompatibility. In this work, we have successfully demonstrated the low toxicity of graphene nanomaterials on an in vitro BBB model and its individual components, astrocytes, and endothelial cells, using resistance measurements in the forms of TEER and an EIS chip designed to capture the real-time effects of the graphene. The graphene nanomaterials showed little toxicity toward both the tissue model and the cellular components providing proof for graphene's potential as a successful vehicle for drug delivery applications. 


\subsection{References}

1. Liu, Y., Yu, D., Zeng, C., Miao, Z., Dai, L. (2010) Biocompatible graphene oxide-based glucose biosensors. Langmuir 26, 6158-6160.

2. Biswas, S., Drzal, L.T. (2008) A novel approach to create a highly ordered monolayer film of graphene nanosheets at the liquid-liquid interface, Nano Letters 9, 167-172.

3. Hurt, R.H., Monthioux, M., Kane, A. (2006) Toxicology of carbon nanomaterials: Status, trends, and perspectives on the special issue, Carbon 44, 1028-1033.

4. Li, Y., Liu, Y., Fu, Y., Wei, T., Guyader, L.L., Gao, G., Liu, R.S., Chang, Y.Z., Chen, C. (2012) The triggering of apoptosis in macrophages by pristine graphene through the MAPK and TGF-beta signaling pathways, Biomaterials 33, 402-411.

5. Chang, Y., Yang, S.T., Liu, J.H., Dong, E., Wang, Y., Cao, A., Liu, Y., Wang, H. (2010) In vitro toxicity evaluation of graphene oxide on A549 cells, Toxicology Letters 200, 201-210.

6. Fenoglio, I., Greco, G., Tomatis, M., Muller, J., Raymundo-Pinero, E., Beguin, F.O., Fonseca, A., Nagy, J.B., Lison, D., Fubini, B. (2008) Structural defects play a major role in the acute lung toxicity of multiwall carbon nanotubes: Physicochemical aspects, Chemical Research in Toxicology 21, 1690-1697.

7. Pulskamp, K., Diabaté, S., Krug, H.F. (2007) Carbon nanotubes show no sign of acute toxicity but induce intracellular reactive oxygen species in dependence on contaminants, Toxicology Letters 168, 58-74.

8. Alwarappan, S., Erdem, A., Liu, C., Li, C.Z. (2009) Probing the electrochemical properties of graphene nanosheets for biosensing applications, The Journal of Physical Chemistry C, Nanomaterials and Interfaces 113, 8853-8857.

9. Li, C.Z., Alwarappan, S. (2010) Simultaneous detection of dopamine, ascorbic acid and uric acid at electrochemically activated carbon nanotube biosensors, Nanomedicine NBM 6, 52-57.

10. Liu, C., Alwarappan, S., Chen, Z., Kong, X., Li, C.Z. (2009) Membraneless enzymatic biofuel cells based on graphene nanosheets, Biosensors and Bioelectronics 25, 1829-1833.

11. Zhang, Y., Ali, S.F., Dervishi, E., Xu, Y., Li, Z., Casciano, D., Biris, A.S. (2010) Cytotoxicity effects of graphene and single-wall carbon nanotubes in neural phaeochromocytoma derived PC12 cells, ACS Nano 4, 3181-3186. 
12. Shao, Y., Wang, J., Wu, H., Liu, J., Aksay, I.A., Lin, Y. (2009) Graphene based electrochemical sensors and biosensors: A review, Electroanalysis 22, 10271036.

13. Chen, H., Müller, M.B., Gilmore, K.J., Wallace, G.G., Li, D. (2008) Mechanically strong, electrically conductive, and biocompatible graphene paper, Advanced Materials 20, 3557-3561.

14. Liu, Z., Chen, K., Davis, C., Sherlock, S., Cao, Q., Chen, X., Dai, H. (2008) Drug delivery with carbon nanotubes for in vivo cancer treatment, Cancer Research 68, $6652-6660$.

15. Prabhulkar, S., Li, C.Z. (2010) Assessment of oxidative DNA damage and repair at single cellular level via real-time monitoring of $8-\mathrm{OHdG}$ biomarker, Biosensors and Bioelectronics 26, 1743-1749.

16. Sun, X., Liu, Z., Welsher, K., Robinson, J., Goodwin, A., Zaric, S., Dai, H. (2008) Nano-graphene oxide for cellular imaging and drug delivery, Nano Research 1, 203-212.

17. Zhang, Z., McGoron, A., Crumpler, E., Li, C.Z. (2010) Co-culture based bloodbrain barrier in vitro model, a tissue engineering approach using immortalized cell lines for drug transport study. Applied Biochemistry and Biotechnology 163, 278-295.

18. Hondroulis, E., Liu, C., Li, C.Z. (2010) Whole cell based electrical impedance sensing approach for a rapid nanotoxicity assay, Nanotechnology 21, 315103.

19. Li, C.Z., Nishiyama, K., Taniguchi, I. (2000) Electrochemical and spectroelectrochemical studies on cobalt myoglobin, Electrochimica Acta 45, 2883-2888.

20. Hummers, W.S., Jr., Offeman, R.E. (1958) Preparation of Graphitic Oxide, Journal of the American Chemical Society 80, 1339.

21. Poland, C.A., Duffin, R., Kinloch, I., Maynard, A., Wallace, W.A.H., Seaton, A., Stone, V., Brown, S., MacNee, W., Donaldson, K. (2008) Carbon nanotubes introduced into the abdominal cavity of mice show asbestos-like pathogenicity in a pilot study, Nature Nanotechnology 3, 423-428.

22. Warheit, D.B., Laurence, B.R., Reed, K.L., Roach, D.H., Reynolds, G.A.M., Webb, T.R. (2004) Comparative pulmonary toxicity assessment of single-wall carbon nanotubes in rats. Toxicological Sciences: an official journal of the Society of Toxicology 77, 117-125. 
23. Sayes, C.M., Gobin, A.M., Ausman, K.D., Mendez, J., West, J.L., Colvin, V.L., (2005) Nano-C60 cytotoxicity is due to lipid peroxidation, Biomaterials 26, 75877595.

24. Sayes, C.M., Marchione, A.A., Reed, K.L., Warheit, D.B. (2007) Comparative pulmonary toxicity assessments of c60 water suspensions in rats: Few differences in fullerene toxicity in vivo in contrast to in vitro profiles, Nano Letters 7, 23992406.

25. Fan, H., Wang, L., Zhao, K., Li, N., Shi, Z., Ge, Z., Jin, Z. (2010) Fabrication, mechanical properties, and biocompatibility of graphene-reinforced chitosan composites, Biomacromolecules 11, 2345-2351.

26. Tian, F., Cui, D., Schwarz, H., Esorada, G.G., Kobayashi, H. (2006) Cytotoxicity of singlewall carbon nanotubes on human fibroblasts, Toxicology in Vitro: an international journal published in association with BIBRA 20, 1202-1212.

27. Brayner, R. (2008) The toxicological impact of nanoparticles. NanoToday 3, 4855.

28. Pumera, M. (2007) Carbon nanotubes contain residual metal catalyst nanoparticles even after washing with nitric acid at elevated temperature because these metal nanoparticles are sheathed by several graphene sheets, Langmuir 23, 6453-6458. 


\section{Chapter 4}

\section{ELECTRICAL FIELD MANIPULATION OF CANCER CELL BEHAVIOR MONITORED BY WHOLE CELL BIOSENSING DEVICE}

This chapter was submitted as follows (with slight modifications): Hondroulis, E., Melnick, S.J., Wu, Z.Z., Zhang, X., Li, C.Z. (2013) Electrical field manipulation of cancer cell behavior monitored by whole cell biosensing device, Biomedical Microdevices, 15, 657-663. 


\subsection{Introduction}

After successfully showing the EIS' capability of monitoring cell behavior through the nanotoxicity studies, our interest in cell electronics led us to further maximize the EIS' potential. By using electrical signals, biosensors can provide direct, real-time monitoring of biological processes, and in turn, local electric fields generated by the devices can influence biological processes. This integration of cells and electronic devices ultimately led us to investigate the effects of electric fields on cell behavior. Electrically directed and coordinated cell movement plays a significant role in mammalian cell behavior starting from embryonic development. The effects of exogenous electric fields on physiology and their possible relationship to diseases have interested researchers for years [1-3]. The use of electric fields has become popular in fields such as gene and cellular therapies [4-6], and has even progressed to clinical trials for drug delivery [7], however; still little is known how electric fields may interact with intracellular signaling pathways to potentially alter cell physiology.

Living cells are associated with electrical characteristics due to the cell membrane transport processes and are thus responsive to and even generate electric fields and currents. Cells control the exchange of electrically charged ions across their membrane creating a membrane potential with different amounts of electrical charges inside and outside the cell. A shift in membrane potential will alter the exchange of ions across it and vice versa. For instance, it has been shown that alteration in membrane potential can alter the signal pathways involved in mitosis of the cell and thus its proliferation [8]. 
Recently, there has been interest in the therapeutic use of alternating electric fields as a treatment for cancer. Since the electrical and physical properties of cancer cells differ from normal proliferating cells, electric fields may induce differential effects in normal and cancer cells. For example, cancer cells exhibit a lower membrane electrical potential compared to normal cells. Cancer cells also exhibit disorganized growth, weak interactions with their neighboring cells and do not exhibit contact inhibition of their growth [9]. Consequently further research is warranted to establish the role of electric field therapy for the treatment of cancer.

According to the National Cancer Institute each year more than 22,000 women in the United States develop ovarian cancer and because of this, we decided to use the EIS [11-12] to monitor the effects of external alternating electric fields on the behavior of ovarian cancer cells HTB-77'M (SKOV3) compared to normal human umbilical vascular endothelial cells CRL-1730 frequencies $(50 \mathrm{kHz}-2 \mathrm{MHz})$ and at low-intensity $(<2 \mathrm{~V} / \mathrm{cm})$. Electric fields with these properties have been shown to inhibit growth in vivo [13] in support of this line of research. The EIS will measure in real-time the electrode surface impedance changes produced by growing cell monolayers over the electrodes and detecting any changes in resistance associated with changes in the cell layer after electric field exposure to determine the greatest degree of growth inhibition for these types of cancer cell lines. 


\subsection{Experimental Details}

\subsubsection{Cell culture}

HTB-77 ${ }^{\mathrm{TM}}$ and CRL-1730 ${ }^{\mathrm{TM}}$ cells were purchased from American Type Culture Collection (ATCC, Rockville, MD, USA) and were cultured in McCoy's 5A Modified Medium and Dulbecco's Modified Eagle Medium respectively, each containing 10\% fetal bovine serum, $0.3 \mathrm{mg} \mathrm{ml}^{-1}$ L-glutamine, $100 \mathrm{U} \mathrm{ml}^{-1}$ penicillin and $100 \mathrm{mg} \mathrm{ml}^{-1}$ streptomycin. The cell cultures were placed in an incubator $\left(37{ }^{\circ} \mathrm{C}, 5 \% \mathrm{CO}_{2}\right.$ atmosphere $)$ for 24 hours prior to the experiment so that the cells reached confluency with a final concentration of $10^{5}$ cells $\mathrm{ml}^{-1}$. $0.4 \mathrm{ml}$ of cell suspension was inoculated into each well in the EIS chip for the experiments.

\subsubsection{Electrical impedance sensing (EIS)}

The EIS chip design was previously reported [11]. In short, individual tissue culture wells of volume $9 \times 9 \times 10 \mathrm{~mm}^{3}$ are placed over an array of eight detecting gold electrodes $(250 \mu \mathrm{m}$ in diameter $)$ each linked to a gold counter electrode $\left(7 \times 46 \mathrm{~mm}^{2}\right)$.

\subsubsection{Application of external electric field}

To incorporate the external electric field to the EIS chip, a unique system of a pair of insulated wires (BLK KYNAR 100', conductor area $0.25 \mathrm{~mm}$ ) was designed to be placed in conjunction with the 8 well array design of the EIS chip. The wires were placed in 4 of the wells with the other 4 wells used as the control. The wires were placed $1 \mathrm{~mm}$ apart to allow spacing to encompass the whole electrode area. Figure 4.1 shows a schematic of the wire setup and the resulting electric field surrounding the electrodes. A 
Leader LFG-1300S Function Generator was used to provide the square AC waves at the desired frequencies.

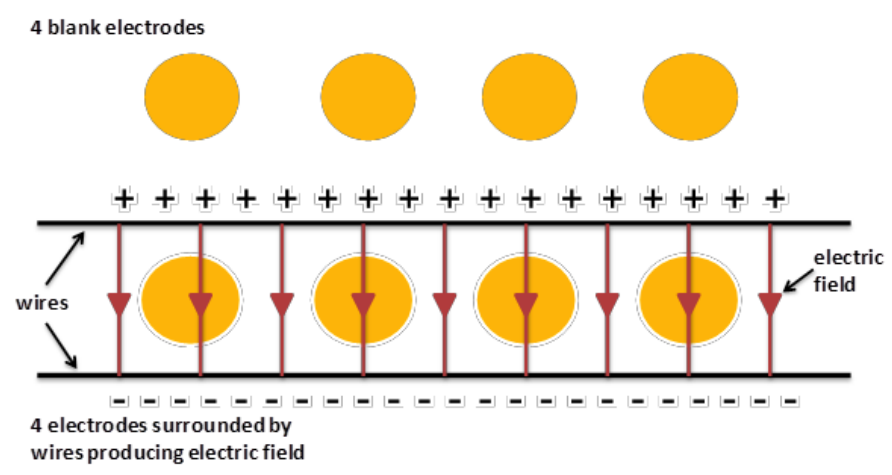

Figure 4.1 - Schematic of wire setup for application of external alternating electric fields to the EIS chip. The two wires (black lines) were spaced at approximately $1 \mathrm{~mm}$ apart to encompass the entire electrode

(gold circles) on the EIS chip. The red lines represent the resulting electric field generated

\subsubsection{Immunofluorescence Staining}

Propidium iodide (PI) was purchased from Calbiochem (San Diego, CA) and diluted to $50 \mu \mathrm{g} / \mathrm{ml}$ with DI water. $10^{5}$ cells $/ \mathrm{ml}$ were added to standard petri dishes, one with wires placed on the bottom spaced $1 \mathrm{~mm}$ apart to apply an external electric field of $200 \mathrm{kHz}$ and one without wires as the control. $25 \mu \mathrm{l}$ of PI was added to each dish and incubated in the dark for 10 minutes. Fluorescence intensity was determined using a confocal microscope (Perkin Elmer UltraView Vox system, USA). With an excitation wave length of $530 \mathrm{~nm}$ and an emission filter of $620 \mathrm{~nm}$. PI attaches to the DNA of the cell, and thus cells with broken membranes will be targeted.

\subsubsection{Cell Viability Assay}

Trypan blue was purchased from Sigma Aldrich. $10^{5}$ cells $/ \mathrm{ml}$ were added to standard petri dishes, one with wires placed on the bottom spaced $1 \mathrm{~mm}$ apart to apply an external electric field of $200 \mathrm{kHz}$ and one without wires as the control. After 40 hours, 
the cells were removed with $0.25 \%$ trypsin/EDTA (GIBCO), alloquotted into centrifuge tubes and were spun for 5 minutes at $100 \mathrm{xg}$. The supernatant was discarded and the cells were resuspended with $1 \mathrm{ml}$ PBS (Fisher Scientific). A 1:1 ratio of 0.4\% Trypan Blue and cell suspension was made and was allowed to sit for 3 minutes for the cells to incorporate the dye. $20 \mu \mathrm{l}$ of the cell suspension was then added to a hemocytometer to perform a cell count. The $\%$ viability was calculated using the following equation:

viable cells $(\%)=$ total number of viable cells per $\mathrm{ml}$ of aliquot $\times 100$ total number of cells per $\mathrm{ml}$ of aliquot

\subsection{Results}

\subsubsection{Optimal Frequency}

Five frequencies of alternating electric fields that sample a broad radiofrequency range, 50, 100, 150 and $200 \mathrm{kHz}$ and $2 \mathrm{MHz}$, were tested on both SKOV3 and HUVEC to find the optimal frequency that would most hinder the growth of the SKOV3 cells without harming the normal HUVECs. Intermediate frequencies of around $100 \mathrm{kHz}$ have previously been reported to not have any detrimental effects on cells [14], however,

according to Kirson et. al. [13], specific types of cancer cells may behave differently under the range of $100 \mathrm{kHz}$ to $1 \mathrm{MHz}$ frequencies with the theory that the electric fields disrupt the normal mitotic process of proliferating cells. The choice of frequencies is in part based on this study. Frequencies in the lower $(50 \mathrm{kHz})$ and higher $(2 \mathrm{MHz})$ range were also included. 
Using the EIS biosensor, we monitored the proliferation rate of the cells under the influence of the alternating electric fields in real-time by analyzing the change in resistance values of the detecting electrodes. Proliferating cells will gradually attach and spread across the electrode surface creating an increase in resistance values. Any change in proliferation is detected by a decrease the resistance values. Figures 4.2 (a) and (b) show the resistance values obtained from the HUVECs and the SKOV3 respectively in the target range under 100,150 and $200 \mathrm{kHz}$ applied at the start of the run compared to the cells alone, both over a timeframe of 40 hours. The EIS biosensor was able to detect no noticeable difference in the resistance values when the alternating electric field was applied to the HUVECs compared to the control, thus indicating no obvious effect of the electric fields of the three frequencies on the HUVECs proliferation. 
(a)

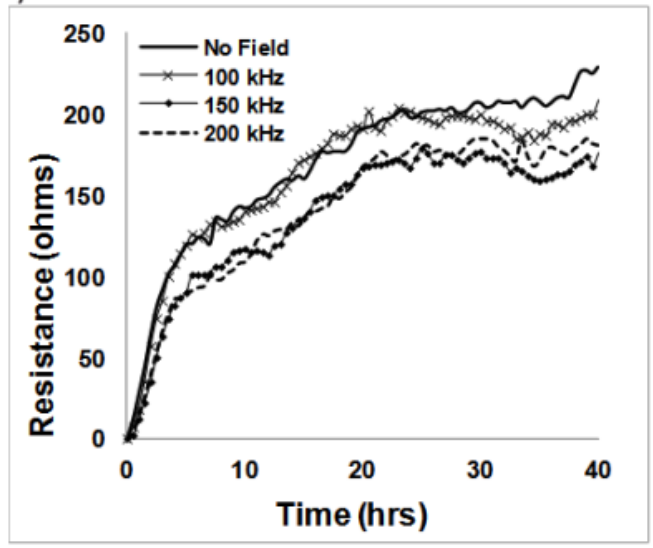

(c)

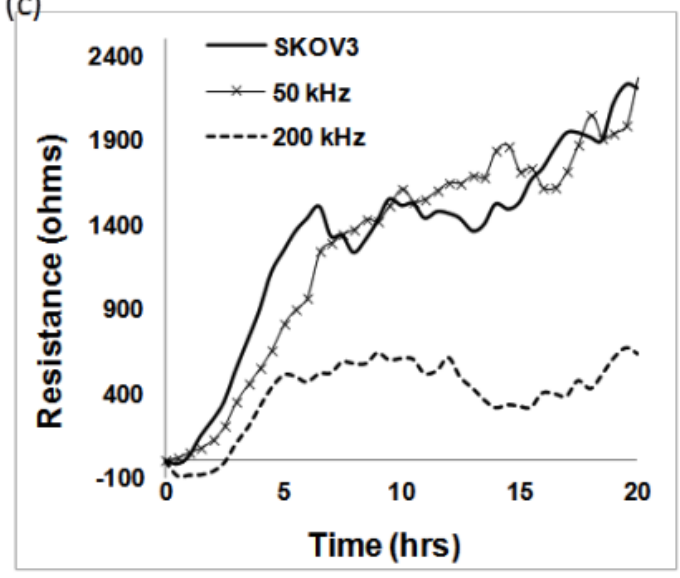

(b)

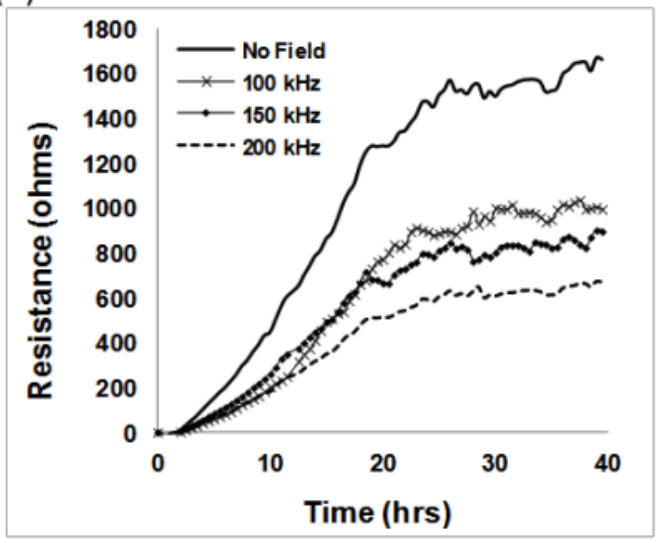

(d)

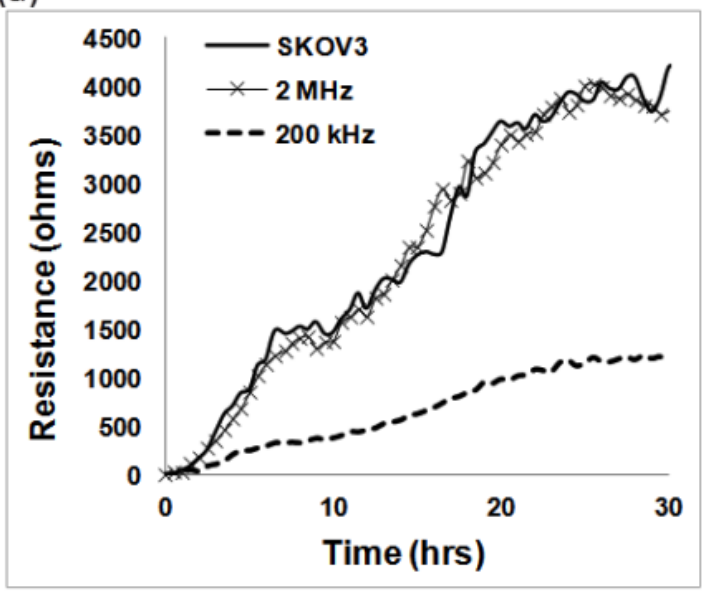

Figure 4.2. Resistance values of HUVECs (a) and SKOV3 (b) under electric fields of frequencies 100, 150 and $200 \mathrm{kHz}$. No apparent effect was noticed for the normal HUVECs, however, a significant decrease in resistance values was observed for the SKOV3 for all three frequencies. For further comparison, $50 \mathrm{kHz}$

(c) and $2 \mathrm{MHz}$ (d) frequencies were tested on SKOV3 and showed no apparent effect on the cell proliferation as seen in the similar resistance curves to the control. $200 \mathrm{kHz}$ showed the largest decrease out of all the frequencies

In contrast, the SKOV3 had lower resistance values compared to the control with $200 \mathrm{kHz}$ providing the lowest resistance values out of the three frequencies. These results indicate that the growth and proliferation rate of the SKOV3 was hindered by the alternating electric field at each frequency evaluated with $200 \mathrm{kHz}$ being the most effective frequency. The resistance values still increased over time with the applied 
external electric fields; however, the overall values were lower than the control. This difference can be attributed to a slower rate of proliferation and attachment of the cells to the electrodes and thus showing growth inhibition. For justification that this range of frequencies is optimal for disrupting the SKOV3 cell proliferation, $50 \mathrm{kHz}$ and $2 \mathrm{MHz}$ frequencies were tested as well on the SKOV3 and were compared with the results from $200 \mathrm{kHz}$ (Figures 4.2 (c), (d) respectively). Neither $50 \mathrm{kHz}$ nor $2 \mathrm{MHz}$ affected the SKOV3 proliferation compared to the $200 \mathrm{kHz}$ frequency, and thus we focused more closely on this frequency.

\subsubsection{Focus on $200 \mathrm{kHz}$}

In the subsequent experiment, the $200 \mathrm{kHz}$ field was applied to the cells after they reached confluency on the EIS electrodes. This was done to determine whether the field affected the cells before or after attachment. Most cell types need to attach to a substrate in order to proliferate, however, it has been shown that cancer cells have a lower tendency for adhesion which in turn could lead to metastasis [15]. The SKOV3 were

placed in the wells with the wires in place at the beginning of the run without applying the external electric field. The resistance changes produced by the attachment of cells to the electrodes were monitored for 40 hours, allowing the cells to reach confluency, and then the $200 \mathrm{kHz}$ field was applied. With the addition of the field, there was a noticeable decrease in resistance values over time indicating disruption of cell attachment to the electrodes (Figure 4.3 (a)). 
In addition to the measurement of resistance, the effects of the alternating electric fields on the SKOV3 cells were evaluated by examining digital images taken of the detecting electrodes; the electrode with SKOV3 cells after 40 hours once they reached confluency the electrode after 1 hour of $200 \mathrm{kHz}$ applied field to the confluent cells and the electrode after another 40 hours of exposure to the electric field (Figure 4.3 (b), (c), (d) respectively). Prior to the application of the alternating electric field, the image of the electrode shows a confluent monolayer of cells covering it as is expected without any external stimulus. Normal proliferating cells attached to a substrate will have a flattened morphology as they extend themselves along the surface as shown in Figure $3 \mathrm{~b}$. However, once the $200 \mathrm{kHz}$ electric field was applied, the cell morphology changed to a more round shape even after only an hour of exposure to the field, indicating a disruption in the attachment of the cells to the electrode. Finally, after 40 hours of exposure to the electric field, the cell number diminished significantly indicating a disruption in the cell proliferation. 
(a)
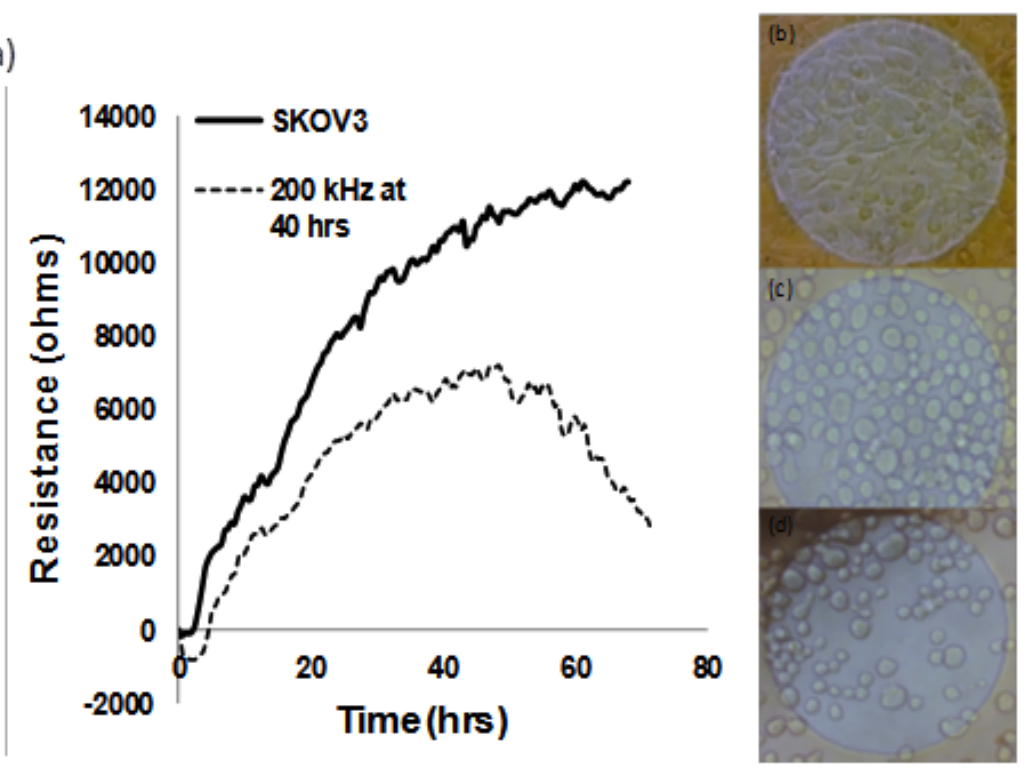

Figure 4.3 - Resistance values of SKOV3 cells when subjected to $200 \mathrm{kHz}$ electric field after 40 hours on the electrode (a). Digital images were taken of this electrode to visualize the cell attachment process.

Figure $4 \mathrm{~b}$ shows the electrode after the cells reached confluency over the electrode. After this, the $200 \mathrm{kHz}$ field was applied and within an hour another image was taken (c). The cells have changed morphology to a more rounded shape compared to the initial image. After an additional 40 hours of exposure to the electric field, another image was taken (d) which shows a significant decrease in cell number on the electrode

\subsubsection{Immunofluorecence Staining and Cell Viability Assay}

Two additional methods for measuring cell viability after exposure to the alternating electric fields were performed to independently correlate the results obtained by the EIS. Immunofluorecence images were taken using PI, a fluorescent molecule that binds to the DNA of cells. Since PI is impermeable to cell membranes, viable cells will not incorporate the molecule and thus it can be used for cell viability assays. Figures 4.4 (a) and (b) show the fluorescence images of the SKOV3 without and with the $200 \mathrm{kHz}$ field after 40 hours of exposure respectively. The cells that were subjected to the field showed more fluorescence than the control indicating a higher occurrence of cell death. 
Trypan Blue exclusion test for cell viability was also performed. Trypan Blue is a dye that cannot penetrate the intact cell membranes of viable cells, thus indicating the total amount of viable cell in a sample. Figure 4.4 (c) is a chart showing the percent viability estimated by the number of attached SKOV3 after exposure to the alternating electric fields in the target range of 100,150 and $200 \mathrm{kHz}$. Similar to the EIS data, after exposure to $200 \mathrm{kHz}$, the cells exhibited the least amount of cell viability.

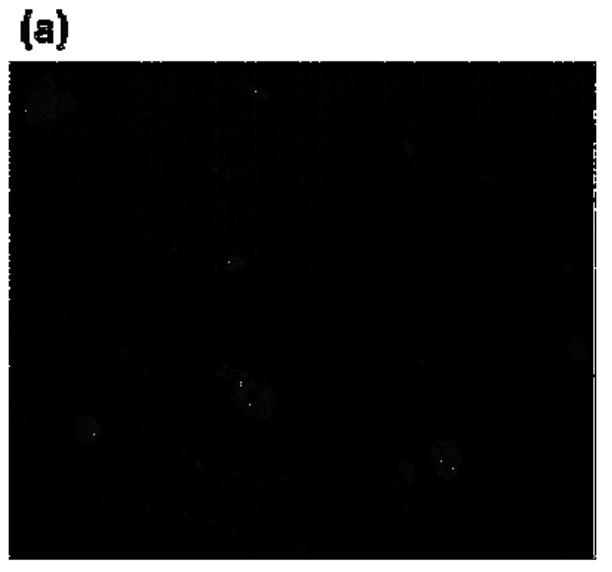

\section{(b)}

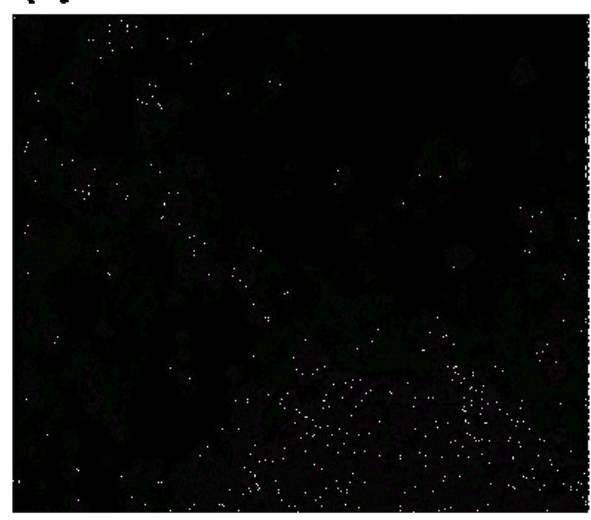

(c)

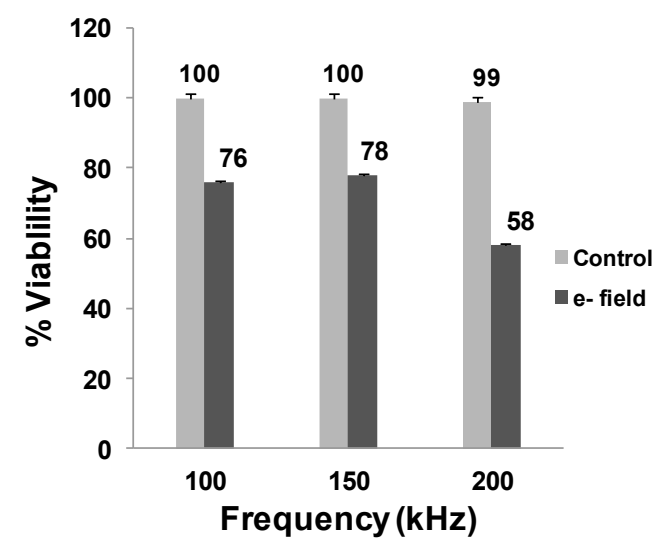

Figure 4.4 - Fluorescence imaging using propiduim iodide (PI). SKOV3 cells were grown on petri dish, one control (a) with no external electric field and one with wires providing $200 \mathrm{kHz}$ frequency (b). After 40 hours, the cells were stained with PI and the cells exposed to $200 \mathrm{kHz}$ showed significant cell death as seen in the increase in fluorescence compared to the control. To further justify the effects of the $200 \mathrm{kHz}$ electric field on SKOV3, Trypan Blue exclusion test for cell viability was performed for 100, 150 and 200 $\mathrm{kHz}$ (c). $200 \mathrm{kHz}$ showed the lowest percent viability of $58 \%$ 


\subsection{Discussion}

Research on the effects of alternating electric fields on biological samples has been a growing interest for biomedical researchers over the years. Cells have intrinsic electrical properties that are implicit to metabolism and other cellular functions. Many of the electrical properties are derived from the cellular membrane consisting of a lipid bilayer embedded with various transmembrane proteins creating ionic channels that comprise the cell's transmembrane potential. Evidence suggests that cellular properties such as proliferation, adhesion, differentiation, morphology and migration, and function are influenced by external alternation electric fields suggesting a relationship between these properties and the electrical properties of cells. A deeper understanding of this relationship will yield a more comprehensive view of cell function and the role that electric field therapies may play in the treatment of diseases such as cancer.

Cancer cells have been shown to have different membrane properties than regular cells. One property that may play a large role in cancer behavior is the membrane fluidity since cancer cells seem to have higher membrane fluidity than non-cancer cells. Increased membrane fluidity also affect the cell's motility and deformation [16] leading to a hindered cell-matrix adhesion and ultimately specific cell responses that influence cell adhesion, motility, shape, orientation, differentiation, and survival. Cells that are attached and thus capable of proliferating have a flattened appearance due to cell spreading. As we have shown, once subjected to the field, the SKOV3 cells changed morphology within only an hour of exposure to the $200 \mathrm{kHz}$ applied field. The cells 
acquired a more round shape which could be attributed to the increase in membrane fluidity of the cells under the electric field.

Another important feature for cell survival is the membrane potential. Cancer cells also exhibit an increase in negative surface charge of their membrane [17] compared to normal cells and thus have cell membrane potentials that are lower than the cell membrane potential of healthy cells. When subjected to external electric fields, the membrane experiences most of the potential drop in the cell leading to conformational changes in proteins and enzymes embedded within the membrane ultimately affecting the cell's capability for proliferation and differentiation [18]. For example, biochemical and physiological changes occur when weak electric currents are applied to a cell due to a change in transmembrane potential induced on the cell membrane. Since the membrane is flexible, permeation of the cell membrane occurs leading to a higher exchange of materials across the membrane, a process known as electroporation [19]. This process has been widely used in biomedical research in areas such as drug delivery [20-21] and gene transfer [22] because of its reversibility. In this study, we show that a low intensity electric field at $200 \mathrm{kHz}$ has a detrimental effect on cancerous SKOV3 cells without affecting the non-cancerous HUVEC cells. 


\subsection{Conclusion}

Many current treatments for cancer are effective; however, a major limitation in these treatments is their toxicities and side effects. Electric field therapies as an adjuvant for cancer treatment show considerable promise; however, further preclinical and clinical investigation is required. The outcome of this research will improve our fundamental understanding of the behavior of cancer cells to alternating electric fields and define a strategy and optimal parameters of electrotherapy for clinical and drug delivery applications. This whole cell-based biosensor will enhance our understanding of the responsiveness of cancer cells to electric field therapy and demonstrate potential therapeutic opportunities for electric field therapy in the treatment of cancer. 


\subsection{References}

1. Barker, A.T., Dixon, R.A., Sharrard, W.J.W., Sutcliffe, M.L. (1984) Pulsed Magnetic Field Therapy for Tibial Non-Union, The Lancet 323, 994-996.

2. Ieran, M., Bagnacani, M., Annovi, M., Moratti A., Cadessi, R. (1990) Effect of low frequency pulsing electromagnetic field on skin ulcers of venous origin in humans: a double-blind study, Journal of Orthopaedic Research: official publication of the Orthopaedic Research Society 8, 276-282.

3. Sandyk, R. (1997) Therapeutic effects of alternating current pulsed electromagnetic fields in multiple sclerosis, Journal of Alternative and Complementary Medicine 3, 365-386.

4. Golzio, M., Teissié, J., Rols, M.P. (2002) Direct visualization at the single-cell level of electrically mediated gene delivery, Proceedings of the National Academy of Sciences of the United States of America 99, 1292-1297.

5. Song, L., Chau, L., Sakamoto, Y., Nakashima, J., Koide, M., Tuan, R. (2004) Electric field-induced molecular vibration for noninvasive, high-efficiency DNA transfection, Molecular Therapy: the journal of the American Society of Gene Therapy 9, 607-616.

6. Teissié, J., Escoffre, J., Rols, M., Golzio, M. (2008) Time dependence of electric field effects on cell membranes. A review for a critical selection of pulse duration for therapeutical applications, Radiology and Oncology 42, 196-206.

7. Fantozzi, F., Arturoni, E., Barbucci, R. (2010) The effects of the electric fields on hydrogels to achieve antitumoral drug release, Bioelectrochemistry 78, 191-195.

8. Blackiston, D.J., McLaughlin, K.A., Levin, M. (2009) Bioelectric controls of cell proliferation, Cell Cycle 8, 3527-3536.

9. Lock, F.E., Underhill-Day, N., Dunwell, T., Matallanas, D., Cooper, W., Hesson, L., Recino, A., Ward, A., Pavlova, T., Zabarovsky, E., Grant, M.M., Maher, E.R., Chalmers, A.D., Kolch, W., Latif, F. (2010) The RASSF8 candidate tumor suppressor inhibits cell growth and regulates the Wnt and NF-kappaB signaling pathways, Oncogene 29, 4307-4316.

10. Luong, J.H.T., Male, K.B., Glennon, J.D. (2008) Biosensor technology: technology push versus market pull, Biotechnology Advances 26, 492-500.

11. Hondroulis, E., Liu, C., Li, C.Z. (2010) Whole cell based electrical impedance sensing approach for a rapid nanotoxicity assay, Nanotechnology 21, 315103. 
12. Hondroulis, E., Zhang, Z., Chen, C., Li, C.Z. (2012) Impedance Based Nanotoxicity Assessment of Graphene Nanomaterials at the Cellular and Tissue Level, Analytical Letters 45, 272-282.

13. Kirson, E.D., Dbaly, V., Tovarys, F., Vymazal, J., Soustiel, J.F., Itzhaki, A., Mordechovich, D., Steinberg-Shapira, S., Gurvich, Z., Schneiderman, R., Wasserman, Y., Salzberg, M., Ryffel, B., Goldsher, D., Dekel, E., Palti, Y. (2007) Alternating electric fields arrest cell proliferation in animal tumor models and human brain tumors, Proceedings of the National Academy of Sciences of the United States of America 104, 10152-10157.

14. Elson, E., (1995) Biologic effects of radiofrequency and microwave fields: in vivo and in vitro experimental results, in: Bronzino JD (Ed.), The Biomedical Engineering Handbook, CRC Press, Inc., Boca Raton, FL, pp. 1417-1423.

15. Hirohashi, S. (1998) Inactivation of the E-cadherin-mediated cell adhesion system in human cancers, The American Journal of Pathology 153, 333-339.

16. Sok, M., Sentjurc, M., Schara, M., Stare, J., Rott, T. (2002) Cell membrane fluidity and prognosis of lung cancer, The Annals of Thoracic Surgery 73, 15671571 .

17. Szachowicz-Petelska, B., Dobrzynska, I., Sulkowski, S., Figaszewski, Z.A. (2010) Characterization of the cell membrane during cancer transformation, Journal of Environmental Biology/Academy of Environmental Biology 31, 845-850.

18. Tsong, T.Y. (1990) Electrical modulation of membrane proteins: enforced conformational oscillations and biological energy and signal transductions, Annual Review of Biophysics and Biophysical Chemistry 19, 83-106.

19. Mir, L.M. (2001) Therapeutic perspectives of in vivo cell electropermeabilization, Bioelectrochemistry 53, 1-10.

20. Charoo, N.A., Rahman, Z., Repka, M.A., Murthy, S.N. (2010) Electroporation: an avenue for transdermal drug delivery, Current Drug Delivery 7, 125-136.

21. Zhao, X., Zhang, M., Yang, R. (2010) Control of pore radius regulation for electroporation-based drug delivery, Communications in Nonlinear Science and Numerical Simulation 15, 1400-1407.

22. Lin, X., Dean, D. (2011) Electroporation-Mediated Gene Transfer Increases Alveolar Fluid Clearance In Murine Lungs, American Journal of Respiratory and Critical Care Medicine 183, A2099. 
Chapter 5

TARGETED ELECTRICAL FIELD MANIPULATION OF CANCER CELLS USING ANTIBODY FUNCTIONALIZED NANOPARTICLES 


\subsection{Introduction}

Electrical properties of cells determine most of the cellular functions, predominantly proliferation and differentiation. In particular, the transmembrane potential, the voltage difference across the membrane produced by the balance of intracellular and extracellular ionic concentrations, is responsible for controlling mitosis, DNA synthesis, and the majority of other cell cycle phenomena [1]. Several studies have previously been done to derive the relationship between transmembrane potential and cell proliferation. Initially, Cone and Tongier (1973) investigated the effects of transmembrane modification on the mitotic activity of Chinese hamster ovary cells [2]. Their study showed that decreasing the cells transmembrane potential ultimately stopped the mitotic process in the cells with the process being reversible once the transmembrane potential returned to a normal value. More recently, MCF-7, human adenocarcinoma, membranes have been shown to hyperpolarize during the G0/G1 phase of proliferation [3]. Manipulation of these electrical properties may provide a powerful electrotherapy option for the treatment of cancer as cancerous cells have been shown to have more electronegative membrane potential than normal proliferating cells, thus, further studies on cancer electrotherapy is warranted.

Previously, we used our EIS to explore the responses of cancerous SKOV3 cells and normal HUVEC cells to low intensity $(<2 \mathrm{~V} / \mathrm{cm})$ AC electric fields, determining that the optimal frequency for SKOV3 proliferation arrest was $200 \mathrm{kHz}$, without harming the non-cancerous HUVECs [4]. We observed a slower proliferation rate in the cancer cells through the lower resistance curves of the EIS in real-time as the external field was 
applied compared to a control with no applied field, digital images of the cells on the EIS electrode and florescence staining (propidium iodide) of the cells before and after application of the external field. We now want to determine if these effects are cell type dependant and so for this study, human breast adenocarcinoma cells (MCF7) were chosen as another type of cancer cell for comparison as according to the American Cancer Society, every year over 200,000 American women are diagnosed with breast cancer. The MCF7, along with the non-cancerous MCF10a, were subjected to the range of frequencies $(50 \mathrm{kHz}-2 \mathrm{MHz})$ similar to the previously tested SKOV3 and HUVEC to determine the optimal frequency that would most hinder the proliferation of the MCF7.

Due to electrostatic forces, the interior of the cell has uniform potential and a voltage drop across the plasma membrane. With the application of any external electric field, the first electrostatic force encountered would be the membrane potential. Cancerous cells have been shown to have lower cell and cytoplasmic conductivity as well as a lower membrane capacitance compared to non-cancerous cells [5]. This outermost electrically negative zone is composed of negatively charged sialic acid molecules found on the tops of glycoproteins extending outward from the cell membrane. The zeta potential, the potential that exists at the electrical double layer of a particle or cell, is created from these sialic acid residues. Cancer cells have significantly more sialic acid molecules and thus a greater surface negativity. Thus, any external factor that would affect these residues would change the surface negativity of the cell. 
In 1990, Seeger and Wolz correlated the electronegativity of cancer cell membranes with membrane degeneration throughout the process of carcinogenesis [6]. This process involves the degradation of the external cell membrane initially, causing more permeability to water-soluble substances to potassium, magnesium, and calcium migrate from the cells and sodium and water accumulate in the cell interior. This is then followed by degenerative changes in the inner membrane of the mitochondria causing loss of anchorage of critical mitochondrial enzymes. Since the membrane potential in a cancer cell is lower than the membrane potential of a healthy cell, the electrical field across the membrane of a cancer cell is reduced. The reduction in membrane electrical field strength will in turn cause alterations in the metabolic functions of the cell.

The ultimate fate of these cells after they endure the effects of the applied field is the next focus. We first sought to enhance the effects of the externally applied field by incorporating HER2 antibody functionalized gold nanoparticles (HER2-AuNPs) to specifically target the two types of cancer cells and monitor the real-time consequences on cellular viability under the electric field using the EIS. Gold nanoparticles have been extensively used in biomedical applications and studies due to their nontoxic properties, and this was shown in our study of nanotoxicity in Chapter 2. HER2, human epidermal growth factor receptor 2, is a cell membrane surface-bound receptor tyrosine kinase that is responsible for intracellular signal transduction and ultimately cell growth and differentiation [7]. HER2 overexpression leads to cancerous cell proliferation and is seen in cancers such as breast cancer, ovarian cancer, stomach cancer, and even lung cancer [8], and both SKOV3 and MCF7 cells overexpress HER2 markers on their surface 
membrane, so the HER2 antibody fit our study. The motivation behind specifically targeting the cancer cells with the HER2-AuNPs is that the nanoparticles would bind to the HER2 receptors on the membrane of the cancer cells, thus affecting the cells' zeta potential as the binding of charged nanoparticles to the cell surface plasma membrane will change the zeta potential value of the cells. The zeta potential of the AuNPs, HER2AuNPS and cells before and after incorporation of the HER2-AuNPs will be taken to monitor this phenomenon. We also expect to see a difference with the application of the electric field to the combination of HER2-AuNPs and cell. We also intend to test the cell death mechanism by using an Annexin V/ EthD-III assay to determine if the cells undergo apoptosis or necrosis after the application of the applied electric field.

\subsection{Experimental Details}

\subsubsection{Cell culture}

HTB-77'TM (SKOV3) and CRL-1730 ${ }^{\mathrm{TM}}$ (HUVEC) cells were purchased from American Type Culture Collection (ATCC, Rockville, MD, USA) and were cultured in McCoy’s 5A Modified Medium and Dulbecco's Modified Eagle Medium respectively, each containing $10 \%$ fetal bovine serum, $0.3 \mathrm{mg} \mathrm{ml}^{-1} \mathrm{~L}$-glutamine, $100 \mathrm{U} \mathrm{ml}^{-1}$ penicillin and $100 \mathrm{mg} \mathrm{ml}^{-1}$ streptomycin. The HTB-22 ${ }^{\mathrm{TM}}$ (MCF7) and CRL-10317 ${ }^{\mathrm{TM}}$ (MCF10a) were graciously donated from the Research Institute at Miami Children's Hospital, Miami, FL, and were both cultured in Eagle's Minimum Essential Medium containing 10

$\%$ fetal bovine serum, $0.3 \mathrm{mg} \mathrm{ml}^{-1}$ L-glutamine, $100 \mathrm{U} \mathrm{ml}^{-1}$ penicillin and $100 \mathrm{mg} \mathrm{ml}^{-1}$ streptomycin. The cell cultures were placed in an incubator $\left(37{ }^{\circ} \mathrm{C}, 5 \% \mathrm{CO}_{2}\right.$ atmosphere) for 24 hours prior to the experiment so that the cells reached confluency 
with a final concentration of $10^{5}$ cells $\mathrm{ml}^{-1} \cdot 0.4 \mathrm{ml}$ of cell suspension was inoculated into each well in the EIS chip for the experiments.

\subsubsection{Electrical impedance sensing (EIS)}

The EIS chip design was previously reported [4]. In short, individual tissue culture wells of volume $9 \times 9 \times 10 \mathrm{~mm}^{3}$ are placed over an array of eight detecting gold electrodes $(250 \mu \mathrm{m}$ in diameter $)$ each linked to a gold counter electrode $\left(7 \times 46 \mathrm{~mm}^{2}\right)$.

\subsubsection{Application of external electric field}

The design of the application of the external electric field to the EIS chip was previously described [4]. In brief, a unique system of a pair of insulated wires (BLK KYNAR 100', conductor area $0.25 \mathrm{~mm}$ ) was designed to be placed in conjunction with the 8 well array design of the EIS chip. The wires were placed in 4 of the wells with the other 4 wells used as the control. The wires were placed $1 \mathrm{~mm}$ apart to allow spacing to encompass the whole electrode area. Figure 2 shows a schematic of the wire setup and the resulting electric field surrounding the electrodes. A Leader LFG-1300S Function Generator was used to provide the square AC waves at the desired frequencies.

\subsubsection{Synthesis of AuNPs}

Hydrogen tetrachloroaurate $\left(\mathrm{HAuCL}_{4}\right)(40 \mathrm{ml}, 1.0 \mathrm{mM})$ was added to an Erlenmeyer flask $(250 \mathrm{ml})$, stirred and brought to the boil on a hotplate. Trisodium citrate $\left(\mathrm{Na}_{3} \mathrm{C}_{6} \mathrm{H}_{5} \mathrm{O}_{7}\right)(4 \mathrm{ml}, 1 \%)$ was added to the boiling solution. Three minutes after the addition of trisodium citrate, and 10 minutes of stirring, AuNPs were formed. The size of 
the AuNPs was characterized by the Zetasizer (Malvern Instruments, Woodstock, GA) and found to be $20 \mathrm{~nm}$.

\subsubsection{HER2 antibody functionalization of AuNps}

The HER2 antibody preparation was done following the procedure of Zhu et al. [9]. The AuNPs solution was concentrated 5X and the $\mathrm{pH}$ of the AuNPs solution for antibody labeling was adjusted to $\mathrm{pH} 8.5 \sim 9.0$ with $0.2 \mathrm{ml}$ of $\mathrm{K}_{2} \mathrm{CO}_{3}(0.1 \mathrm{M})$. Purified Anti-ErbB2/Her2 Monoclonal Antibody ( $\left.5 \mu \mathrm{L}, 1 \mathrm{mg} \mathrm{mL}^{-1}\right)$ was added to the AuNPs solution $(750 \mu \mathrm{L}, 5 \mathrm{X})$ and stirred gently at room temperature for $1 \mathrm{~h}$. The conjugate was stabilized by adding BSA $(90 \mu \mathrm{L}, 10 \%)$ in sodium borate $(20 \mathrm{mM})$ for a final concentration of $1 \%$ and the solution was incubated for another $15 \mathrm{~min}$. The mixture was then centrifuged at $7000 \mathrm{rcf}$ for $15 \mathrm{~min}$. Two phases can be obtained: a clear to pink supernatant of unbound antibodies and a dark red, loosely packed sediment of the AuNPs-Abs conjugates. The supernatant was discarded and the pellet was resuspended in BSA/PBS $(100 \mu \mathrm{L}, 1 \%)$. After another centrifugation at $7000 \mathrm{rcf}$ for $15 \mathrm{~min}$, the supernatant was removed and the pellet was resuspended in 100 buffer $(100 \mu \mathrm{L})$, containing sodium phosphate $(20 \mathrm{mM})$, Tween $20(0.25 \%)$, sucrose $(10 \%)$, and BSA (5\%). The conjugate was stored at $4^{\circ} \mathrm{C}$ until required for use.

\subsubsection{Apoptosis / Necrosis Assay}

Apoptotic/Necrotic Cells Detection Kit was purchased from PromoKine (Germany). The kit contains FITC-Annexin V in TE buffer containing $0.1 \%$ BSA and $0.1 \% \mathrm{NaN}_{3}(\mathrm{pH} 7.5$ ), Ethidium Homodimer III (EthD-III) in PBS and 5X Binding Buffer. A 1:5 dilution of Binding Buffer to DI water was made. After runs with the EIS, the cells 
were detached from the wells on the chip with $0.25 \%$ Trypsin/EDTA and suspended with

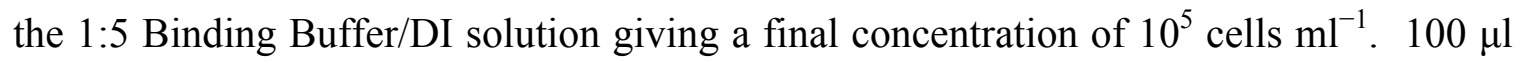
of the cell suspension was placed in a microcentrifuge tube to which $5 \mu$ of FITCAnnexin V and $5 \mu \mathrm{l}$ of Ethidium Homodimer III solutions were added to each tube. The samples were incubated at room temperature for 15 minutes in the dark, after which the cells were washed and resuspended with the 1:5 Binding Buffer/DI solution. Fluorescence intensity was determined using a confocal microscope (Perkin Elmer UltraView Vox system, USA) with FITC and Texas Red filter sets.

\subsubsection{Zeta potential measurement}

The Zetasizer Nano ZEN 3600 (Malvern Instruments, United Kingdom) was used to measure the zeta potential of the AuNPs, HER2-AuNPS and the HER2-AuNPS with each cell type, SKOV3, HUVEC, MCF7 and MCF10a.

\subsection{Results}

\subsubsection{Optimal frequency for $M C F 7$}

As done before with the SKOV3 cells, the MCF7 and MCF10 cells were subjected to five different frequencies of alternating electric fields 50,100, 150 and 200 $\mathrm{kHz}$ and $2 \mathrm{MHz}$, to find the optimal frequency that would most hinder the growth of the MCF7 cells without harming the normal MCF10a cells. Figure 5.1 shows the EIS results of the MCF10a (5.1 (a), (c)) and the MCF7 (5.1 (b), (d)) for the intermediate frequencies $(100,150,200)$ and the extreme frequencies $(50 \mathrm{kHz}, 2 \mathrm{MHz})$ respectively. 
(a)
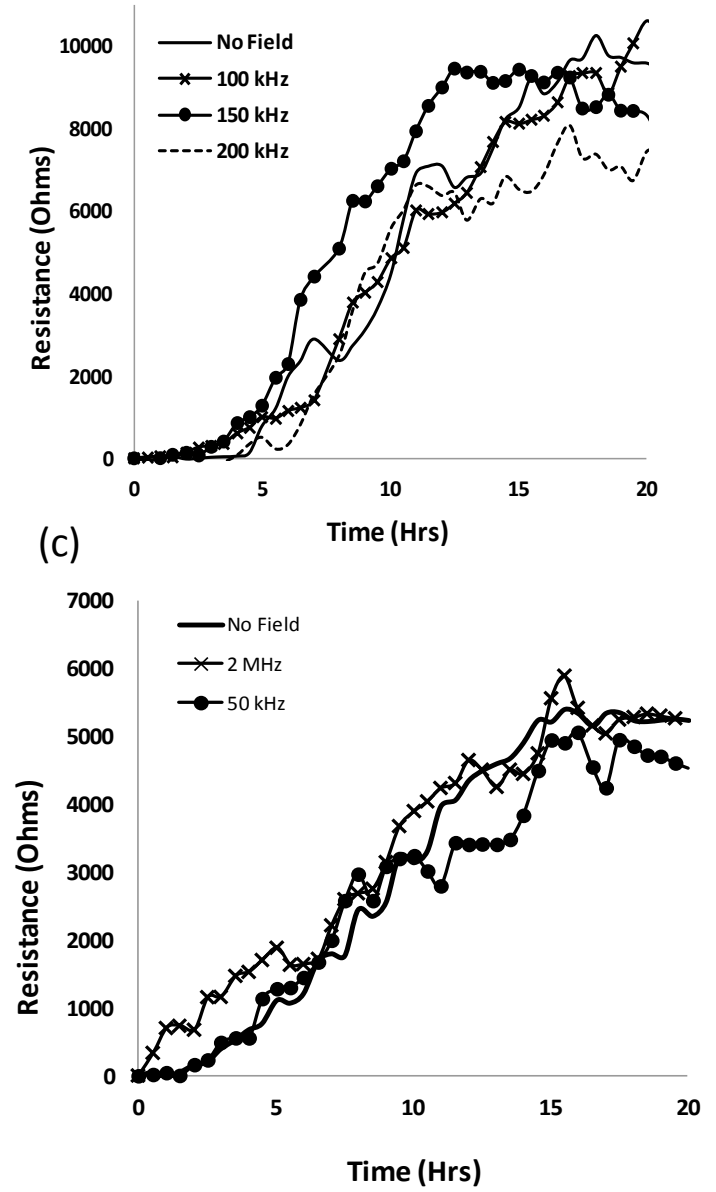

(b)
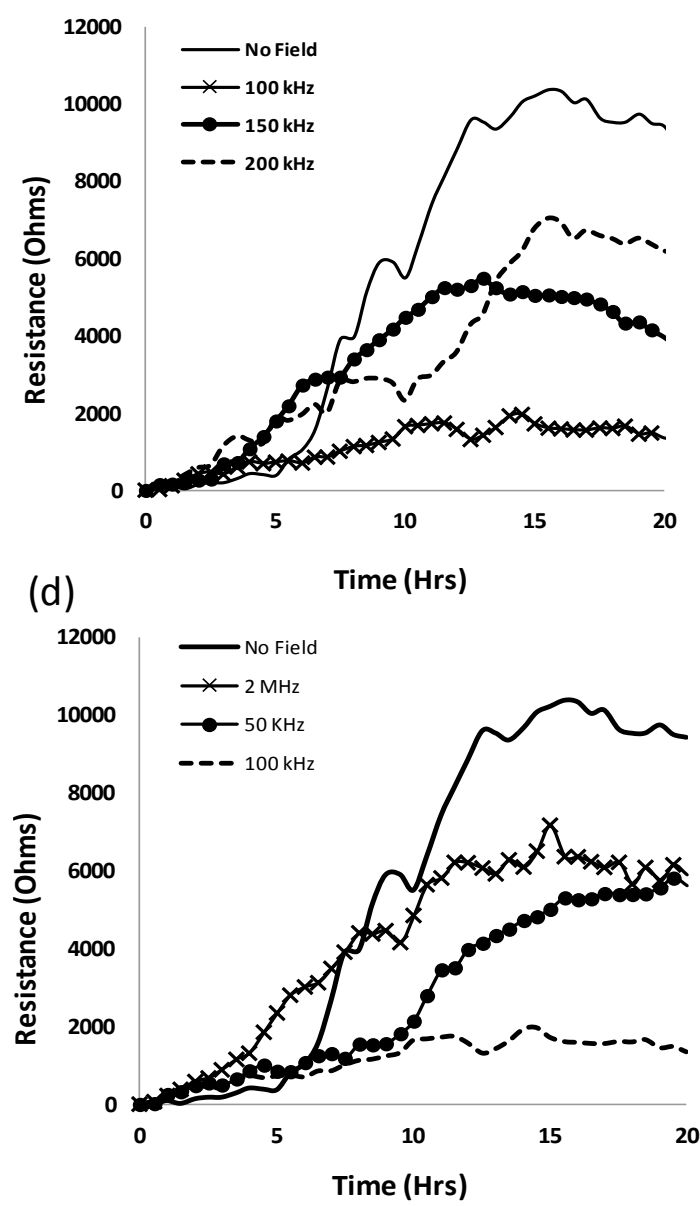

Figure 5.1 - Resistance values of MCF10a (a) and MCF7 (b) under electric fields of frequencies 100, 150 and $200 \mathrm{kHz}$. No apparent effect was noticed for the normal MCF10a, however, a significant decrease in resistance values was observed for the MCF7 for all three frequencies. $50 \mathrm{kHz}$ and $2 \mathrm{MHz}$ frequencies were tested on both MCF10a (c) and MCF7 (d). The MCF10a showed no apparent effect on the cell proliferation as seen in the similar resistance curves to the control. $100 \mathrm{kHz}$ showed the largest decrease out of all the frequencies for the MCF7

The breast cancer cell lines behaved in a similar manner to the ovarian cancer cell lines tested previously as did the noncancerous MCF10a to the HUVECs. Under the influence of the electric field at all five frequencies, the resistance values for the MCF10a cells followed a trend of proliferating cells gradually attaching and spreading across the electrode surface creating an increase in resistance values. This can be seen in Figures 
5.1 (a) and (c) which show the resistance values of the MCF10a when exposed to the intermediate range frequencies $(100,150,200 \mathrm{kHz})$ and the extreme frequencies $(50 \mathrm{kHz}$, $2 \mathrm{MHz}$ ) respectively. However, the MCF7 exhibited a variation of trends in resistance profiles with the different frequencies of the applied field. Shown in Figure 5.1 (b), 150 and $200 \mathrm{kHz}$ decreased the resistance profiles of the MCF7, however, the MCF7 have the lowest resistance profile with $100 \mathrm{kHz}$ indicating the most effect on the cell proliferation at this frequency. The extreme frequencies were also tested to justify that the intermediate frequencies are the target frequencies suitable for cancer electrotherapy. The MCF10a cells retained a similar profile with the applied field as without (Figure 5.1 (c)). In Figure 5.1 (d), the MCF7 show more of a difference when the extreme frequencies are applied compared to the previously tested SKOV3. The higher frequency of $2 \mathrm{MHz}$ had an effect on the MCF7 proliferation as can be seen in the lower resistance profile compared to the control with no field applied. This could be due to the more sensitive membrane of the MCF7 compared to that of the other types of cancer cells. Cancer cells, in general, lower membrane potentials with lower stiffness compared to their normal counterpart as was measured by the Young's modulus though atomic force microscopy (AFM) [10]. In addition, The MCF7 type of breast cancer cells was observed to have a lower Young's modulus in comparison with other types of cancer cells, potentially giving the cells a weaker membrane. $50 \mathrm{KHz}$ also slowed down the proliferation of the MCF7 cells; however, the $100 \mathrm{kHz}$ affected the proliferation of these cells the most. 


\subsubsection{HER2-AuNPs targeted enhancement}

Gold nanoparticles are being use in targeted therapies in biomedical engineering such as gene and drug delivery transfection vectors, DNA-binding agents and in various imaging systems due to their inert properties [11]. In this study, we functionalized our AuNPs with a HER2 antibody for a targeted delivery of the particles to the cell membrane since HER2 is overexpressed in both breast and ovarian cancers. We tested the two types of cancer cells, SKOV3 and MCF7, as well as the non-cancerous HUVECs and MCF10a, under their respective optimal frequencies, 200 and $100 \mathrm{KHz}$, with and without the integration if the HER2-AuNPS to determine any enhancement in the effects of the applied electric field.

The first concern with using the metallic nanoparticles under the applied electric field would be the potential heating of the nanoparticles. AuNPS are being used for cancer hyperthermia studies [12], however, these studies use nearinfrared (NIR) laser light, [13] radiowaves, [14] or even ultrasound [15]. To make sure temperature would not be a factor for the cancer cells under the intermediate frequencies determined for the two types of cancer cells, we tested the temperature of the wells at incremental times of 6 hours for the SKOV3 and 4 hours for the MCF7 for an entire run. Figure 5.2 (a) and (b) shows the average temperature of the 8 wells on one chip for the SKOV3 and the MCF7, respectively. Here we do not see any significant change in temperature when the HER2AuNPS were incorporated for either type of cell, indicating no apparent thermal effects from the nanoparticles. 
(a)

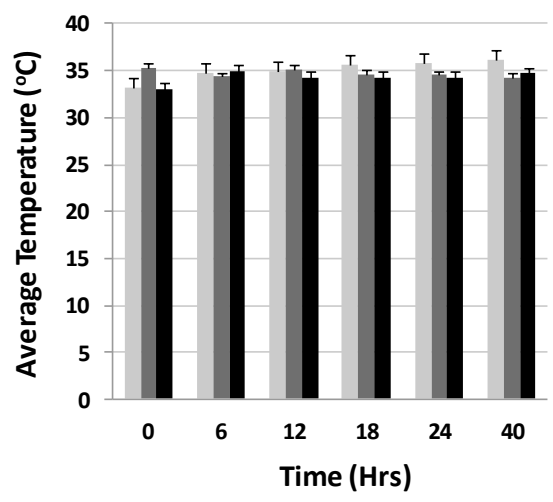

(b)

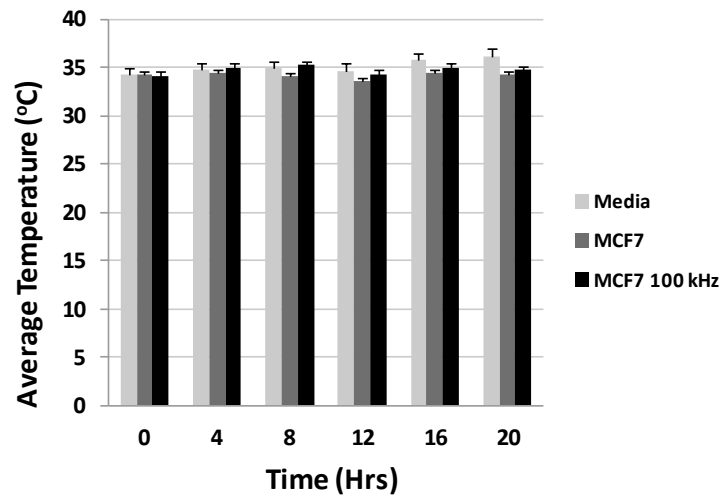

Figure 5.2 - Average temperature readings for the 8 wells on a chip at various time points throughout an EIS run for SKOV3 (a) and MCF7 (b)

Figure 5.3 (a) and (c) shows the resistance values obtained for the noncancerous HUVECs and MCF10a, respectively. As in the previous experiment, there is no noticeable change in the resistance values when the electric field was applied to the cells compared to the control cells with now applied field. Also, with the incorporation of the HER2-AuNPs, there is still no apparent effect in the resistance profiles. However, a noticeable decrease in the growth profiles of the SKOV3 and MCF7 was observed with the application of the HER2-AuNPs and the electric fields compared to just the field itself indicating specific inhibitory effects on dividing cells in culture (Figure 5.3 (b) and (d)). 
(a)

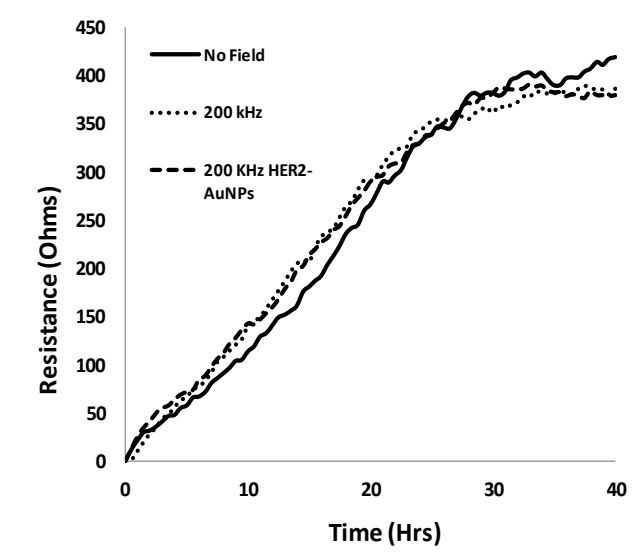

(c)

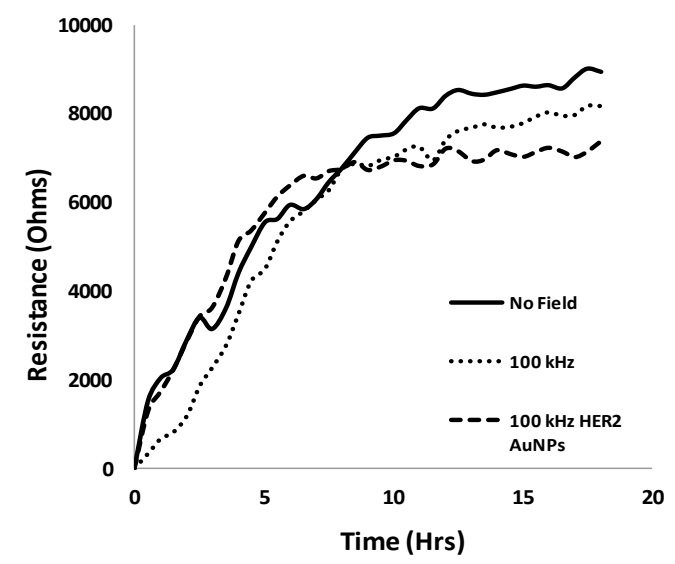

(b)

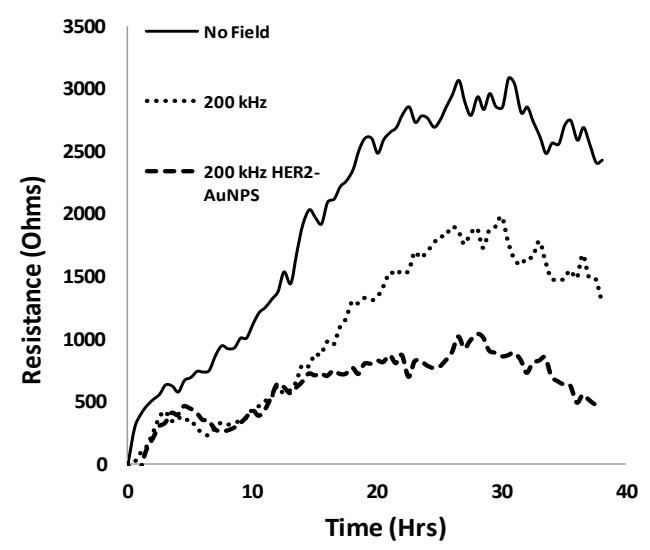

(d)

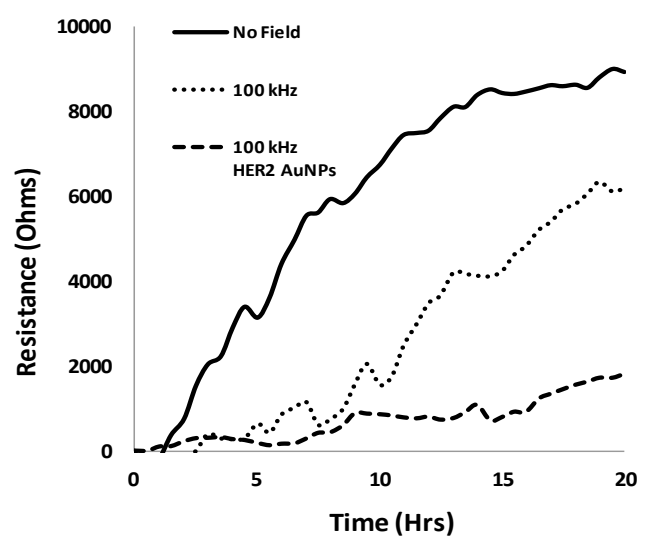

Figure 5.3 - Resistance values for HUVECs (a), SKOV3 (b), MCF10a (c) and MCF7 (d) under the effects of the optimal frequencies (SKOV3 200kHz, MCF7 100kHz) with and without the application of HER2-AuNPS

\subsubsection{Apoptosis / Necrosis Assay}

Apoptosis and necrosis are the two major processes leading to cell death. Apoptosis is the process of programmed cell death caused by a cascade of biochemical signals within the cell and can be triggered from a variety of external factors usually in the form of stress towards the cell. In the case of apoptosis, the cell prepares itself by performing changes within, one of them being changes in the phospholipid content of the cell membrane. 
Apoptotic cells can be easily identified with the protein Annexin V, which is binds to phosphatidylserine, a protein located in the cell membrane. Under normal circumstances, the phosphatidylserine is found in the inner layer of the cell membrane double layer. In the early stages of apoptosis, these phosphatidylserine proteins move to the outer layer of the membrane where Annexin V labeled with fluorescein (FITC) can bind, staining apoptotic cells green.

Necrosis is a traumatic cell death that results from any acute damage caused to the cell where the cell membrane integrity is compromised. This results in the cytosol and organelles within the cell to spill into the surrounding environment. Ethidium homodimer III (EthD-III) is a highly positively charged nucleic acid probe which binds to DNA, thus is used to classify necrotic cells by staining them with red fluorescence.

To further understand the effects of the externally applied field to the cells, an Annexin V/ EthD-III assay was performed to determine the cell death mechanism with green fluorescent membrane staining indicating apoptotic cells, and red fluorescent nuclear staining necrotic cells. Figure $\mathbf{5 . 4}$ shows the fluorescent staining of MCF7 cells after 20 hours of exposure to $100 \mathrm{kHz}$ electric field. The image on the left shows EthD-III stained cells (necrotic) and the image on the right shows Annexin V stained cells (apoptotic). There are significantly more cells stained with the Annexin V indicating the death mechanism triggered from the applied electric field to be apoptosis. 

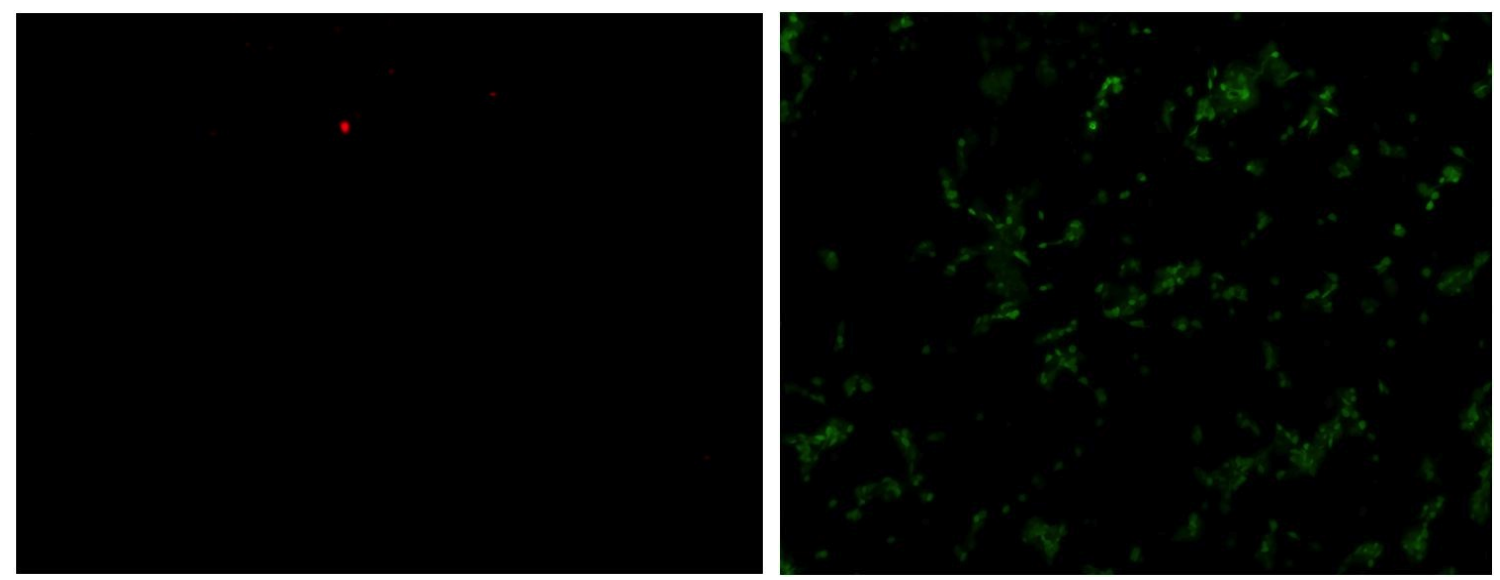

Figure 5.4 - Fluorescent staining of MCF7 cells after 20 hours of exposure to $100 \mathrm{kHz}$ electric field. The image on the left shows EthD-III stained cells (necrotic) and the image on the right shows Annexin V stained cells (apoptotic).

\subsubsection{Zeta Potential Measurements}

In order to understand the effects of the applied electric field with targeted nanoparticle enhancement, the next focus of the study was to observe the zeta potential of the cells before and after exposure to the nanoparticles. Zeta potential is the electrostatic potential near the surface of a particle and usually this surface charge is counterbalanced by charges of opposite sign in the surrounding solution. With the nanoparticles, once in contact with the cell membrane, the surface charges of the particles may affect the cells membrane properties with negatively charged ions or molecules will decrease and positively charged ions will increase the surface zeta potential of the cell [16-17], thus attachment of negatively charged nanoparticles on the cell's membrane will cause its zeta potential to become more negative. 
We measured the zeta potential of our AuNPs before and after functionalization with the HER2 antibody to see if the antibody would affect the nanoparticles' zeta potential. We then measured the zeta potential of the two cancer cell lines, SKOV3 and MCF7, with and without the incorporation of the HER2-AuNPS and compared the results to those for the non-cancerous cell lines, HUVEC and MCF10a, respectively (Figure 5.5). In all cases, the bare AuNPS had the lowest zeta potentials with values of $-37.4 \pm$ $0.7,-40.0 \pm 0.05,-43.3 \pm 0.7$, and $-39.3 \pm 0.4$ as shown in Figure 5.5 (a), (b), (c) and (d), respectively. With the functionalization of the HER2 antibody, the zeta potentials increased slightly for each case $(-30.5 \pm 1.4,-37.1 \pm 1.2,-41.6 \pm 1.0,-35.5 \pm 0.6)$. The cells themselves had initial zeta potentials of $-19.2 \pm 0.9$ (HUVEC), $-19.3 \pm 0.8$ (SKOV3), $-20.5 \pm 0.9$ (MCF10a) and $-28.3 \pm 1.3$ (MCF7). After incubation with the HER2-AuNPS, the cancerous cell showed a significant decrease in zeta potentials compared to the non-cancerous cells. For the HUVECs, the zeta potential slightly increased to $-18.3 \pm 0.9$, and the MCF10a also showed a slight increase to $-18.9 \pm$ 2.3.(Figure 5.5 (a), (c), respectively). The case was different for both cancerous cell types as the zeta potentials dropped after HER2-AuNPS functionaliztion for the SKOV3 to $-25.3 \pm 1.3$, and for the MCF7 to $-37.6 \pm 1.3$ (Figure 5.5 (b), (d), respectively). 
(a)

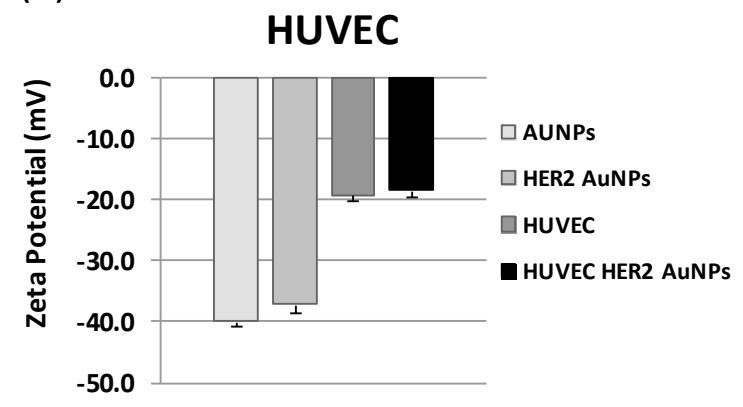

(c)

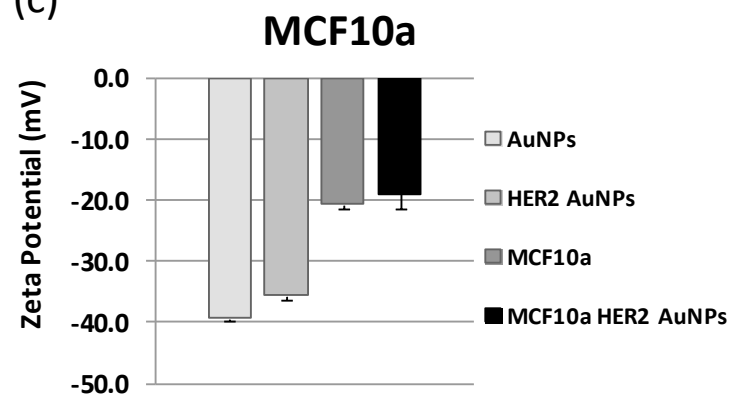

(b)

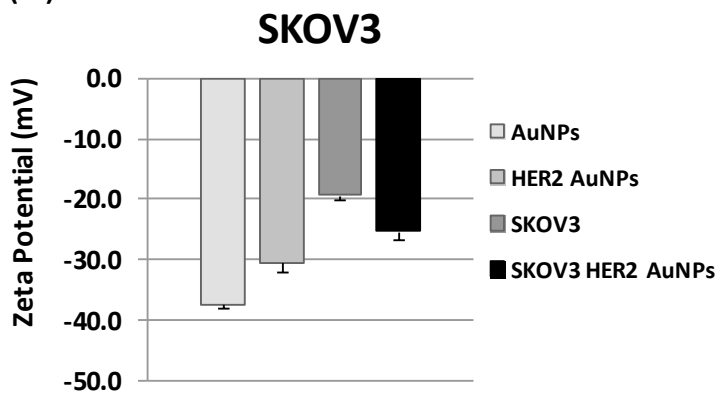

(d)

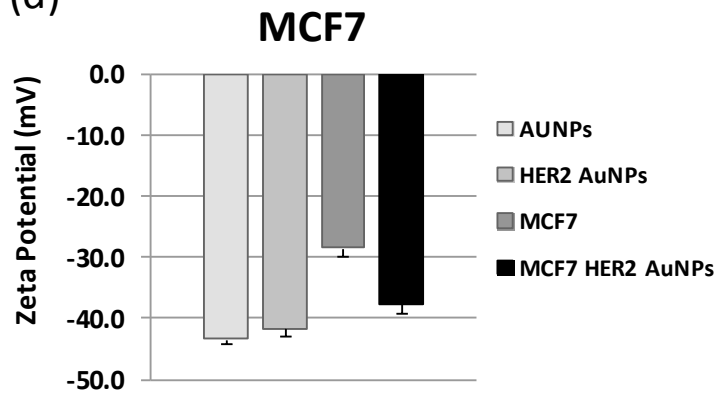

Figure 5.5 - Zeta potential values for HUVECs (a), SKOV3 (b), MCF10a (c), and MCF7 (d). With the integration of the HER2-AuNPs, the zeta potential of both cancer cells decreased in comparison to the two noncancerous cell types.

\subsection{Discussion}

The cell membrane provides a barrier for the cell and its surroundings and as a result is the first line of defense for the cell to survive. The membrane controls the exchange of electrically charged ions across the cell membrane thus creating the cell membrane potential. It is this potential that is the underlying characteristic of the cell that could distinguish between normal and cancerous cells. It was been noted before that cancerous cell have a lower membrane potential, and it has been shown that the cell's membrane changes during cancer transformation, in particular the membrane's fluidity and charge [18-19]. Therefore, by altering the cell membrane potential, one could possibly control the fate of the cell. 
Cancerous cell membranes have a higher number of negatively charged sialic acids, which regulate intercellular contacts and the interaction of charged macromolecules with the cell surface [20]. It is the number of sialic acids that lead to any cell's overall negative membrane potential and ultimately determines a cell's zeta potential [21]. Sialyation is one of the factors that cause the cancer cell membrane to be more electronegative and consequently, any factor that increases or decreases the number of sialic acid residues will change the degree of membrane negativity.

We had proposed that gold nanoparticles functionalized with specific antibodies to target the cancer cells would enhance the effects of the electric field towards the cells without affecting the non-cancerous cells due to the different membrane properties of the cancerous cells. In our study, the antibody used targeted HER2 glycoprotein receptor on the cell membrane. Since sialic acids are generally found at the end of most glycoproteins, and the specific cancer cells tested overexpress the HER2 receptor, we can deduce that there would be more HER2-AuNPs attracted to the cancer cells as opposed to the regular cells. With more negatively charged HER2-AuNPs attached to the cancer cell membrane, the cell membrane could more vulnerable to the effects of the external electric field due to the decrease in surface charge. An important consequence of the existence of electrical charges on the surface of particles is that they will exhibit certain effects under the influence of an applied electric field. Since the changes in zeta potential values depend on cell surface charge, nanoparticle surface charge and their interaction we observed a decrease in zeta potentials of the cells after nanoparticle incorporation leaving the cells more vulnerable to the detrimental effects of the applied electric field. 
There was also a noticeable difference in the behavior between the two types of cancer cells. The breast cancer cell line, MCF7 was affected by a lower frequency than the ovarian cancer cell line, SKOV3. This could be due to the MCF7 having a more simplified cytoskeleton compared with MCF10A, which results in less stiffness and easier deformation [22].

\subsection{Conclusion}

Cancer electrotherapy treatments are showing considerable promise to avoid the negative side effects of traditional cancer treatments such as chemotherapy. We previously demonstrated that cancer cell proliferation is affected by externally applied alternating electric fields in the intermediate frequency range of $100 \mathrm{kHz}-200 \mathrm{kHz}$. In this study, we demonstrated that different types of cancer cells are affected by different optimal frequencies of these electric fields. To further understand the effects of the applied fields on the cells, we performed an Annexin V/ EthD-III assay to conclude the fate of the cells as apoptosis. We also observed a decrease in proliferation with the addition of HER2-AuNPs to target the cancer cells and enhance the effects of the electric field towards the cells without affecting the non-cancerous cells. With the attached nanoparticles, the zeta potential of the SKOV3 and the MCF7 before and after incorporation of the HER2-AuNPs decreased compared to their non-cancerous counterparts. The decrease in membrane potential would thus leave the cells more vulnerable to the detrimental effects of the applied electric field. The outcome of this research will improve our fundamental understanding of the behavior of cancer cells and define optimal parameters of electrotherapy for clinical and drug delivery applications. 


\subsection{References}

1. Sundelacruz, S., Levin, M., Kaplan, D.L. (2009) Role of Membrane Potential in the Regulation of Cell Proliferation and Differentiation, Stem Cell Reviews and Reports 5, 231-246.

2. Cone, C.D., Jr., Tongier, M., Jr. (1973) Contact inhibition of division: Involvement of the electrical transmembrane potential, Journal of Cellular Physiology, 82, 373-386.

3. Qiao, G., Duan, W., Chatwin, C., Sinclair, A., Wang, W. (2010) Electrical properties of breast cancer cells from impedance measurement of cell suspensions, Journal of Physics: Conference Series 224, 012081

4. Hondroulis, E., Melnick, S.J., Wu, Z.Z., Zhang, X., Li, C.Z. (2013) Electrical field manipulation of cancer cell behavior monitored by whole cell biosensing device. Biomedical Microdevices, 15, 657-663.

5. Wonderlin, W.F., Woodfork, K.A., Strobl, J.S. (1995) Changes in membrane potential during the progression of MCF-7 human mammary tumor cell through the cell cycle, Journal of Cellular Physiology, 165, 177-185.

6. Seeger, P.G., Wolz, S., 1990 Successful Biological Control of Cancer: By Combat against the Causes. Gesamtherstellung: Neuwieder Verlagsgesellschaft $\mathrm{mbH}$,

7. Lantz, E., Cunningham, I., Higa, G.M. (2010) Targeting HER2 in breast cancer: overview of long-term experience, International Journal of Women's Health 1, $155-171$.

8. Menard, S., Casalini, P., Campiglio, M., Pupa, S., Agresti, R., Tagliabue, E. (2001) HER2 over-expression in various tumor types, focusing on its relationship to the development of invasive breast cancer, Annals of Oncology 12, S15-S19.

9. Zhu, X., Hondroulis, E., Liu, W., Li, C.Z. (2013) Biosensing Approaches for Rapid Genotoxicity and Cytotoxicity Assays upon Nanomaterial Exposure, Small DOI: $10.1002 / \mathrm{smll} .201201593$

10. Morkvẻnaitè-Vilkončienė, I., Ramanavičienė, A., Ramanavičius, A. (2013) Atomic force microscopy as a tool for the investigation of living cells, Medicina (Kaunas). 49, 155-164.

11. Ghosh, P.S., Kim, C. K., Han, G., Forbes, N.S., Rotello, V.M. (2008) Efficient gene delivery vectors by tuning the surface charge density of amino acidfunctionalized gold nanoparticles, ACS Nano 2, 2213-2218. 
12. Kennedy, L.C., Bickford, L.R., Lewinski, N.A. , Coughlin, A.J., Hu, Y., Day, E.S., West, J.L., Drezek, R.A. (2010) A New Era for Cancer Treatment: GoldNanoparticle-Mediated Thermal Therapies, Small 7, 2.

13. Hirsch, L.R., Stafford, R.J., Bankson, J.A., Sershen, S.R., Rivera, B., Price, R.E., Hazle, J.D. , Halas, N.J., West, J.L. (2003) Nanoshell-mediated near-infrared thermal therapy of tumors under magnetic resonance guidance, Proceedings of the National Academy of Sciences of the United States of America, 100, 13549.

14. Gannon, C.J., Patra, C.R., Bhattacharya, R., Mukherjee, P., Curley, S.A. (2008) Intracellular gold nanoparticles enhance non-invasive radiofrequency thermal destruction of human gastrointestinal98 cancer cells, Journal of Nanobiotechnology 6, 2.

15. Jolesz, F.A., Hynynen, K. (2002) Magnetic resonance image-guided focused ultrasound surgery, The Cancer Journal. 8, S100

16. Altankov, G., Richau, K., Groth, T., (2003) The role of surface zeta potential and substratum chemistry for regulation of dermal fibroblasts interaction, Materialwiss Werkst, 34, 1120-1128.

17. Siliva Filho, F.C., Santos, A.B., de Carvalho, T.M., de Souza, W. (1987) Surface charge of resident, elicited, and activated mouse peritoneal macrophages, Journal of Leukocyte Biology, 41, 143-149.

18. Dobrzynska, I., Szachowicz-Petelska, B., Figaszewski, Z., Sulkowski, S. (2005) Changes in electric charge and phospholipid composition in human colorectal cancer cells, Molecular and Cellular Biochemistry, 276, 113-119.

19. Szachowicz-Petelska, B., Figaszewski, Z., Sulkowski, S. (2007) Altered membrane free unsaturated fatty acid composition in human colorectal cancer tissue, Molecular and Cellular Biochemistry, 294, 237-242.

20. Rosenberg, S.A., Einstein, A.B. Jr. (1972) Sialic Acids on The Plasma Membrane of Cultured Human Lymphoid Cells: Chemical Aspects and Biosynthesis, The Journal of Cell Biology, 53, 466-473.

21. Cure, J.C. (1995) On the electrical characteristics of cancer, Second International Congress of Electrochemical Treatment of Cancer, Jupiter, Florida

22. Qiao, G., Wang, W., Duan, W., Zheng, F., Sinclair, A.J., Chatwin, C.R. (2012) Bioimpedance Analysis for the Characterization of Breast Cancer Cells in Suspension, IEEE Transactions on Biomedical Engineering, 59, 2321-2329. 
Chapter 6

\section{CONCLUSIONS}


In this doctoral study, a whole cell electrical impedance sensing (EIS) biosensor was used to analyze the cell behavior in real-time. The biosensor proved to be a rapid technique to get more information about living cells without disturbing the cellular subsystems creating a versatile, noninvasive tool that is able to provide quantitative information with respect to alteration in cellular function when subjected to the various stimuli.

The capability of the biosensor to monitor the cellular behavior was first demonstrated in Chapters 2 and 3 by testing human and environmental toxicity of nanoscale materials in 2D and 3D cell culture models. These studies also provided insight on the ability of the EIS biosensor to monitor the kinetic effects of the cellular reaction pattern towards various nanoparticles, allowing better understanding of the nanoparticlecell interaction over time. Results indicated that the EIS chip exhibited a stable and reproducible response when measuring the effects of various nanomaterials-AuNPs (10, $100 \mathrm{~nm}), \operatorname{AgNPs}(10,100 \mathrm{~nm})$, SWCNTs (cut, uncut) and CdO-towards CCL-153 and RTgill-W1 cells.

After the initial nanotoxicity studies, the biosensor was ultimately used to test the effects of external alternating electric fields in combination with antibody targeted nanoparticle therapy on the behavior of cancer cells as seen in chapters 4 and 5 . Electrotherapy for cancer treatment is very promising alternative to traditional methods such as chemotherapy since as it eliminates the toxic chemicals and possible immunogenic responses in the host tissue. The cancer electrotherapy study improved our fundamental understanding of the behavior of cancer cells to alternating electric fields by 
showing that a low intensity electric field at $200 \mathrm{kHz}$ frequency has a detrimental effect on cancerous SKOV3 cells without affecting the non-cancerous HUVEC cells. We also demonstrated that the applied electric field affects different types of cancer cells at different frequencies as seen with the MCF7 cells and their optimal frequency of 100 $\mathrm{kHZ}$.

We then sought to enhance the effects of the electric field by altering the cancer cell's electronegative membrane properties with antibody functionalized nanoparticles. With the attached nanoparticles, the zeta potential of the SKOV3 and the MCF7 before and after incorporation of the HER2-AuNPs decreased compared to their non-cancerous counterparts. The decrease in membrane potential would thus leave the cells more vulnerable to the detrimental effects of the applied electric field. This research and allowed us to define a strategy and optimal parameters of antibody targeted nanoparticle electrotherapy for clinical and drug delivery applications. The outcome of this research will improve our fundamental understanding of the behavior of cancer cells to alternating electric fields and define a strategy and optimal parameters of electrotherapy for clinical and drug delivery applications. This whole cell-based biosensor will enhance our understanding of the responsiveness of cancer cells to electric field therapy and demonstrate potential therapeutic opportunities for electric field therapy in the treatment of cancer. 
VITA

\section{EVANGELIA HONDROULIS}

Bachelor of Science, Biomedical Engineering, 1996 -2000, Columbia University, New York, NY

Ph.D. Candidate, Biomedical Engineering, 2007-present, Florida International University, Miami, FL (Expected Graduation: December 2013)

\section{PUBLICATIONS}

E. Hondroulis, S.J. Melnick, Z.Z. Wu, X. Zhang, C-Z. Li, 2013, Electrical field manipulation of cancer cell behav ior monitored by whole cell biosensing device. Biomedical Microdevices, Vol. 15, Iss. 4, 657-663

E. Hondroulis, J. Nelson, C-Z. Li, 2013, Nanobioelectronics for Noninvasive Neuronal Therapy. Babak Kateb, John D. Heiss (Eds.), The Textbook of Nanoneuroscience and Nanoneurosurgery (473-481), CRC Press

E. Hondroulis, J. Nelson, C-Z. Li, Biomarker Analysis for Nanotoxicology. Ramesh C. Gupta (Ed.), Biomarkers in Toxicology, Elsevier (in press)

E. Hondroulis, P. Shah, X. Zhu, C-Z. Li, Biosensing Devices for Toxicity Assesment of Nanomaterials, Vijaykumar B. Sutariya, Yashwant Pathak (Eds.), Biointeraction of Nanoparticles, CRC Press (in press)

E. Hondroulis, C-Z .Li, 2012, Whole Cell Impedance Biosensoring Devices, Reineke, Joshua (Ed.), Nanotoxicity Methods and Protocols, Methods in Molecular Biology, Vol. 926 Humana Press

E. Hondroulis, Z. Zhang, C-Z. Li, 2012, Impedance based Nanotoxicity Assessment of Graphene Nanomaterials at the Cellular and Tissue Level. Analytical Letters, Vol. 45, Iss. 2-3

E. Hondroulis, C. Liu, C-Z. Li, 2010, Whole cell based biosensing device for in vitro nanotoxicity assay at cellular and tissue level. Nanotechnology 21315103

E. Hondroulis, C-Z. Li, 2009, Development of Cell Impedance Based Sensing System for the Nanotoxicity Assay. IFMBE Proceedings, 113-116

X. Zhu, E. Hondroulis, W. Liu and C-Z. Li, 2013. Biosensing Approaches for Rapid Genotoxicity and Cytotoxicity Assays upon Nanomaterial Exposure. Small

DOI: $10.1002 / \mathrm{smll} .201201593$ 


\section{PRESENTATIONS}

E. Hondroulis, C-Z. Li, “Targeted Electrical Field Manipulation of Cancer Cells Using Antibody Functionalized Nanoparticles"

29th Southern Biomedical Engineering Conference, 2013, Miami, FL

E. Hondroulis, C-Z. Li, “Targeted Electrical Field Manipulation of Cancer Cells Using Antibody Functionalized Gold Nanoparticles"

NanoFlorida 2012, Tampa, FL

*Awarded best oral presentation

E. Hondroulis, C-Z. Li, “Targeted Electrical Field Manipulation of Cancer Cells Using Antibody Functionalized Gold Nanoparticles"

Pittcon Conference 2012, Orlando, FL

E. Hondroulis, C-Z. Li, "Electrical Biosensor for Assessing Cancer Cell Behavior upon Electrical Field Manipulation"

Pittcon Conference \& Expo 2011, Atlanta, GA

E. Hondroulis, C-Z. Li "Impedance Sensing Approach for In Vitro Nanotoxicity Assay at Cellular and Tissue Level"

Conference \& Expo 2010, Orlando, FL

E. Hondroulis, C-Z. Li "Electrical Impedance Sensing Approach for Rapid Nanotoxicity Assay"

American Chemical Society Annual Conference, 2009, Salt Lake City, UT

E. Hondroulis, C-Z. Li "Development of Cell Impedance Based Sensing System for the Nanotoxicity Assay"

25th Southern Biomedical Engineering Conference, 2009, Miami, FL

\section{POSTERS}

E. Hondroulis, C. Liu, C-Z. Li "Development of Cell Impedance Based Sensing System for the Nanotoxicity Assay"

EDC BioTech Conference, 2008, Miami, FL 